\title{
Reproductive health services in KwaZulu Natal, South Africa: A situation analysis study focusing on HIV/AIDS services
}

\author{
Lewis Ndhlovu \\ Population Council \\ Catherine Searle \\ Population Council \\ Robert A. Miller \\ Population Council \\ Andrew A. Fisher \\ Population Council \\ Ester Snyman
}

See next page for additional authors

Follow this and additional works at: https://knowledgecommons.popcouncil.org/departments_sbsr-hiv

Part of the Demography, Population, and Ecology Commons, Health Policy Commons, Immune System Diseases Commons, International Public Health Commons, Medicine and Health Commons, Public Health Education and Promotion Commons, Virus Diseases Commons, and the Women's Health Commons

How does access to this work benefit you? Let us know!

\section{Recommended Citation}

Ndhlovu, Lewis, Catherine Searle, Robert A. Miller, Andrew A. Fisher, Ester Snyman, and Nancy L. Sloan. 2003. "Reproductive health services in KwaZulu Natal, South Africa: A situation analysis study focusing on HIV/AIDS services," Horizons Final Report. Washington, DC: Population Council. 


\section{Authors}

Lewis Ndhlovu, Catherine Searle, Robert A. Miller, Andrew A. Fisher, Ester Snyman, and Nancy L. Sloan 


\title{
Hprizons
}

Reproductive Health Services in KwaZulu Natal, South Africa

\author{
A Situation Analysis Study \\ Focusing on HIV/AIDS Services
}
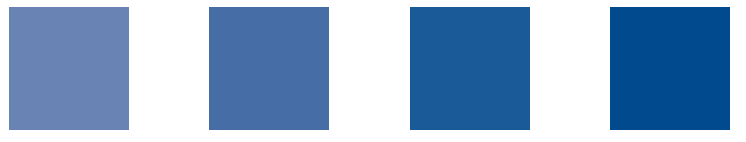

Horizons Program

KwaZulu Natal Department of Health 


\title{
Reproductive Health Services in KwaZulu Natal, South Africa:
}

\section{A Situation Analysis Study Focusing on HIV/AIDS Services}

\author{
Lewis Ndhlovu ${ }^{1}$ \\ Catherine Searle ${ }^{1}$ \\ Robert Miller \\ Andrew Fisher ${ }^{3}$ \\ Ester Snyman ${ }^{4}$ \\ Nancy Sloan ${ }^{5}$
}

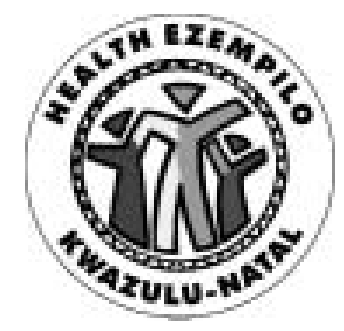

Hgrizons

${ }^{1}$ Horizons/Population Council, South Africa; ${ }^{2}$ Horizons/Population Council, New York;

${ }^{3}$ Horizons/Population Council, Washington DC; ${ }^{4}$ KwaZulu Natal Department of Health, South Africa; ${ }^{5}$ Population Council, New York 


\section{Acknowledgments}

We would like to thank Professor R.W. Green-Thompson, director general of KwaZulu Natal Department of Health, and Professor S.J.H. Hendricks, deputy director-general, District Health System, for their support of the research. We would also like to acknowledge all district managers and their management teams for their assistance and support throughout; the fieldworkers for their tireless effort; and all the facility management and staff for their assistance and participation during data collection. We would like to thank the Italian Health Cooperation for their financial contribution to make the study possible. Lastly we would like to thank the Maternal, Child \& Women's Health Sub-Directorate for the central role they played in making the study possible.

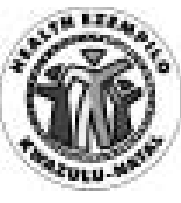

The KwaZulu Natal Department of Health aims to achieve optimal health status for all persons in KZN by developing sustainable, coordinated, integrated and comprehensive health systems at all levels, based on the primary health care approach through the district health system.

USAID

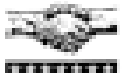

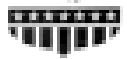

This study was supported by the Horizons Program, which is implemented by the Population Council in collaboration with the International Center for Research on Women, International HIV/AIDS Alliance, Program for Appropriate Technology in Health, Tulane University, Family Health International, and Johns Hopkins University. Horizons is funded by the U.S. Agency for International Development, under the terms of HRN-A-00-97-00012-00. The opinions expressed herein are those of the authors and do not necessarily reflect the views of the U.S. Agency for International Development.

Published in October 2003.

\section{(P) Population Council}

The Population Council is an international, nonprofit, nongovernmental institution that seeks to improve the wellbeing and reproductive health of current and future generations around the world and to help achieve a humane, equitable and sustainable balance between people and resources. The Council conducts biomedical, social science, and public health research and helps build research capacities in developing countries. Established in 1952, the Council is governed by an international board of trustees. Its New York headquarters supports a global network of regional and country offices.

Copyright (C) 2003 The Population Council Inc. 


\section{Table of Contents}

\section{Abbreviations/ Acronyms}

\section{Executive Summary}

Chapter 1 Background and Study Methodology 7

$\begin{array}{ll}\text { Situation Analysis methodology } & 7\end{array}$

$\begin{array}{ll}\text { Public health services in South Africa } & 7\end{array}$

Sample design 9

$\begin{array}{ll}\text { Organization of the report } & 14\end{array}$

Chapter 2 Study Facilities and I ntegration of Services 15

$\begin{array}{ll}\text { Number and type of facilities } & 15\end{array}$

$\begin{array}{ll}\text { Facility size and patient load } & 15\end{array}$

$\begin{array}{ll}\text { Operating times } & 18\end{array}$

$\begin{array}{ll}\text { Availability of services } & 18\end{array}$

$\begin{array}{ll}\text { Infrastructure } & 22\end{array}$

Availability of staff and supervision $\quad 24$

Availability of health education materials $\quad 26$

$\begin{array}{ll}\text { Availability of equipment } & 28\end{array}$

$\begin{array}{ll}\text { Availability of essential drugs } & 30\end{array}$

Availability of laboratory tests $\quad 31$

Management and record keeping 33

Summary of service availability and service integration 35

Chapter 3 Characteristics, Training, and Experience of Staff 36

Sociodemographic characteristics of staff 36

$\begin{array}{ll}\text { Training } & 36\end{array}$ 
ANC services provided

Provider restrictions on family planning services

Service providers and RTI/STI services

Summary

\section{Chapter 4 Family Planning Services}

KwaZulu Natal Family Planning Program

Family planning client characteristics

Readiness to deliver FP services

Client-provider interaction and quality of FP service delivery

Clients' experience with and views about service provision

Client awareness and knowledge of HIV/AIDS 66

Travel and waiting times

Summary

\section{Chapter 5 Antenatal Care Services}

KwaZulu Natal Antenatal Care Program

ANC patient characteristics

Readiness of facilities to provide ANC services

ANC medications

Availability of supportive ANC materials

Observation of general ANC patient-provider interactions

Clients' experiences and views about general ANC services 85

Associated sexually transmitted infection and HIV services

Accessibility of service facility, travel, and waiting times 
Chapter 6 Sexually Transmitted I nfections Services 98

$\begin{array}{ll}\text { STI program in KZN } & 98\end{array}$

$\begin{array}{lr}\text { STI client characteristics } & 98\end{array}$

$\begin{array}{ll}\text { Capacity of facilities to provide STI services } & 100\end{array}$

Client-provider interaction and the quality of STI service delivery 103

$\begin{array}{ll}\text { Client awareness and knowledge of HIV/AIDS } & 115\end{array}$

$\begin{array}{ll}\text { Travel and waiting times } & 117\end{array}$

$\begin{array}{ll}\text { Summary } & 117\end{array}$

Chapter 7 Voluntary Counseling and Testing Services 119

$\begin{array}{ll}\text { KZN VCT services } & 119\end{array}$

$\begin{array}{ll}\text { VCT client characteristics } & 121\end{array}$

Readiness of facilities to deliver VCT services $\quad 121$

Infrastructure, equipment, and staff 125

Client-provider interaction and the quality of VCT service delivery 126

$\begin{array}{ll}\text { Pretest counseling } & 128\end{array}$

$\begin{array}{ll}\text { Posttest counseling } & 131\end{array}$

Clients' experience with and views about service provision $\quad 136$

Summary 142

$\begin{array}{ll}\text { Chapter } 8 \text { Follow-up } & 144\end{array}$

$\begin{array}{ll}\text { References } & 149\end{array}$

$\begin{array}{ll}\text { Appendix } & 155\end{array}$ 


\section{Abbreviations/ Acronyms}

$\begin{array}{ll}\text { AIDS } & \text { Acquired immunodeficiency syndrome } \\ \text { ANC } & \text { Antenatal care } \\ \text { ARVs } & \text { Antiretrovirals } \\ \text { CHC } & \text { Community health center } \\ \text { CHW } & \text { Community health worker } \\ \text { DHS } & \text { District health system } \\ \text { DOH } & \text { Department of Health } \\ \text { DOTS } & \text { Directly observed treatment short-course } \\ \text { EC } & \text { Emergency contraception } \\ \text { FP } & \text { Family planning } \\ \text { GCIS } & \text { Government Communication and Information Unit } \\ \text { HIV } & \text { Human immunodeficiency virus } \\ \text { HRD } & \text { Human Resource Development } \\ \text { HST } & \text { Health Systems Trust } \\ \text { IEC } & \text { Information, education, and communication } \\ \text { ICPD } & \text { International Conference on Population and Development } \\ \text { IUDs } & \text { Intrauterine device } \\ \text { KZN } & \text { KwaZulu Natal, South Africa } \\ \text { LAM } & \text { Lactational amenorrhea method } \\ \text { MCWH } & \text { Maternal, Child and Women's Health } \\ \text { MMR } & \text { Maternal mortality rate } \\ \text { MTCT } & \text { Mother-to-child transmission } \\ \text { MVA } & \text { Manual vacuum aspiration } \\ \text { ORT } & \text { Oral rehydration therapy } \\ \text { OIs } & \text { Opportunistic infections } \\ \text { PEP } & \text { Post-exposure prophylaxis } \\ \text { PHC } & \text { Primary health care } \\ \text { PMTCT } & \text { Prevention of mother-to-child transmission } \\ \text { POP } & \text { Progestin-only pills } \\ \text { RH } & \text { Reproductive health } \\ \text { RTIs } & \text { Reproductive tract infections } \\ \text { SAHR } & \text { South African Health Review } \\ \text { SADHS } & \text { South Africa Demographic and Health Survey } \\ \text { SDP } & \text { Service delivery points } \\ \text { STI } & \text { Sexually transmitted infections } \\ \text { TB } & \text { Tuberculosis } \\ \text { TBA } & \text { Traditional birth attendant } \\ \text { TOP } & \text { Termination of pregnancy } \\ \text { TT } & \text { Tetanus toxoid } \\ \text { UNFPA } & \text { United Nations Population Fund } \\ \text { VCT } & \\ \text { WHO } & \text { Voluntary counseling and testing } \\ & \end{array}$


KZN Situation Analysis

\section{Executive Summary}

\section{Background}

Reproductive health $(\mathrm{RH})$ research using the Situation Analysis approach-an assessment of the availability and quality of services - has proven popular and useful in Africa, where more than 25 such studies were implemented during the 1990s. Since the first study in Kenya in 1989, Situation Analysis methodology has evolved from a narrow focus on family planning to cover all reproductive health services.

This report describes a 2002-2003 study in KwaZulu Natal that expanded the methodology to cover important HIV/AIDS-related issues, including:

- The availability and quality of voluntary counseling and testing (VCT) services.

- The extent of integration of family planning (FP), antenatal care (ANC), and sexually transmitted infection (STI) services with HIV prevention.

- The extent of condom promotion and other HIV prevention strategies.

The goal of the study was to obtain information from a representative sample of provincial health care facilities in KwaZulu Natal offering RH services to identify gaps in service delivery and determine priorities for integration to meet the growing demand for HIV/AIDS-related services.

\section{Methodology}

The core methodological components of the study are:

- Gathering data on the functioning of services through observations and interviews.

- Documenting the actual quality of care delivered to clients through direct observations of service delivery.

- Using exit interviews to investigate clients' perceptions.

Three types of facilities in KwaZulu Natal were the focus of sampling: hospitals (at district, regional, and provincial levels), community health centers, and clinics. To select facilities for the study, a complete list of provincially administered service delivery points was compiled from lists submitted by various government offices. All 12 community health centers in the province were purposely included. In the final sample, 98 facilities received one-day visits from teams of four nurses who had trained for three weeks in the use of the research instruments. From the 98 health facilities, the following number of provider-client interactions were observed: 93 FP, 154 ANC, 97 STI and $74 \mathrm{VCT}$. After receiving services, clients were interviewed, including 229 service providers. 


\section{${ }^{H}{ }^{\text {rizons }}$}

\section{Findings}

\section{Family planning}

Most of the province's FP facilities have adequate infrastructure, availability of contraceptives, equipment, logistics, and other necessities to provide services. Elements to support infrastructure are widely available, including electrical and telephone service, working toilets for clients, and designated areas for examination. Certain contraceptives, including injectables, orals, and male condoms, are widely available, although stockouts of all these methods were reported at 12 to 18 percent of facilities during the six months prior to the study (with condoms being the most frequently stocked-out method). IUDs and female condoms are not widely available. Many items of basic equipment for delivering services are almost always available.

Critical weaknesses in training, supervision, client education, and other key program elements remain for many FP services. A large staff of professional nurses deliver FP services, but the nursing staff have had little FP in-service training during the last three years, and almost half the nurses have never had any at all. Supervision takes place at most facilities, but there is room for improving the helpfulness of supervisory visits. There are few signs about the availability of FP services, and educational materials are generally not available for clients to take home. Many facilities also have inadequate seating for waiting clients, long waiting times, insufficient privacy for counseling, and unsafe water.

During counseling, providers focus on basic facts about different FP methods and often neglect to raise difficult issues. The $89 \mathrm{FP}$ clients interviewed were all females, generally young, with a median age of 22 years (one quarter were age 19 or less). Most were single and had not completed high school. Most were also mothers, the majority of whom did not want more children.

How to use a method, how it works, and how effective it is are discussed more frequently with clients than are contraindications, disadvantages, side effects and their management, or the possibility of switching methods, as well as partnership and HIV-related issues. Clients usually receive a choice of two or more methods, but providers are biased in favor of injectables, the most commonly discussed method and the one accepted by about three-quarters of all new, restarting, and switching clients.

Providers promote condoms but often do not explain how to use them or cover the more complex issues related to their use. Nurses promote condom use for preventing both STI and HIV transmission and pregnancy. About 70 percent of clients were encouraged to use condoms, an important prevention message in this high-prevalence region. Forty-eight percent of providers mentioned at least one risk factor for HIV infection. Yet providers seldom discuss specifics of condom use, cover the sensitive issues of negotiating and gaining partner cooperation, or bring up other HIV prevention strategies, such as abstinence (discussed during 13 percent of provider-client discussions) and mutual monogamy (10 percent). 


\section{KZN Situation Analysis}

\section{Antenatal care}

ANC clients are more likely to receive traditional medical exams than tests for syphilis and HIV. Nearly 30 percent of ANC patients in the sample were less than 20 years old. Most had at least some high school education and were unmarried. Forty percent had at least one living child.

Such basic exams as weight, blood pressure, urinalysis, and abdominal palpation for fetal presentation are conducted with nearly all patients, while many tests - syphilis, hemoglobin, and HIV - are performed with far fewer patients. Less than 75 percent of ANC patients are tested for syphilis (the standard in KwaZulu Natal is to test every woman for syphilis), and just over 20 percent are voluntarily tested for HIV or referred for VCT.

RH services are not widely integrated into ANC services. Patient reports indicate that there were many missed opportunities to receive additional services at the time of their ANC visit. Fewer than 10 percent of those who reported that they received services in addition to general ANC services received counseling on child immunization, growth monitoring, oral rehydration therapy, breastfeeding, or gender-based violence. Most important in this region of high HIV prevalence, only about a third of women are counseled on HIV, STIs, prevention of mother-to-child HIV transmission, and condom use. Even though all women at the ANC clinics are already pregnant, many still continue to have sex, yet only 4 percent received condoms to prevent infection.

Services and treatment for prevention of mother-to-child HIV transmission are generally not available to ANC clients. Nevirapine and referral for prevention of mother-to-child HIV transmission (PMTCT) services are available at most hospitals but only at 42 percent of community health centers and 17 percent of clinics, the types of facilities that most clients attend. On average, only five pregnant women and three newborns per facility receive nevirapine, even though more than 30 percent of the women attending ANC facilities are believed to be HIVpositive.

ANC clients know that infections can be sexually transmitted, but many have misconceptions about STIs. The vast majority of ANC patients indicate that they know that infections such as HIV can be sexually transmitted, and most say they know the common signs and symptoms of STIs. Almost all know that use of condoms prevents HIV transmission. However, in unprompted questions, only 40 percent identified genital lesions or sores as signs of STIs. Only a minority of ANC patients know about nonsexual HIV transmission through exposure to infected blood and through perinatal transmission and about prevention strategies other than condom use.

Clients report overall satisfaction with services, except with long waiting times. Most patients walk to the ANC facility, leaving home early and arriving early (by 9 am), thus creating crowded conditions and long waiting times: a median of 1.5 hours, but with about a quarter reporting 2.5 hours or longer. The long waiting time was a source of dissatisfaction for patients. However, consistent with similar surveys, most patients report being satisfied with services.

The majority of ANC facilities are well equipped to offer services. Approximately 80 percent of these facilities possess all the basic ANC equipment, supplies, and medicines assessed in the 


\section{Hgrizons}

Situation Analysis. Exceptions include labor inducers and painkillers, which are unavailable at about 15 percent of clinics. Educational materials dealing with topics other than HIV/AIDS are rarely available for patients to take home.

\section{Sexually transmitted infections}

Facilities have basic equipment and medicine to treat STIs even though they cannot conduct laboratory tests for STIs, including HIV. In an average month, community health centers providing STI services serve about 500 clients, with about one-sixth that number seen at hospitals and clinics. Only about one-third of the STI clients receiving services at public health services were men, suggesting that men seek STI care at alternative locations (from traditional healers, at the workplace or other private clinics, or from pharmacies), or tend to seek less care overall.

Most of the facilities providing STI services have speculums and other basic equipment, supplies, and medications, but are unable to offer lab tests for STIs. Most rely on syndromic management for diagnosis and treatment of STIs, even though it has been shown to be less effective in diagnosing infections in women, who are often asymptomatic. Only 36 percent have the ability to conduct HIV tests.

There is some integration of other reproductive health topics into STI counseling, but this occurs with relatively few clients. Consultations between providers and clients focus primarily on STI diagnosis and treatment. Condoms are most frequently mentioned as a means of preventing STIs, including HIV. As in other services, counselors infrequently discuss condom negotiation skills, how to use a condom, or other prevention strategies such as abstinence, partner reduction, and mutual monogamy. While family planning is discussed with about 23 percent of STI clients, disproportionately more with female than male clients, other reproductive health topics such as breast cancer, prevention of mother-to-child HIV transmission, nutrition, and gender-based violence are discussed with less than a fifth of all clients.

While STI service providers recommend condom use to both men and women, most men receive condoms from STI service providers, while most women do not. Condom use was recommended to 97 percent of the male clients and 83 percent of the females; 71 percent of males received supplies of male condoms, compared to only 34 percent of females.

Clients reported positive experiences with the provider. When asked about communication with the provider, clients overwhelmingly gave a very positive picture. Just under 100 percent said that the provider explained the examination procedures to them, the results of the examination, and how to take the medication.

\section{Voluntary counseling and testing}

Client load for VCT, a relatively new service, is much less than for other reproductive health services. Compared with family planning, STI, or ANC services, relatively few clients take 


\section{KZN Situation Analysis}

advantage of VCT services. About 52 percent of the 98 facilities offer VCT, yet among the 32 facilities where VCT clients were observed and interviewed, client load averages 32 VCT clients a month, compared to 268 clients for FP, 233 for ANC, and 125 for STI services.

Of the $67 \mathrm{VCT}$ clients who provided exit interviews, the median age was 26 years, with 18 percent under age 20 . The vast majority were female ( 78 percent) and single ( 86 percent). All of the 23 clients who tested HIV-positive were females.

Counselors appear to be generally sensitive to the emotional needs of clients. Most of the counseling (78 percent) is conducted one-on-one in privacy by lay counselors. Both the nurse/observers of the counseling and the clients in exit interviews report that counselors are very attentive to establishing rapport, respecting confidentiality, listening to client concerns, responding to questions, and giving emotional support.

While condom use and living positively are generally promoted during counseling, other important topics are covered inconsistently. VCT counselors discuss prevention strategies if the test is negative, emphasizing condom use (mentioned during pre-test counseling with 71 percent of 63 clients) over abstinence and monogamy, which were mentioned to approximately a third of the same clients. In post-test counseling, counselors discussed living positively and the need for referral to other medical services with 87 percent of HIV-positive clients. But other key topics are discussed inconsistently during post-testing counseling, including treatment options (with 46 percent of HIV-positive clients), pregnancy and prevention of mother-to-child transmission (26 percent), and possible violence as a result of disclosure to a partner (14 percent).

Clients receive their information on VCT from health providers and radio. In exit interviews, clients said that their main source of information on VCT came from a health provider (40 percent), followed by radio ( 33 percent) and a friend ( 21 percent). This suggests that providers are an important source of information on VCT for clients.

The potential to monitor clients on antiretroviral drugs is fairly good. VCT is the entry point for treatment, care, and support. Slightly more than 40 percent of all facilities have the ability to provide clients with viral load counts and CD4 cell counts, and 77 percent of these facilities have a DOTS program for TB. This suggests a fairly substantial capacity to monitor and assist HIV clients when antiretrovirals become more widely available in the public sector.

\section{Recommendations}

Results of the study were presented to a large audience that included participants from the National Department of Health, the KwaZulu Natal Department of Health, NGOs, and donor agencies in a dissemination seminar held in Durban on 1-2 July 2003, in collaboration with two other ANCrelated operations research studies sponsored by the Frontiers Program. Attendees also heard a panel of health department staff present their views on high-priority issues for follow-up. Audience members added approximately 40 additional issues, and then through a group process mechanism (with each person having five votes), voted on their highest-priority recommendations. Some of 


\section{Hgrizons}

these recommendations, which directly relate to the study data, include the following:

- Strengthen links with communities and utilization of RH services by males and youth.

- Strengthen supportive supervision for nurses through establishing supervisory positions with transport.

- Increase information and emphasis on VCT and mother-to-child HIV transmission in ANC services.

- Provide counseling training for all health care providers (and include counseling for dealing with domestic violence).

- Offer VCT and STI services at every contact with clients in all RH services.

- Increase gender sensitivity in RH services to increase the attractiveness of VCT and STI services to males.

In addition, the group recommended high-priority actions not directly related to the data, including:

- Improve "care for the caregivers" by developing a more supportive environment for providers and attending to health, welfare, and problems of staff related to workload and number of staff per facility.

- Address staff exodus and turnover.

The Horizons Program expects to provide support for work on some of these topics that will likely lead to future operations research studies exploring ways to strengthen HIV/AIDS prevention efforts through an integrated approach with other services. 
KZN Situation Analysis

\section{Chapter 1 \\ Background and Study Methodology}

\section{Situation Analysis Methodology}

In the 1990s, reproductive health studies using the Situation Analysis approach proved popular and useful in Africa, where more than 25 Situation Analysis studies were implemented (Miller 1998). Since the first study in Kenya in 1989, the methodology has evolved considerably. First, services wider than FP have been assessed. Macro International in Kenya expanded the methodology to cover the sick child, ANC, and reproductive tract infections (RTIs) services in addition to FP services (Ministry of Health 2000). In Vietnam, a Situation Analysis study also covered services for termination of pregnancy, in addition to FP, ANC, and RTI services (Nhan et al. 2000). Program changes were measured over time with repeat studies, and sample sizes were generally increased.

However, in all these studies, at least three core components of this methodology remained constant: (1) gathering data on the functioning of subsystems through the use of observations and interviews, (2) documenting the actual quality of care delivered to clients by using direct observations of the delivery of services, and (3) investigating clients' perceptions through the use of exit interviews.

While the standard Situation Analysis studies have expanded in order to investigate a wider range of services, including RTIs and ANC, this methodology has not been used to address the many specific and critical components of HIV/AIDS programs. In the study reported here, this methodology has once again been expanded to include HIV/AIDS services. The expanded approach has involved the development of new instruments as well as adding HIV/AIDS issues to instruments used in earlier studies.

\section{Public Health Services in South Africa}

After the first democratic election in South Africa in 1994, a restructuring process began in the health care system that aimed to change a hospital- and curative-based system to a primary health care approach (PHC), with the district health system (DHS) providing service delivery. The goal was to transform South Africa's fragmented and centralized health system into a unified national and regional service accessible to all South Africans.

The district health system is intended to operate as a self-contained segment of the national health care system. Districts have clear administrative and geographical boundaries, encompassing all institutions and individuals providing health care, which may be under government, social security, nongovernmental organization, private, or traditional control. The system also includes hospitals at first referral level and the necessary laboratory, diagnostic, and logistic support services. 


\section{${ }^{H}$ rizons}

Services provided by the primary health care system include FP services, STI management services, maternal and child health services, and, in some cases, HIV/AIDS education, counseling, and testing. District health authorities have identified the need to integrate HIV/AIDS, ANC, and FP services with other PHC services in hospitals, clinics, and community health centers, to allow for more comprehensive reproductive health services. However, despite the commitment shown toward integrated services in policy, few successful examples of integration are documented and best practices are lacking for the implementation of integrated services (Askew, Fassihan, and Maggwa 1998). Adar and Stevens (2000) report that integration has challenged service providers and that some resist increasing the number of services provided.

A Maternal, Child and Women's Health (MCWH) Subdirectorate was established within the national Department of Health (DOH) to formulate policy, set standards, undertake national planning, provide support at the provincial level, and coordinate the reorganization of $\mathrm{MCWH}$ services. MCWH and HIV/AIDS/STI units are separate entities at the national level, while child, adolescent, and youth health services are situated in the MCWH cluster. Given the quasi-federal nature of South Africa, individual provinces are responsible for how they cover MCWH and HIV/AIDS/STIs, and a great deal of variation exists in terms of management structures and health service delivery. Provinces are divided into health districts, with District Health Authorities in charge of service administration. Some problems noted in implementing this system include the slow reorganization of municipal boundaries and structures, the lack of clarity in terms of municipal health service expectations and responsibilities, the lack of resources and infrastructure, and financial and equity pressures. ${ }^{1}$ This is especially the case in rural areas (SAHR 2002).

Although a survey by Health Systems Trust provides some information on the availability of reproductive health services in KwaZula Natal (KZN) (SAHR 2002; Viljoen et al. 2001; SAHR 2000), gaps remain in the information available at the provincial level and by facility type.

Early in 2001, the KwaZulu Natal Department of Health approached the Population Council to seek technical and financial assistance in assessing reproductive health $\mathrm{RH}$ services in the province. The Department was interested in addressing issues of quality of services and readiness to provide these services for a wide range of RH topics, with an emphasis on HIV/AIDS-related issues. In light of the Population Council's extensive experience with Situation Analysis studies conducted under the Africa Operations Research/Technical Assistance Project I and II and more recent UNFPA-funded studies in the Arab Region and Vietnam (as well as recent Macro International experience), the subdirectorate approached the Population Council to generate the desired information in order to strengthen their policies and program activities.

\footnotetext{
${ }^{1}$ Per capita funding of nonhospital PHC in KZN varies quite widely among districts, with the most deprived areas receiving the least funding (SAHR 2002).
} 
KZN Situation Analysis

\section{Sample Design}

\section{Sample selection}

KZN is divided into 10 health districts plus the metropolitan area of Durban. The metropolitan area is under the jurisdiction of the metropolitan council, while the 10 districts are further divided into 51 local councils. Local and district authorities share power and functions. District boundaries were finalized only late in 2000 (Barron and Sankar 2000). According to figures from the DOH, most PHC services are under provincial administration. More recently the provinces have moved toward taking the responsibility for health services. Where the capacity exists, however, services have been delegated to municipal and local levels (SAHR 2002). Therefore, it is apparent that most health services remain (and will continue to remain) under the jurisdiction of the KZN Provincial Government.

The goal of the Situation Analysis study was to obtain information from a representative sample of primary health care facilities in KZN that offer RH services. Given that services are predominantly provided by provincial authorities, facilities operated by local authorities (town and urban councils) were excluded.

The sampling unit in this study is the service delivery point (SDP). In KZN three main types of SDP facilities exist: the hospital (at the district, regional, and provincial levels), the community health center, and the clinic. A complete list of provincially administrated SDPs was drawn up. This was compiled from lists submitted by district offices and from information provided by the Government Communication and Information Unit (GCIS). SDPs in each district were arranged alphabetically by type and numbered. A table of random numbers was used to select a proportional number of clinics and hospitals for each district. Since there were only 12 community health centers in the province, all of these were selected. Substitute facilities were identified in the same manner for clinics and hospitals. Table 1.1 provides details on the sample selection. 


\section{Hgrizons}

Table 1.1 Total number and sample number of facilities in districts, KZN Situation Analysis 2002

\begin{tabular}{lcccccccc}
\hline Districts & \multicolumn{2}{c}{ Clinics } & \multicolumn{2}{c}{$\begin{array}{c}\text { Community } \\
\text { health } \\
\text { centers }\end{array}$} & Hospitals & \multicolumn{2}{c}{ Total } \\
& Total & Sample & Total & Sample & Total & Sample & Total & Sample \\
\hline Ethekwini & 56 & 11 & 7 & 7 & 8 & 2 & 71 & 20 \\
21 Ugu & 32 & 8 & 0 & 0 & 4 & 1 & 39 & 9 \\
22 uMgungundlovu & 24 & 5 & 3 & 3 & 3 & 1 & 27 & 10 \\
23 Uthukela & 22 & 5 & 0 & 0 & 3 & 1 & 25 & 6 \\
24 Umzinyathi & 26 & 6 & 0 & 0 & 5 & 1 & 31 & 7 \\
25 Amajuba & 13 & 3 & 0 & 0 & 3 & 1 & 16 & 4 \\
26 Zululand & 51 & 11 & 0 & 0 & 6 & 1 & 57 & 12 \\
27 Umkhanyakude & 48 & 10 & 0 & 0 & 5 & 1 & 53 & 11 \\
28 uThungulu & 44 & 9 & 0 & 0 & 6 & 1 & 50 & 10 \\
29 Ilembe & 18 & 4 & 2 & 2 & 4 & 1 & 22 & 6 \\
43 Sisonke & 18 & 4 & 0 & 0 & 4 & 1 & 22 & 5 \\
Total & $\mathbf{3 5 2}$ & $\mathbf{7 6}$ & $\mathbf{1 2}$ & $\mathbf{1 2}$ & $\mathbf{5 1}$ & $\mathbf{1 2}$ & $\mathbf{4 1 3}$ & $\mathbf{1 0 0}$
\end{tabular}

Seven facilities initially sampled were excluded from the study because of their relative inaccessibility and were replaced with substitutes. A total of seven substitutions were also made in the field, where facilities were closed or when the team could not locate or gain access to the facility. For the final sample, fieldworkers visited 100 service delivery points, one of which refused them access.

\section{Data collection}

Data were collected at 99 SDPs, although inventories were only completed at 98 facilities. Table 1.2 provides a breakdown for each service of the number of facilities where the interaction between providers and clients was observed (Obs) and where client exit interviews (Exit) were conducted. The number of instruments completed for each service type is also provided below. 
KZN Situation Analysis

Table 1.2 Number of facilities where research instruments were completed and number of instruments completed

\begin{tabular}{|c|c|c|c|c|c|c|c|c|c|}
\hline & \multicolumn{2}{|c|}{ ANC } & \multicolumn{2}{|c|}{ FP } & \multicolumn{2}{|c|}{ RTI } & \multicolumn{2}{|c|}{ VCT } & \multirow[t]{2}{*}{ Staff } \\
\hline & Obs & Exit & Obs & Exit & Obs & Exit & Obs & Exit & \\
\hline $\begin{array}{l}\text { Number of } \\
\text { facilities where } \\
\text { instruments were } \\
\text { completed }\end{array}$ & 52 & 52 & 56 & 54 & 59 & 59 & 32 & 31 & 96 \\
\hline $\begin{array}{l}\text { Number of } \\
\text { instruments } \\
\text { completed in total }\end{array}$ & 154 & 151 & 93 & 89 & 97 & 92 & 74 & 67 & 229 \\
\hline
\end{tabular}

\section{Data collection instruments}

This Situation Analysis study examines the comprehensive supply of RH services including FP, ANC, RTI, VCT services in KZN.

For each RH service examined, indicators from relevant subsystem were measured in order to help program managers and administrators answer the following basic questions:

1. Is each subsystem in place, that is, is it potentially ready to provide services?

2. If in place, is each subsystem functioning, that is, is it providing some level of service to clients?

3. If functioning, is each subsystem providing quality services in terms of:

- Choice

- Provider-client information exchange, in terms of:

- Understanding clients

- Providing information to clients

- Provider competence, in terms of:

- Qualifications

- Technical skills and knowledge

- Client-provider relations

- Mechanisms to encourage continuity

- Client access and satisfaction 


\section{${ }^{H}{ }^{\text {rizons }}$}

The following 10 instruments were adapted or developed for the study:

- Inventory

- Interview schedule for staff providing RH services.

- Observation guide for interaction between ANC clients and service providers.

- Exit interview for ANC patients.

- Observation guide for interaction between FP clients and service providers.

- Exit interview for FP clients.

- Observation guide for interaction between RTI patients and service providers

- Exit interview for RTI patients.

- Observation guide for interaction between VCT clients and service providers.

- Exit interview for VCT clients.

\section{Selection and training of fieldworkers}

All fieldworkers had extensive nursing experience, and many were also trainers. Twenty female nurses from facilities all over KZN participated in the training. The training took place from 8 to 28 September 2002. Training was provided by Population Council staff with participation by the Department of Health. During this time fieldworkers developed an understanding of the KZN protocols on RH services. The main focus of the training was an extensive review of the 10 data collection instruments. This review was aided by role-playing both the observations and the client interviews. Fieldworkers alternated in the roles of observer, interviewer, client, and staff. Consistency in coding responses was achieved by having fieldworkers observe and code the same role-play as a group, share codes, and discuss factors influencing their code selection. This was repeated until nearly all interviewers/observers used the same codes in the group role plays. The four client exit interviews were translated into the local language, isiZulu, by the field workers, which also helped to familiarize them with the content. Language consistency was achieved through the use of translation groups that concurred on all translation decisions. The translated versions were then tested on fellow fieldworkers in further role-plays of exit interviews. During this time, the instruments were reviewed extensively and relevant changes were made.

During the final week of training, a field pretest was carried out in four clinics in Ugu District (District 21). Fieldworker teams spent the day at a facility conducting as many observations and exit interviews as possible for each service, interviewing staff providing RH services, and completing the inventory.

The last two days of training were spent developing an itinerary for data collection. Members of teams did not visit SDPs where they worked and generally did not collect data in their own district. Each team had 25 SDPs to visit over a six-week period. Fieldwork was conducted from 30 September to 7 November 2002. 


\section{KZN Situation Analysis}

\section{Implementation of study}

Composition of teams. A team of fieldworkers visited each SDP in order to efficiently conduct observations and exit interviews as well as the inventory. Fieldworkers elected four colleagues as team leaders, and then allocated themselves to teams. The most experienced fieldworkers were chosen as team leaders. Four teams were formed, three with four members and one with five. Two fieldworkers were chosen as field coordinators. Team leaders were responsible for arranging logistics, introducing the team at SDPs, checking and collating instruments at the end of each day, and reporting on the progress of the fieldwork. The field coordinators ensured that teams had instruments and collected completed instruments. Field coordinators also helped with arranging transport logistics and with driving in some cases.

Workshop. After the first five days of fieldwork, a review workshop was held. This provided fieldworkers an opportunity to raise issues they encountered and to review instruments for consistency and errors. Some of the issues raised included transport problems, especially because much of the terrain was rough and the DOH vehicles were small and old. Teams also had problems getting transport arranged through the Department. The distance between SDPs was also raised as an issue. The teams often had to travel at night, especially over the weekends. This problem was aggravated by a departmental ruling that travel after 4:00 p.m. in government vehicles needed special permission. This was time consuming to arrange and resulted in several delays.

Another issue was that although health care was supposed to be integrated, there were still "days for services" and other systems to regulate client flow. In addition, there were difficulties in collecting data at hospitals, where service statistics were difficult to find and collect. Some services were also divided into stations, especially for ANC and FP. The teams reported that clients received different parts of the service at separate stations. For example, blood pressure and weight was taken at one station, and then the client moved elsewhere. In addition, information on FP methods was provided to all the FP clients in the same room and then they went individually to choose their method. This made the observation more difficult to complete and meant that the same fieldworker had to do all the observations. There were also a few reports of managers not being available, and expressions of suspicion or hostility from a few senior staff. Fieldworkers, however, reported being well received in most cases.

A debriefing meeting was held with the teams after the fieldwork was completed. Team leaders provided an overview of their findings and of problems experienced in the field that may have affected the quality of the data collected.

\section{Ethical issues}

Ethical issues raised by this research include the privacy and confidentiality of client's information, especially in the case of VCT clients, where information about HIV status was collected. The identity of service providers and clients was protected by not recording names, and by using a code to identify participants. In addition, exit interviews were carried out with as much privacy as 


\section{${ }^{H}{ }^{\text {rizons }}$}

possible. The use of all instruments involved reading a statement of informed consent to the participants detailing the goals of the study and stating clearly that participation was voluntary and would not affect their access to or use of services. In the case of VCT clients, fieldworkers considered the psychological well-being of clients who had been diagnosed as HIV-positive, and clients who were obviously emotionally distressed were not approached for the exit interview. Another issue raised during the training concerned the observer's responsibility to the client's welfare. All fieldworkers were instructed that, if they judged the clients to be endangered by the actions of a service provider, they should intervene and correct the problem. However, fieldworkers reported that they did not actually face a situation requiring such an intervention. Fieldworkers were, however, sometimes asked by clients to provide information during exit interviews, and agreed to do so after the completion of the interview. Staff and facility managers were also reassured that their performance was not being evaluated and that findings would not be reported by facility.

\section{Organization of the Report}

The report is divided into eight chapters. Chapter 2 provides a description of the characteristics of the study facilities, as well as a discussion on the availability and integration of services provided at these facilities. Chapter 3 examines the characteristics, training, and experience of the staff working at the surveyed SDPs. Chapters 4-7 focus on specific services provided at the SDPs, starting with FP services, followed by ANC services, RTI services, and VCT services. Each of these chapters addresses four key areas: (1) a description of services offered in KZN; (2) an assessment of the capacity of the facilities to provide each service; (3) an evaluation of clientprovider interaction and the quality of services provided; and (4) a presentation of clients' experiences with and views about the services provided. Chapter 8 provides a description of the data interpretation workshop held with key stakeholders and provides recommendations for next steps. 
KZN Situation Analysis

\section{Chapter 2 \\ Study Facilities and I ntegration of Services}

This chapter outlines the major findings from the inventory. The chapter presents information on the functioning of key subsystems, including physical infrastructure, logistics and record keeping, and the equipment, supplies, and commodities currently available at the facility.

\section{Number and Type of Facilities}

A total of 99 health facilities were surveyed over a period of six weeks (one hospital from the sample of 100 SDPs refused access to fieldworkers). Inventories were completed for 98 SDPs, as fieldworkers were unable to complete an inventory at one hospital where the facility manager was away. Table 2.1 provides data on the location of facilities surveyed. SDPs were predominantly located in rural areas - two-thirds were rural, 22 percent were in peri-urban and 11 percent were in urban areas. ${ }^{2}$ Data were collected on 10 hospitals, ${ }^{3} 12$ community health centers, and 76 clinics. A high percentage of clinics ( 76 percent) and hospitals ( 60 percent) were situated in rural areas, while community health centers (CHCs) were concentrated in peri-urban areas ( 58 percent). Of the 98 SDPs where full data was collected, 19 had begun to implement youth-friendly services but only had been officially designated a youth-friendly center.

Table 2.1 Percentage of facilities by type and location

\begin{tabular}{lcccc}
\hline Location of facility & $\begin{array}{c}\text { All facilities } \\
(\mathbf{n}=\mathbf{9 8})\end{array}$ & $\begin{array}{c}\text { Hospitals } \\
(\mathbf{n}=\mathbf{1 0})\end{array}$ & $\begin{array}{c}\text { CHCs } \\
(\mathbf{n}=\mathbf{1 2})\end{array}$ & $\begin{array}{c}\text { Clinics } \\
(\mathbf{n}=\mathbf{7 6})\end{array}$ \\
\hline Urban $(\mathrm{n}=11)$ & 11 & 10 & 33 & 8 \\
Peri-urban $(\mathrm{n}=22)$ & 22 & 30 & 58 & 16 \\
Rural $(\mathrm{n}=65)$ & 66 & 60 & 8 & 76 \\
Total & $\mathbf{9 9 *}$ & $\mathbf{1 0 0}$ & $\mathbf{9 9 *}$ & $\mathbf{1 0 0}$ \\
* Totals do not add up to $100 \%$ because of rounding. & & &
\end{tabular}

\section{Facility Size and Patient Load}

Statistics are generally not well kept at facilities, and are not recorded in a standardized manner across services. This was generally found to be the case regardless of the location (rural, periurban, or urban) or type of facility. Service statistics are submitted to various district offices

\footnotetext{
${ }^{2}$ Percents sometimes do not add up to 100 because of rounding off.

${ }^{3}$ Twelve hospitals were visited, but one hospital refused access to interviewers, and interviewers were unable to fill out an inventory for another hospital.
} 


\section{${ }^{H}{ }^{\text {rizons }}$}

without having rigorous documentation. Fieldworkers reported that in some cases figures were filled in on sheets of paper, which were then submitted without a copy being filed at the facility. In addition, no central statistics were kept at some hospitals. When different services kept records separately, data collection was difficult. Data presented in Table 2.2 therefore should be interpreted with caution. Fieldworkers reported that the number of clients seen in a month is probably underestimated in the available data.

When service statistics are disaggregated by facility type, it is clear that hospitals tend to provide more specialized services (for example, termination of pregnancy [TOP]) than clinics. And CHC's see higher numbers of patients for ANC, FP, and STI management. On average, CHCs provide a wider range of services and see a higher number of clients than clinics. Hospitals see the least number of clients on average for RH services. CHCs also perform more pap smears than clinics or hospitals. However, as expected, although most referrals for TOP came from clinics, most (manual vacuum aspirations) MVAs were performed at hospitals. HIV/AIDS-related services (such as VCT and nevirapine for preventing mother to child transmission) were provided on average to more clients at CHCs than at hospitals, and to the least number of clients at clinics. CHCs also referred more clients for directly observed treatment short-course (DOTS) than hospitals, with clinics referring the lowest number of clients on average. 
Table 2.2 Percentage of 98 facilities with data available, and total, median, and mean number of clients served in August 2002*

\begin{tabular}{|c|c|c|c|c|}
\hline RH service/function & $\begin{array}{l}\text { Percent of } \\
\text { facilities } \\
\text { with data }\end{array}$ & $\begin{array}{l}\text { Number of } \\
\text { clients }\end{array}$ & $\begin{array}{c}\text { Median } \\
\text { number of } \\
\text { clients }\end{array}$ & $\begin{array}{c}\text { Mean } \\
\text { number of } \\
\text { clients }\end{array}$ \\
\hline Management of STIs & 94 & 11,522 & 52 & 125 \\
\hline Total FP clients & 94 & 24,652 & 149 & 268 \\
\hline Under 18 & 82 & 2,336 & 10 & 29 \\
\hline Total antenatal care visits & 84 & 19,134 & 118 & 233 \\
\hline First visit & 62 & 3,245 & 26 & 53 \\
\hline Repeat visits & 60 & 12,335 & 108 & 209 \\
\hline Under 18 & 31 & 940 & 10 & 31 \\
\hline TOP referrals & 44 & 182 & - & 4 \\
\hline TOPS (MVA) performed & 44 & 41 & - & 1 \\
\hline Pap smears given & 71 & 329 & - & 5 \\
\hline Results for pap smears given & 62 & 217 & - & 4 \\
\hline VCT clients & 67 & 2,140 & 10 & 32 \\
\hline HIVIAIDS tests conducted & 71 & 2,097 & 11 & 30 \\
\hline Clients returning for HIV results & 69 & 1,753 & 9 & 26 \\
\hline Mothers given nevirapine & 57 & 292 & - & 5 \\
\hline Newborns given nevirapine & 54 & 161 & - & 3 \\
\hline $\begin{array}{l}\text { Clients counseled for abuse \& } \\
\text { violence }\end{array}$ & 45 & 25 & - & 0.5 \\
\hline $\begin{array}{l}\text { Clients referred for post-exposure } \\
\text { prophylaxis (rape) }\end{array}$ & 70 & 17 & - & 0.4 \\
\hline Clients referred for DOTS & 68 & 4,528 & 6 & 68 \\
\hline AIDS clinical patients & 8 & 235 & 27 & 29 \\
\hline & $\begin{array}{c}\text { Statistics } \\
\text { available at } \\
\text { facilities } \\
\text { (Percent) }\end{array}$ & $\begin{array}{c}\text { Total } \\
\text { number } \\
\text { supplied }\end{array}$ & $\begin{array}{l}\text { Median } \\
\text { number } \\
\text { supplied }\end{array}$ & $\begin{array}{c}\text { Mean } \\
\text { number } \\
\text { supplied }\end{array}$ \\
\hline Male condoms distributed & 93 & 184,859 & 1,000 & 2,031 \\
\hline Female condoms distributed & $4^{* *}$ & 992 & 196 & 248 \\
\hline $\begin{array}{l}\text { High-dosage combined oral } \\
\text { contraceptives (COC) (Ovral) }\end{array}$ & 76 & 8,720 & 32 & 117 \\
\hline
\end{tabular}




\section{Herizons}

When service statistics were disaggregated by location, it is clear that more clients are receiving STI, FP, ANC, and VCT services in urban facilities than in rural or peri-urban facilities. Similarly, more clients received nevirapine, pap smears, and referral for DOTS in urban facilities. Possible explanations for this pattern include infrastructure and human resources constraints in rural facilities, and higher client demand for, and greater awareness of services in urban areas.

\section{Operating Times}

A key determinant of accessibility to services is operating times. Longer operating times, especially after regular hours, may ensure that more people are able to use services. Information reported here is based on the observed opening and closing times of SDPs as well as the hours and number of days SDPs reported being open. This provides a balance between information provided by the facility and actual observed data. However, in some cases interviewers were unable to reach facilities before they opened or, in the case of 24-hour facilities, data is based only on reported operating hours. Fieldworkers were unable to observe the opening time of 11 percent of facilities. Ten percent of facilities surveyed were open 24 hours a day and 25 percent were open seven days a week. Most of the remaining facilities were open five days per week. Opening hours were usually from 7:00 a.m. to 4:00 p.m. (including a lunch break for staff).

Fieldworkers also recorded the time the first client and last client were seen. This shows when clients use the services. The first client was seen before 8:00 a.m. in 50 percent of facilities, while the last client was seen before 1:00 p.m. in 50 percent of facilities and by 3:00 p.m. in 75 percent of facilities, indicating that clients tended to be seen in the mornings and early afternoons.

Fieldworkers reported that staff encourage clients to come early. Staff reported that they preferred to use the afternoons for administrative work and cleaning the facility. This results in clients waiting in long queues in the morning, and limits access to services. In rural areas, fieldworkers also found that some facilities had few clients because of bad weather and local transport problems.

\section{Availability of Services}

Although the KZN Department of Health is committed to providing primary health care at all facilities and to integrating services, information on the availability of services offered is needed in order to measure how well these commitments are actually met

Table 2.3 presents the percentage of all surveyed facilities offering $\mathrm{RH}$ services, as well as a breakdown of services by facility type. FP, STI, and ANC services were available at more than 90 percent of all facilities. Far fewer facilities offered emergency contraception services (67 percent), maternity care (64 percent), management of obstetrical complications (60 percent), and cervical and breast cancer screening (58 percent). Fifty-two percent of facilities offered VCT services, 44 percent post-exposure prophylaxis (PEP), 28 percent PMTCT, and 27 percent rape counseling services. Only 4 percent of the facilities offered TOP services, and none offered colposcopy services. Given the high rates of undetected cervical cancer in South Africa, of concern is the low 
availability of cervical cancer screening services (pap smears and colposcopy). According to DOH policy, all services except complications (or referrals) should be provided at the primary level of care.

When data were examined by facility type, the pattern of services offered remained the same, with the exception of HIV/AIDS services (PEP, VCT, and PMTCT), which were offered at far more hospitals and $\mathrm{CHCs}$ than at clinics. In addition, obstetrical complications were not managed at many clinics (55 percent). Another service offered at far fewer clinics than hospitals or CHCs was cervical cancer screening. TOP was offered only at hospitals.

It appears that HIV/AIDS services have not been comprehensively integrated into PHC and that there is room for expansion of these services. However, it must be noted that PMTCT and PEP services are relatively new and that KZN is still in the process of "rolling these services out."

The availability of services does not necessarily mean that these services are offered on a "onestop" basis or by the same staff member. Services tended to be offered in separate departments at hospitals and CHCs. In addition, particularly in the case of ANC services, services tended to be offered only on specific days rather than throughout the week. Reasons given for "days for services" included that blood specimens were collected only on a certain day, and lack of trained staff to provide daily services.

The Department of Health specifies that facilities should have copies of the latest sexual and reproductive health protocols and guidelines on hand. Table 2.4 shows the percentage of facilities with key RH protocols available. Facilities usually did not have these available, with the exception of the guidelines on syndromic management of STIs (94 percent), KZN guidelines for the management of pregnancy ( 71 percent) and the cervical cancer screening policy (63 percent). Fewer facilities had the policies or protocols on adolescent health (16 percent), contraceptive policy (27 percent), termination of pregnancy ( 27 percent), PMTCT (30 percent), sterilization (31 percent), and treatment of rape survivors (48 percent). 


\section{Hgrizons}

Table 2.3 Percentage of facilities offering RH services

\begin{tabular}{lcccc}
\hline RH service & $\begin{array}{c}\text { All facilities } \\
(\mathbf{n}=\mathbf{9 8})\end{array}$ & $\begin{array}{c}\text { Hospitals } \\
(\mathbf{n}=\mathbf{1 0})\end{array}$ & $\begin{array}{c}\text { CHCs } \\
(\mathbf{n}=\mathbf{1 2})\end{array}$ & $\begin{array}{c}\text { Clinics } \\
\text { (n= 76) }\end{array}$ \\
\hline Family planning & 99 & 100 & 100 & 99 \\
Emergency contraception & 67 & 70 & 100 & 62 \\
Termination of pregnancy & 4 & 20 & 8 & 1 \\
Antenatal care/postpartum care & 93 & 90 & 100 & 92 \\
Maternity care/delivery services & 64 & 70 & 83 & 61 \\
Management of obstetrical & & & & 55 \\
complications & 60 & 70 & 83 & \\
STI counseling, diagnosis, and & & & 100 & 96 \\
treatment & 97 & 90 & 83 & 43 \\
VCT & 52 & 80 & 42 & 16 \\
PMTCT (including counseling & & 100 & & \\
and nevirapine) & 28 & & 92 & 50 \\
Pap smear/cervical cancer & & 80 & 25 & 26 \\
screening, breast cancer & 58 & 30 & 75 & 38 \\
screening & 27 & 50 & 0 & 0 \\
Rape counseling & 44 & 0 & &
\end{tabular}

Table 2.4 Percentage of facilities with protocols on sexual and reproductive health available $(n=97)$

\begin{tabular}{lr}
\hline Protocols & Percent \\
\hline Choice on termination of pregnancy act/protocol & 27 \\
Sterilization act/protocol & 31 \\
Cervical cancer screening policy/protocol & 63 \\
National contraceptive policy guidelines & 27 \\
Adolescent/youth health policy guidelines & 16 \\
KZN protocol for management of rape victims & 48 \\
KZN guidelines for management of pregnancy & 71 \\
Guidelines on syndromic management of STIs & 94 \\
Protocol for PMTCT of HIV in KZN & 30
\end{tabular}


As illustrated in Figure 2.1, oral contraceptives (combined [COC] and progestin only [POP]) and the two types of injectable contraceptives were available in nearly all facilities. Other family planning methods were not as widely available. Five percent of facilities did not supply male condoms and 18 percent did not supply emergency contraception (EC). Eleven percent of facilities had female condoms and only 3 percent had intrauterine devices (IUDs).

Figure 2.1 Percentage of facilities with FP methods available $(n=97)$

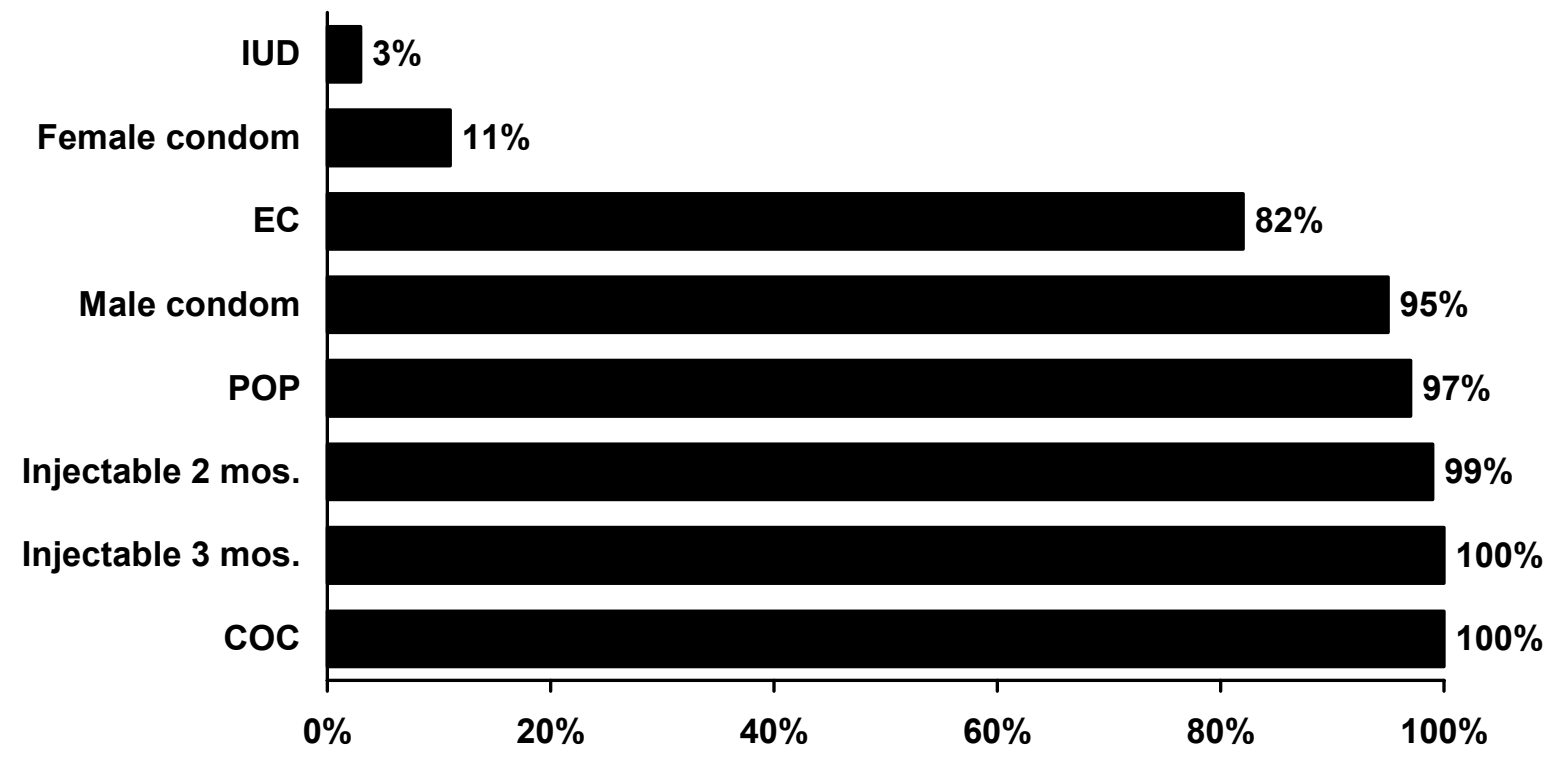

Table 2.5 shows that stock-outs of contraceptives occur at a sizeable proportion of facilities. These may result in negative outcomes for clients. Because a regular supply of condoms remains a vital part of HIV and STI prevention efforts, of concern is that 18 percent of facilities had a stock out of condoms in the last six months. Other method stock-outs included the two-month (15 percent) and three-month injectable contraceptives (13 percent) and combined (13 percent) and progestin-only oral contraceptives (12 percent).

Clinics have the lowest level of stock-outs, while hospitals have the highest rate of stock-outs of oral contraceptives, male condoms, and injectables. Possible reasons for fewer stock-outs at clinics include the higher demand for FP at these facilities and their tradition of providing FP as a standalone service, resulting in the development of a better supply system. 


\section{Hgrizons}

\begin{tabular}{|c|c|c|c|c|}
\hline $\begin{array}{l}\text { Contraceptive } \\
\text { method }\end{array}$ & $\begin{array}{l}\text { All facilities } \\
(n=98)\end{array}$ & $\begin{array}{l}\text { Hospitals } \\
(n=10)\end{array}$ & $\begin{array}{c}\text { CHCs } \\
(n=12)\end{array}$ & $\begin{array}{l}\text { Clinics } \\
(n=76)\end{array}$ \\
\hline Combined pills & 13 & 20 & 17 & 12 \\
\hline Progestin-only pills & 12 & 30 & 17 & 9 \\
\hline IUDs & 2 & 20 & 0 & 0 \\
\hline Male condoms & 18 & 30 & 17 & 17 \\
\hline Female condoms & 4 & 10 & 17 & 1 \\
\hline 2-month injectables & 15 & 30 & 25 & 12 \\
\hline 3-month injectables & 13 & 30 & 17 & 11 \\
\hline
\end{tabular}

\section{Infrastructure}

Key elements of SDP infrastructure that were assessed included availability of electricity, water, telephone lines, seats for waiting clients, and toilet facilities. In addition, the auditory and visual privacy during consultations and examinations was assessed.

Figure 2.2 shows the percent of all facilities meeting the above infrastructural requirements. Electricity is vital for lighting and for operating equipment, while water is necessary for hand washing and for cleaning equipment and facilities. Telephone communications ensure that emergency referrals can be made and that facilities remain in communication with their district offices and supervisors. In general, facilities in KZN have established infrastructure and access to the basic services necessary for the delivery of RH care. Most facilities had electricity (94 percent) and telephone services available (94 percent), although a lower percentage of facilities had an adequate amount of safe water available in examination rooms (81 percent). Fifty-eight percent of facilities had piped water supplied by their municipality, while the remaining facilities were supplied with water from boreholes or delivered by water tankers. The fact that one-third of facilities do not have access to piped water may result in water shortages. This was observed at 19 percent of facilities, which had inadequate clean water available in the examination area on the day of the survey. Fieldworkers reported that some providers did not wash their hands before putting on gloves or after taking them off, which may relate to water shortages and has implications for quality of services.

The examination area was almost always clean (98 percent) and clean linen was available in 84 percent of facilities. Fieldworkers noted that renovations were taking place in several facilities, and that the condition of facilities varied. Although almost all facilities were clean, one clinic had dirty walls, no ceiling, and a floor that was covered in bird droppings. Many clinics were small. For example, one clinic was in a house with only four small rooms. 
Figure 2.2 Percentage of facilities with infrastructural elements in $\mathrm{KZN}^{*}$

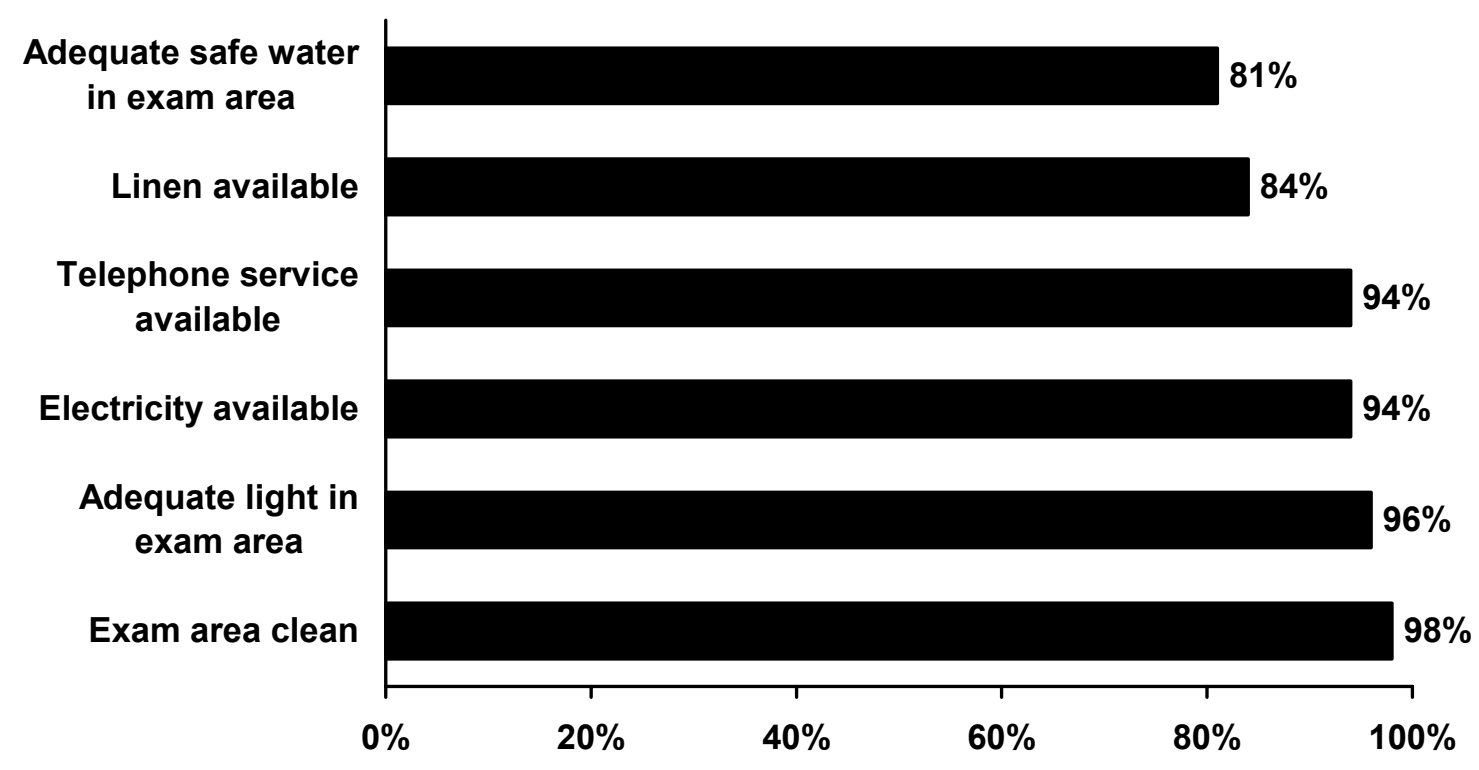

*Exam area clean, adequate light, and electricity available $(n=98)$; telephone service available and adequate safe water $(n=96)$; linen available $(n=97)$.

Not unexpectedly, infrastructure at clinics (which are in rural areas) proved to be less adequate than at other types of facilities. While all CHCs and 9 out of 10 hospitals had sufficient safe water in examination rooms, 22 percent of clinics did not have sufficient water. Similarly, while all CHCs and hospitals had electricity, 8 percent of clinics did not have electricity. One hundred percent of hospitals and CHCs had piped water, while only 37 percent of clinics had piped water. Considering that the SDPs surveyed were likely to be more accessible than other SDPs, these data may overstate the availability of electricity and piped water in very rural areas. However, it is promising that infrastructure other than piped water is largely in place at the SDPs surveyed.

Another issue affecting quality of service is the availability of waiting areas for clients. A waiting room with sufficient seats and working toilets are basic requirements. Nearly all facilities had seats available in their waiting rooms for clients to use ( 99 percent), but in 50 percent of facilities these were judged inadequate for the number of clients attending services. Though all the facilities surveyed had working toilet facilities for clients, fieldworkers reported that these were usually in poor condition and were often dirty. Considering that clients often wait a long time for services (especially in the mornings), improvements in waiting areas deserve attention.

The sensitive nature of RH services requires auditory and visual privacy both for examinations and counseling. Table 2.6 provides the percent of facilities where examinations and counseling sessions are conducted in privacy. In terms of visual privacy, most facilities provided examinations (97 percent) and counseling (91 percent) in an area where other clients could not see them. Auditory 


\section{Hgrizons}

privacy during examinations and counseling was reported in 76 percent of facilities. Of concern was that only slightly more than one-half (51 percent) of the facilities had a designated area for HIV/AIDS or STI counseling. Obviously there are limits in terms of physical infrastructure, especially at clinics, where space is often at a premium and fieldworkers reported that in some facilities there are more counselors than counseling rooms. However, fieldworkers also reported that innovative ways of dealing with these issues were seen in the field, including one clinic where radio music ensured that counseling could not be overheard.

Table 2.6 Percentage of facilities offering designated areas for STI/HIVIAIDS counseling and private areas for RH examinations and counseling

\begin{tabular}{ll}
\hline Private exams and counseling $(n=98)$ & Percent
\end{tabular}

\begin{tabular}{ll}
\hline Designated area for STI/HIV/AIDS counseling & 51
\end{tabular}

$\begin{array}{ll}\text { Private area for examinations where other clients cannot see } & 97\end{array}$

$\begin{array}{ll}\text { Private area for examinations where other clients cannot hear } & 76\end{array}$

$\begin{array}{ll}\text { Private area for counseling where other clients cannot see } & 91\end{array}$

$\begin{array}{ll}\text { Private area for counseling where other clients cannot hear } & 76\end{array}$

\section{Availability of Staff and Supervision}

Staff shortages at PHC facilities are documented, ${ }^{4}$ and fieldworkers confirmed that shortages existed in many of the facilities visited. Facilities were usually staffed by nurses, and 97 percent of facilities had one or more professional nurses. However, facilities tended not to have a large complement of nurses, with 11 percent of facilities having only one professional nurse and 25 percent having two. Few facilities had specialist physicians ( 4 percent full time, 14 percent part time), or physicians (10 percent full time, 37 percent part time). The availability of other staff providing services was also low, especially in the case of laboratory technicians. Ninety-two percent of facilities (100 percent in the case of clinics) had no laboratory technicians on site. This affects the availability of laboratory testing at facilities. It also limits the accessibility of services, since services and sample collection must be coordinated, which usually results in the service being available only one day per week.

Community health workers (CHWs) are not part of the government staff complement and are provided by either nongovernmental organizations (NGOs) or other organizations. Sixty-one percent of facilities had community health workers. Counseling is a vital part of VCT services and

\footnotetext{
${ }^{4}$ For example, SAHR (2002) reports reductions in the total numbers of key health personnel, including professional nurses and medical specialists, and it notes that 36 percent of all KZN health posts are vacant. There have also been reports about this in the media, for example, in the articles "KZN hospitals under pressure" (Health-e News, 27 November,/2002), "KZN salary increases could be scrapped" (Mail and Guardian, 17 to 23 January 2003), and “A losing battle?" (Health-e News, 10 February 2003).
} 


\section{KZN Situation Analysis}

PMTCT, and properly trained and supported CHWs increase access to HIV/AIDS services and lessen the workloads of nursing staff. ${ }^{5}$ However, fieldworkers reported that at some facilities the relationship between CHWs and nurses was strained and that clinic staff felt that CHWs had been "imposed" from outside of their facility. In one case the relationship had deteriorated to such an extent that duplicate counseling services were provided by CHWs and the nursing staff. There is clearly room for expansion and consolidation of this program, especially in the context of HIV/AIDS.

Fieldworkers reported that staff shortages restricted access to services at some facilities. Where only one professional nurse provides all the services, services are offered only on certain days. Fieldworkers reported that retired nursing professionals are often recalled to fill staffing gaps. The shortage of more qualified staff also makes in-service training difficult, because facilities are left with enrolled nurses in charge when professional nurses are participating in in-service courses. Similarly, there was some difficulty in obtaining the release of advanced nurses to implement this study as they were needed at their facilities. One fieldworker had to return to her facility to prevent it from closing because of the shortage of staff.

Another key staffing issue is regular supervision. More than three-quarters of the facilities reported a supervisory visit in the preceding three months. The mean number of visits was four; however, the median number of visits was only two. Figure 2.3 presents the functions performed by the supervisor on their last visit. Most commonly reported activities of supervisors were asking about problems in the facility, and checking to ensure that all the services were provided. Just over onehalf of the supervisors completed the supervisor's checklist and one-half checked the recording and reporting of information. Less than one-half of the supervisors were reported to provided encouragement and motivation or provide recommendations for improving service quality.

\footnotetext{
${ }^{5}$ Lack of adequate staff for VCT services was identified as a problem in the "National Report on the Assessment of the Public Sector's Voluntary Counselling and Testing Programme" (available online from http://www.hst.org.za/pubs/research/vct.pdf).
} 


\section{H ${ }^{\text {rizons }}$}

Figure 2.3 Percentage of facilities at which staff report various supervisory actions $(n=73)$

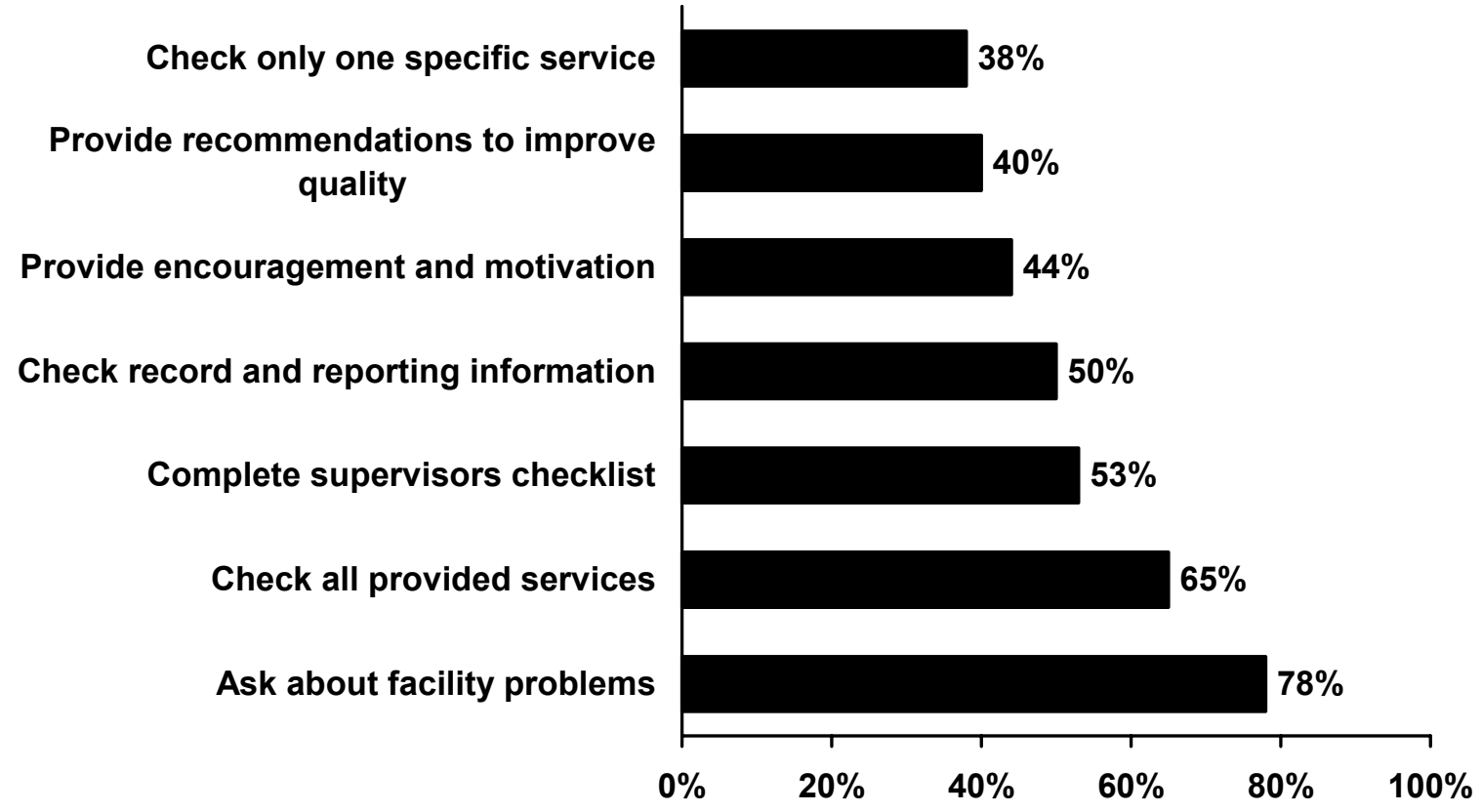

The Department of Health has produced a supervisor's file, which lays out in detail all the supervisory requirements. From the data collected it is apparent that this is not being used adequately. In particular, areas that can be improved are the monitoring and collection of statistics and record keeping, motivation, and ways of improving service quality. Staff morale appears to be a critical issue in the province, ${ }^{6}$ and ways to improve it are urgently needed. In addition, nearly a quarter of facilities had no supervision in the last three months. Given that many facilities are operated by few staff members, more support and professional guidance may be needed to improve service quality.

\section{Availability of Health Education Materials}

Signs alert clients to the availability of services. Services at the facilities surveyed usually were not well advertised with signs. Table 2.7 indicates the percent of facilities with different types of signs for each service. In summary, the percent of facilities having signs for various services were: FP 53 percent, ANC 41 percent, VCT 38 percent, HIV/AIDS 46 percent, STI 48 percent, and other

\footnotetext{
${ }^{6}$ See, for example, "KZN hospitals under pressure" (Health-e News, 27 November 2002), "KZN salary increases could be scrapped" (Mail and Guardian, 17 to 23 January 2003), which reports 15,000 grievances lodged by employees, and "A losing battle?" (Health-e News; 10 February 2003), referring to the 'haemorrhaging' of health professionals.
} 
services 49 percent. Between one-fifth and 37 percent of the facilities had a sign inside advertising services, while under a fifth of all services had a sign outside advertising services. Very few facilities had both inside and outside signs. Signs may be especially important at facilities where new services have recently been added. Lack of signs may also make services hard to find, especially in hospitals, and fieldworkers reported that in one hospital they were unable to locate VCT services which reportedly existed.

Table 2.7 Percentage of facilities with signs or posters advertising RH services

\begin{tabular}{|c|c|c|c|c|}
\hline \multirow[t]{2}{*}{ RH services } & \multicolumn{4}{|c|}{ Location of sign or poster } \\
\hline & Inside & Outside & Both & $\begin{array}{c}\text { Facilities with } \\
\text { signs }\end{array}$ \\
\hline $\mathrm{FP}(\mathrm{n}=95)$ & 35 & 12 & 6 & 53 \\
\hline ANC $(n=96)$ & 21 & 17 & 3 & 41 \\
\hline $\operatorname{VCT}(n=94)$ & 21 & 15 & 2 & 38 \\
\hline HIVIAIDS services $(n=93)$ & 30 & 13 & 3 & 46 \\
\hline STI services $(n=94)$ & 37 & 9 & 2 & 48 \\
\hline Other services $(n=89)$ & 34 & 15 & 0 & 49 \\
\hline
\end{tabular}

Figure 2.4 shows the proportion of all facilities with information, education, and communications (IEC) materials on RH topics. Many facilities did not have IEC materials for clients to take home on RH topics, except for those on HIV/AIDS prevention, which were available in 61 percent of facilities. Very few facilities had materials on TOP, postpartum care, and PMTCT. When data is disaggregated by facility type, it is apparent that hospitals are the most well stocked with IEC materials and that clinics are the least well stocked with them. Materials provide clients with accurate information on complicated issues, which can increase client knowledge considerably. Mechanisms to address how IEC materials are distributed need to be investigated. 


\section{Hgrizons}

Figure 2.4 Percentage of facilities with educational materials available for clients to take home $(n=98)$

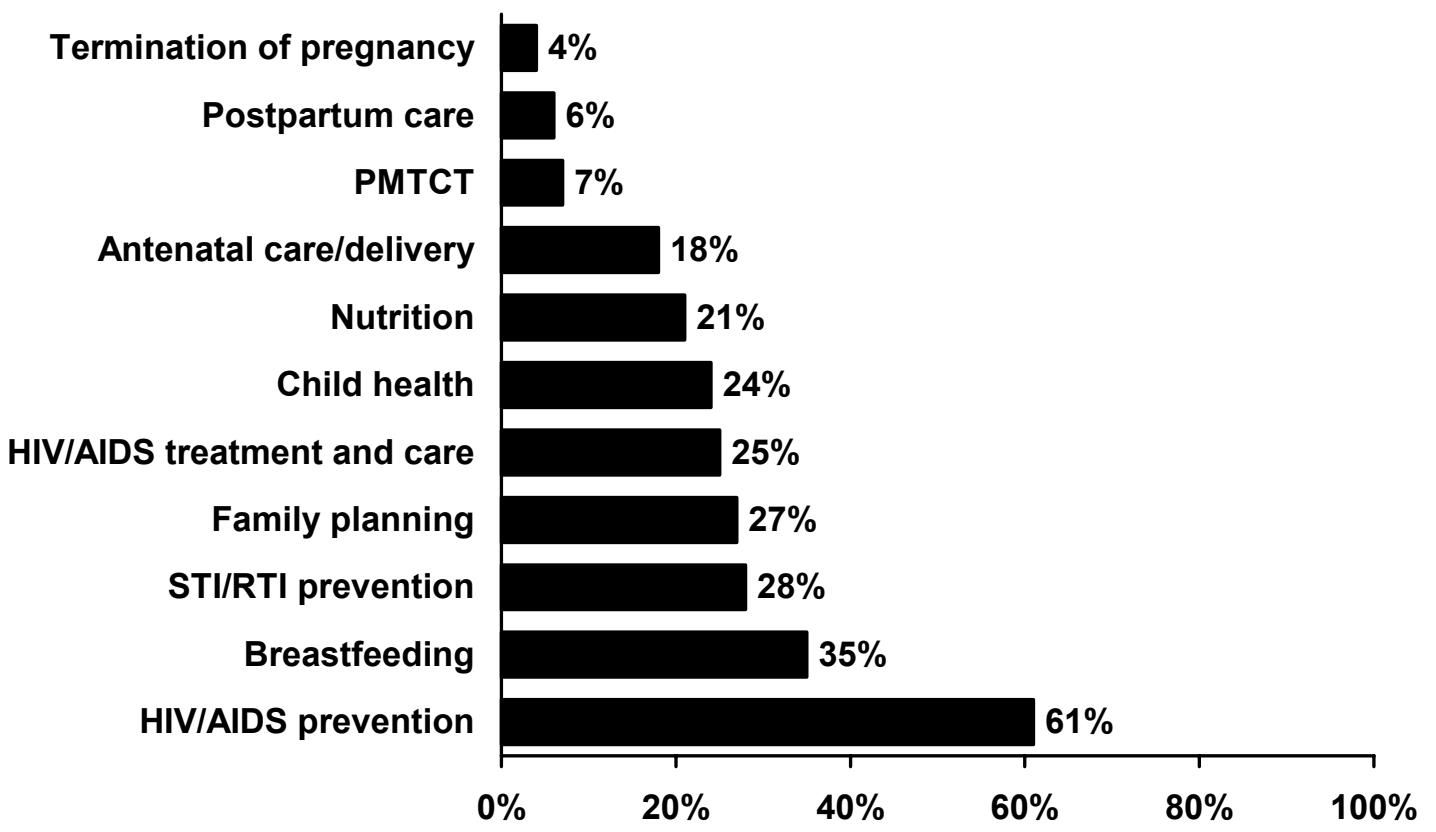

\section{Availability of Equipment}

Essential equipment for conducting reproductive health services can be divided into general equipment required for all service delivery and equipment necessary for specific services and at different levels of service delivery. Table 2.8 presents data on equipment available for all facilities and by facility type.

In terms of general requirements, a stethoscope, blood pressure gauge, thermometer, syringes and needles, an adult scale, and gloves are required to perform most services. It is encouraging that the vast majority of facilities have this equipment available. However, even a small percent of facilities lacking essential equipment is of concern and should be addressed. In addition, when data is disaggregated by facility type, a higher percent of hospitals had all types of equipment than did clinics.

An area needing attention is that of sterilization equipment. More than one-half of all facilities surveyed (56 percent) had none of the three types of sterilizers (including an autoclave and a dry heat sterilizer). Only 2 percent of facilities had all three types of sterilizers, while 5 percent had two types of sterilizers. Twelve percent of facilities had only an autoclave, and 24 percent of facilities had only a sterilizer. Clinics were generally less well equipped with sterilization equipment, with only 5 percent having an autoclave and none having a dry heat sterilizer. 
Lamps for operations were also not widely available, with only 33 percent of facilities having these. Only 25 percent of clinics had a lamp.

In addition, few facilities, especially clinics, had the more expensive equipment such as incubators, $\mathrm{X}$-ray machines, ultrasound scanners, and microscopes. Equipment necessary for specific RH services will be discussed in more detail in chapters that follow.

Table 2.8 Percentage of facilities with equipment available

\begin{tabular}{|c|c|c|c|c|}
\hline Equipment available & $\begin{array}{l}\text { All facilities } \\
(n=98)\end{array}$ & $\begin{array}{l}\text { Hospitals } \\
(n=10)\end{array}$ & $\begin{array}{c}\text { CHCs } \\
(n=12)\end{array}$ & $\begin{array}{l}\text { Clinics } \\
(n=76)\end{array}$ \\
\hline Thermometer & 99 & 100 & 100 & 99 \\
\hline Regular stethoscope & 100 & 100 & 100 & 100 \\
\hline Disposable syringes & 99 & 100 & 100 & 99 \\
\hline Reusable syringes & 3 & 10 & 0 & 3 \\
\hline Disposable gloves & 100 & 100 & 100 & 100 \\
\hline Blood pressure gauge & 99 & 100 & 100 & 99 \\
\hline Doppler for fetal heart rate & 12 & 30 & 42 & 5 \\
\hline Incubator & 20 & 78 & 67 & 5 \\
\hline Sterilizer & 32 & 20 & 50 & 30 \\
\hline Autoclave & 19 & 90 & 50 & 5 \\
\hline Dry heat sterilizer & 2 & 11 & 8 & 0 \\
\hline Lamp for operations & 33 & 56 & 67 & 25 \\
\hline Vacuum aspirator (electric) & 59 & 70 & 67 & 56 \\
\hline Vacuum aspirator (manual) & 37 & 44 & 50 & 33 \\
\hline Microscope & 10 & 40 & 42 & 1 \\
\hline Ultrasound scanner & 12 & 80 & 33 & 0 \\
\hline X-ray machine & 18 & 89 & 75 & 0 \\
\hline Fetoscope & 98 & 100 & 100 & 97 \\
\hline Measuring tape & 95 & 100 & 100 & 93 \\
\hline Scale for adults & 98 & 100 & 100 & 97 \\
\hline Aylesbury spatulas & 52 & 40 & 75 & 49 \\
\hline Colposcope & 3 & 20 & 8 & 0 \\
\hline Speculum & 93 & 90 & 92 & 93 \\
\hline Dildo/penis model & 71 & 80 & 73 & 69 \\
\hline Delivery table & 75 & 70 & 75 & 75 \\
\hline Gynecological exam table & 45 & 70 & 67 & 38 \\
\hline
\end{tabular}




\section{Hgrizons}

\section{Availability of Essential Drugs}

It is encouraging that the majority of facilities have the medications identified by the Department of Health as essential for RH service delivery.

Table 2.9 shows the percent of facilities with essential drugs available. Drugs were generally available for treating STIs, with more than 96 percent of facilities with amoxycillin, ciprofloxacin, doxycycline, erythromycin, and penicillin in stock. In terms of ANC services, 80 percent of facilities had vitamin A and high proportion of facilities had the commodities necessary to provide FP services. Practically all the facilities stocked the two injectables, with 98 percent of facilities stocking norethisterone and 99 percent medroxyprogesterone. Facilities usually stocked both combined oral contraceptives (Nordette, Ovral, and Triphasil) and progesterone-only pills (Microval), although slightly fewer had the latter in stock (96 percent).

More than 95 percent of facilities stocked methyldopa. Fewer facilities had Oxytoxin, Syntometrine, and magnesium sulphate, and the doctor-initiated drugs naloxone and Nepresol. Ninety-three percent of facilities had adrenaline.

However, one area of concern is the low availability of HIV post-exposure treatment. This was originally intended only for health personnel who experience a needle-stick or other accidental exposure to possible HIV infection. However, now facilities are supposed to offer post-exposure treatment to rape victims. Only 51 percent of SDPs currently had post-HIV exposure starter packs. In addition, fieldworkers recorded that medications at one facility had expired (including the starter packs). Mechanisms to ensure regular supply of medications and the discarding of expired medications require strengthening. Drug requirements for specific services will be discussed in more detail in later chapters. 
Table 2.9 Percentage of facilities with essential drugs available ( $n=$ facilities reporting)

\begin{tabular}{|c|c|}
\hline Essential drugs & Percent \\
\hline Syntometrine $(n=97)$ & 79 \\
\hline Oxytoxin $(n=95)$ & 81 \\
\hline Methyldopa $(n=97)$ & 95 \\
\hline Magnesium sulphate $(n=97)$ & 70 \\
\hline Naloxone $(n=95)$ & 66 \\
\hline Nepresol $(n=97)$ & 69 \\
\hline Amoxycillin $(n=98)$ & 98 \\
\hline Ciprofloxacin $(n=97)$ & 97 \\
\hline Doxycycline $(n=98)$ & 99 \\
\hline Erythromycin $(\mathrm{n}=98)$ & 97 \\
\hline Microval $(n=97)$ & 96 \\
\hline Nordette $(n=97)$ & 98 \\
\hline Ovral $(n=97)$ & 99 \\
\hline Penicillin/Pen UK/Benzathine $(n=97)$ & 96 \\
\hline Triphasil $(n=97)$ & 99 \\
\hline Vitamin A $(n=92)$ & 80 \\
\hline Medroxyprogesterone $(n=97)$ & 99 \\
\hline Norethisterone $(n=96)$ & 98 \\
\hline Adrenaline $(n=95)$ & 93 \\
\hline Post-HIV exposure starter pack $(n=95)$ & 51 \\
\hline Emergency/doctor-initiated drugs $(n=97)$ & 75 \\
\hline
\end{tabular}

\section{Availability of Laboratory Tests}

The ability of facilities to conduct laboratory tests varied widely. Table 2.10 provides an indication of the tests available at all facilities and by facility type. Although most facilities were able to do standard urine tests (91 percent), pregnancy tests (78 percent), and common blood tests (72 percent), other laboratory tests were relatively uncommon. Less than half of the facilities could conduct ultrasound scans (48 percent), and importantly, only 36 percent could perform HIV tests. Laboratory testing for STI is controversial in KZN, with the DOH committed to syndromic management of STIs. Thus, while the percent of facilities that can perform vaginal discharge smear 


\section{Hgrizons}

tests (16 percent), or gram stain test (6 percent) is low, this is not considered problematic. Clinics were usually less able to perform HIV tests ( 24 percent) and pap smears (40 percent) than hospitals and CHCs. Facilities in urban areas were more likely to offer laboratory tests than those in periurban areas, and these services are offered least in rural areas. However, more pregnancy tests were available in peri-urban areas than in urban areas.

Table 2.10 Percentage of facilities with laboratory tests available

\begin{tabular}{lcccc}
\hline Laboratory tests & $\begin{array}{c}\text { All facilities } \\
(\mathbf{n}=\mathbf{9 8})\end{array}$ & $\begin{array}{c}\text { Hospitals } \\
(\mathbf{n}=\mathbf{1 0})\end{array}$ & $\begin{array}{c}\text { CHCs } \\
(\mathbf{n}=\mathbf{1 2})\end{array}$ & $\begin{array}{c}\text { Clinics } \\
(\mathbf{n}=\mathbf{7 6})\end{array}$ \\
\hline Pregnancy test & 78 & 80 & 83 & 77 \\
Common blood tests & 72 & 100 & 83 & 67 \\
Urine analysis & 91 & 100 & 83 & 91 \\
HIV test & 36 & 80 & 75 & 24 \\
Ultrasound scan & 48 & 60 & 33 & 1 \\
Pap smear & 12 & 80 & 75 & 40 \\
Vaginal discharge smear & 16 & 40 & 33 & 11 \\
(wet mount) & 6 & 20 & 25 & 1 \\
Gram stain & & &
\end{tabular}

The readiness of facilities to provide antiretrovirals (ARVs) is presented in Table 2.11. In general, a relatively high percent of facilities had the ability to obtain laboratory tests necessary for monitoring ARVs. While only 8 percent of facilities were able to perform viral-load counts and 6 percent CD4 counts, about a third of facilities reported they were able to send blood away for these two tests. Slightly over 40 percent of all the facilities could provide clients with these two ARV monitoring tests. Clinics were less able to provide these services than CHCs or hospitals. However, the World Health Organization (WHO) minimum guidelines for laboratory monitoring of ARVs in resource-poor settings specify that only HIV antibody test and hemoglobin or hemocrit are the absolute minimum requirements, while further tests like CD4 are categorized as desirable and viral-load as optional. ${ }^{7}$

Tuberculosis remains a priority for the DOH, especially in the era of HIV/AIDS. Encouragingly, 77 percent of facilities offered a DOTS program, with 83 percent of CHCs, 80 percent of hospitals, and 75 percent of clinics offering this service. A higher proportion of peri-urban facilities offer these programs ( 86 percent) than urban ( 73 percent) or rural ( 74 percent) facilities.

\footnotetext{
${ }^{7}$ Available online at http://www.who.int.
} 
Table 2.11 Percentage of facilities with tests and services available for delivering ARVs and managing opportunistic infections

$\begin{array}{cccc}\text { All facilities } & \text { Hospitals } & \text { CHCs } & \text { Clinics } \\ (n=98) & (n=10) & (n=12) & (n=76)\end{array}$

\section{Viral load counts}

Done at the facility

Blood sent away to nearby facility

\section{CD4 counts}

Done at the facility

Blood sent away to a nearby facility

DOTS program
8

34

6

35

77
30

14

20

14

80

8

36

\section{Management and Record Keeping}

\section{Disposal management}

Fieldworkers found no evidence indicating the re-use of syringes and needles. However, the correct disposal procedure was not followed for needles in 12 percent of facilities and for medical waste in 25 percent of facilities. Correct disposal of medical waste and sharps is especially important in the context of infectious disease transmission.

\section{Commodity and drug management}

Table 2.12 details the commodity management systems used by the facilities surveyed. More than 80 percent of facilities had inventory books for medicines, equipment, and contraceptives, but less than half had records of reusable commodities. While 81 percent of facilities stored their commodities and drugs correctly according to expiration date, 19 percent did so incorrectly, which could result in waste, or use of medicine after its expiration date.

Fieldworkers also noted that dispensaries were sometimes poorly ventilated and medicines were stored on the floor at times, which could affect their safety and efficacy. 


\section{Hgrizons}

Table 2.12 Percentage of facilities with commodity management books available Type of inventory book available $(n=98) \quad$ Percent

Equipment

Register of medicines

Register of contraceptives

Reusable commodities

Other
83

85

82

47

4

\section{Client records and management}

Nearly all facilities (95 percent) had a client record system in place (Table 2.13). Given that record keeping is required by the $\mathrm{DOH}$, the fact that five facilities have no such system (and that client data was sometimes not available) indicates that more rigorous supervision of record keeping may be needed. Systems in use included logbooks of clients ( 88 percent), client-retained cards (79 percent), and facility-retained cards ( 73 percent). Sixty-three percent of facilities used both facilityand client-retained cards.

Table 2.13 Percentage of facilities with client record systems

\begin{tabular}{lc}
\hline Record systems & Perce \\
\hline Record system in use $(n=97)$ & 95 \\
Type of system & 88 \\
$\quad$ Logbook $(n=93)$ & 73 \\
Facility-retained card $(n=94)$ & 79 \\
Client-retained card $(n=94)$ & 63 \\
Both client- and facility-retained cards $(n=94)$ & 14 \\
Other $(n=87)$ &
\end{tabular}

As illustrated in Table 2.14, 71 percent of facilities used records for keeping track of a client's medical history, 68 percent for service monitoring and evaluation, 62 percent for following up clients who did not return, and 52 percent for sending reports to district or other health offices (multiple responses were possible). When reports were sent, staff reported that feedback was usually nonexistent or inadequate, and only 28 percent of staff reported that they were happy with the feedback received. 
Table 2.14 Use of records by facility managers

\begin{tabular}{lc}
\hline Records used for* & Percent \\
\hline Sending reports $(n=92)$ & 52 \\
Following up clients who did not return $(n=94)$ & 62 \\
Keeping track of client's medical history $(n=94)$ & 71 \\
Monitoring and evaluation $(n=94)$ & 68 \\
Other $(n=92)$ & 28
\end{tabular}

*Note that percentages do not add up to 100 , as multiple responses were possible.

\section{Summary of Service Availability and Service I ntegration}

In summary, most facilities offered FP, ANC, and STI services. Far fewer facilities offered HIV/AIDS services, other maternal services (such as delivery, managing obstetrical complications, and postpartum care), or more specialized services (such as cervical cancer screening, colposcopy, and termination of pregnancy). Levels of service integration therefore vary among facilities. The following chapters on services will address whether integration exists within specific services. Most facilities were staffed with nurses and most also had essential equipment and drugs. Record keeping requires attention. 


\section{Hgrizons}

\section{Chapter 3 \\ Characteristics, Training, and Experience of Staff}

\section{Sociodemographic Characteristics of Staff}

This section presents the sociodemographic characteristics of 229 service providers who were interviewed and their experiences with providing various reproductive health services in the province. Nearly all providers were female ( 97 percent). Their mean age was 41 years, and their mean number of children was two. Just over a half ( 55 percent) were married, 37 percent were single, and the rest were divorced ( 2 percent), widowed ( 5 percent), or separated ( 1 percent).

The dominant religion of this group was Christian, with 79 percent professing to be Protestants and 18 percent Catholics. Other faiths make up only 3 percent of the group. Kwa-Zulu Natal province is predominantly Zulu-speaking and 80 percent of the providers said Zulu was their mother tongue, followed by 13 percent who mentioned Xhosa. The remainder of providers mentioned English or other languages as their mother tongue.

\section{Training}

The professional qualification of health providers, and the amount and quality of in-service training influences the quality of services provided to clients at health facilities. Most providers in KZN were professionally qualified, with 83 percent of them reporting that they were professional nurses. Other professional categories were enrolled nurses ( 7 percent) or advanced midwives ( 3 percent). A small proportion of providers were identified as assistants or some other unspecified group ( 7 percent).

Providers were asked if they had specific in-service training on various reproductive health topics, namely, family planning, antenatal care, sexually transmitted infections, and HIV/AIDS. While these areas are covered in basic training courses, Table 3.1 reveals that over half of the providers said they had never received an in-service training in TOP, FP, PMTCT, HIV/AIDS or the management of opportunistic infections.

Although KZN faces high HIV/AIDS prevalence rates, training of providers on topics relevant to HIV/AIDS has been slow. About a third of providers had received training in the prevention of mother-to-child transmission of HIV. Less than half of providers had received training in the management of opportunistic infections or in HIV/AIDS testing.

Another topic that appears to have been neglected in in-service training is termination of pregnancy. In 1997 the South African government passed the Choice on Termination of Pregnancy Act. The act, which succeeds the restrictive Abortion and Sterilisation Act of 1975, is more liberal, allowing for abortion on request as long as the pregnancy is within the first trimester. Though it is 
four years since the legislation was passed, only a small proportion of service providers have received training in the delivery of termination of pregnancy services.

Though a sizable number of providers had received in-service training of some kind, the majority had received the training more than three years prior to this study. Table 3.1 shows the distribution of providers who received in-service training in reproductive health; and whether the training took place within the past three years or not. The training that a large proportion of service providers had received (antenatal and postnatal care, normal maternity, and management of obstetrics complications) had taken place more than three years earlier. For the rest of the courses, only about 30 percent of providers had attended a course within the past three years. While this represents only about a third of the providers, it is important to note that increasing numbers of providers indicate that in the last three years, they have received training in such HIV/AIDS-related topics as PMTCT, opportunistic infections (OIs), and HIV testing. This suggests that courses about HIV/AIDS are receiving more emphasis.

Table 3.1 Percentage of providers who reported receiving in-service training, and when they attended the courses $(n=226)$

Course attended

When course was attended

$\begin{array}{ccc}3 \text { or more } & \text { Less than } 3 & \begin{array}{c}\text { Never } \\ \text { attended }\end{array} \\ \text { years ago } & \text { years ago } & \end{array}$

\begin{tabular}{lrcc}
\hline Family planning & 27 & 23 & 50 \\
Termination of pregnancy & 4 & 14 & 82 \\
TOP (MVA) & 1 & 11 & 88 \\
Antenatal and postnatal care & 61 & 21 & 18 \\
Normal maternity care & 61 & 21 & 19 \\
Management of obstetrical complications & 59 & 19 & 22 \\
STI/RTI diagnosis, treatment, and & 31 & 33 & 36 \\
counseling & & & \\
PMTCT & 7 & 25 & 68 \\
HIV/AIDS testing & 17 & 27 & 56 \\
Treatment of Ols & 17 & 29 & 54 \\
Pap smears & 32 & 19 & 49 \\
Any other & 16 & 25 & 58
\end{tabular}

Providers were asked about reproductive health services they provided in the past three months. Table 3.2 indicates that the services most frequently provided were STI counseling, diagnosis, and 


\section{Hgrizons}

treatment ( 93 percent), family planning ( 84 percent), postpartum care ( 71 percent), and maternity and delivery services (67 percent). Fewer staff reported providing HIV/AIDS services.

For staff who had provided a service in the past three months, fieldworkers investigated whether they had received in-service training for it. Table 3.2 indicates that a sizable proportion of service providers who were providing a particular service had never received in-service training in this service area. For example, nearly half (46 percent) of providers delivering family planning had never received in-service training in family planning. More than a third of the staff were providing counseling, diagnosis, and treatment for STIs without in-service training on that topic. About the same proportion were treating AIDS patients for opportunistic infections or screening for cervical and breast cancer without relevant in-service training.

Table 3.2 Percentage of staff providing RH services in the last three months, and percentage of these staff who have received in-service training on the service $(n=228)$

\begin{tabular}{lc}
\hline RH service & $\begin{array}{c}\text { Percent of staff } \\
\text { providing service }\end{array}$
\end{tabular}
Percent of those providing service who received in-service training

IUD insertion

$\begin{array}{lc}12 & 40 \\ 84 & 46 \\ 18 & 69 \\ 1 & 100 \\ 67 & 5 \\ 71 & 7 \\ 55 & \text { Data not available } \\ 7 & \text { Data not available } \\ 93 & 34 \\ 39 & 15 \\ 20 & \text { Data not available } \\ 59 & 34 \\ 20 & \text { Data not available } \\ 10 & \text { Data not available } \\ 52 & 32 \\ 10 & \text { Data not available }\end{array}$

Other family planning services

Termination of pregnancy counseling

Termination of pregnancy (MVA)

Normal maternity care/delivery services

Postpartum care

Management of obstetrical complications

Ultrasound diagnosis

STI counseling, diagnosis, and treatment

HIV/AIDS counseling and testing

PMTCT (including counseling and

providing nevirapine)

Treatment of Ols (HIVIAIDS)

Data not available

Post-exposure prophylaxis

Treatment of HIVIAIDS with antiretrovirals

Cervical cancer screening and breast cancer screening

Other providing service 


\section{ANC Services Provided}

In general, health providers deliver the expected standard care stipulated by the Department of Health policy and guidelines. For each of the DOH checklist items, at least 9 out of 10 providers reported that they perform those requirements. More than three-quarters of nurses provide antenatal care services at their facilities. Those who provide such services were asked specifically what services they provide to antenatal clients. The standard care includes providing physical checkups, counseling on nutrition, alerting patients to abnormal symptoms, responding to requests for a syphilis test or a tetanus injection, supplying iron tablets, and stressing the importance of regular clinic visits.

\section{Provider Restrictions on Family Planning Services}

Some health providers in Africa impose restrictions on FP services based on client age, spousal consent, and parity. According to $\mathrm{DOH}$ policy, providers are required to provide contraceptives to young women over 14 years of age without requiring parental consent. This study investigated provider-imposed restrictions on women under age 16 and over age 40. Among 226 providers, 73 percent said that they would provide family planning methods to women under age 16 and among 223 providers, 83 percent said they would provide FP methods to women over age 40. Table 3.3 below shows both the number of providers and the percent who would prescribe specific methods to women under age 16 or over age 40 . For women under age 16,87 percent of the providers who responded to the question said that they would provide the 2 month injection, 64 percent the male condom, 44 percent the POP pill, and 35 percent the 3 month injection. Only about a quarter or less of the providers would prescribe other methods. For women over age 40, 83 percent of the providers would prescribe the 3 month injection, 60 percent sterilization, and 44 percent the pill POP and the male condom. Very few providers would prescribe the IUD or emergency contraception to any age group. 


\section{Herizons}

Table 3.3 Number and percentage of providers who would provide specific family planning methods to women under age 16 and to women over age 40

\begin{tabular}{lcccc}
\hline \multicolumn{1}{c}{$\begin{array}{c}\text { Method } \\
\text { under age }\end{array}$} & $\begin{array}{c}\text { W6uld provide to women } \\
\text { under }\end{array}$ & Percent & Would provide to women over \\
age 40 & n & Percent \\
\hline Pill COCs & $\mathbf{n}$ & 44 & 200 & 44 \\
Pill POP & 193 & 26 & 198 & 25 \\
IUD & 187 & 7 & 197 & 8 \\
2 months injection & 186 & 87 & 195 & 27 \\
3 months injection & 195 & 35 & 203 & 83 \\
Male condom & 190 & 64 & 199 & 44 \\
Female condom & 192 & 28 & 196 & 24 \\
Emergency contraception & 190 & 16 & 197 & 13 \\
Sterilization & 189 & - & 197 & 60
\end{tabular}

Prescription procedures for sterilization were also investigated and found not to be favored by most providers for women less than age 30-only 18 percent of providers would recommend or prescribe sterilization for women in this age group. At the same time, however, 52 percent of providers said their prescription of sterilization would depend on "the woman's circumstances." Though DOH policy states that sterilization should be made available to all women over age 18 years at their request, providers appear to be reluctant to offer this option to younger women.

Overall, providers are aware of the interaction between sexually transmitted infections, HIV/AIDS, and contraceptives. Seventy-one percent of providers said there are some methods that they would never recommend for clients with a sexually transmitted disease. As confirmed by data elsewhere, the IUD tops the list of these methods. Some providers also indicated that they would not recommend combined oral contraceptives and progestin-only pills to clients suspected of having an STI. Most importantly, just over 70 percent of providers said they always recommend dual protection to clients, 19 percent said they recommend dual protection sometimes, and just 10 percent mentioned that they rarely emphasize dual protection.

Moreover, Table 3.4 indicates that just under a quarter (24 percent) of providers said that there are methods that they would never recommend at all, including combined oral contraceptives and IUDs. Negative attitudes among providers toward these methods which are often popular in other countries may help explain the predominant use of injections in the South African FP program. 
Table 3.4 Percentage of staff who would not recommend contraceptives for clients with STIs and not recommend for any client

\begin{tabular}{lcc}
\hline Methods & $\begin{array}{c}\text { Not recommended for STI } \\
\text { clients }(\mathbf{n}=\mathbf{1 5 8})\end{array}$ & $\begin{array}{c}\text { Not recommended at all for } \\
\text { any clients }(\mathbf{n}=\mathbf{5 1})\end{array}$ \\
\hline COCs & 15 & 25 \\
POP & 10 & 12 \\
IUD & 85 & 21 \\
Male condom & 6 & 7 \\
Female condom & Not asked & 5 \\
2-month injectable & 7 & 11 \\
3-month injectable & 7 & 14 \\
Sterilization & 2 & 4 \\
Vasectomy & 1 & N/A \\
Emergency contraception & N/A & 2 \\
Natural methods & 15 & 23 \\
Other FP methods & 3 & 32
\end{tabular}

\section{Service Providers and RTI / STI Services}

A hypothetical question was posed to service providers: "If you think that a client has an RTI/STI, what are all the services that you would provide the client?" Spontaneous responses indicated (Figure 3.1) that providers would provide STI counseling (76 percent), manage the client according to the syndromic approach ( 75 percent), and encourage the client to notify the partner ( 73 percent). Sixty percent of providers said they would provide a diagnosis, and 53 percent said they would refer the client for diagnosis or treatment. Seventeen percent mentioned that they would request a laboratory test. About an equal percentage said they would ask about the client's use of family planning, and 14 percent said they would do a pap smear. 


\section{Hgrizons}

Figure 3.1 Percentage of staff indicating the services they would provide to a client who has an STI or RTI

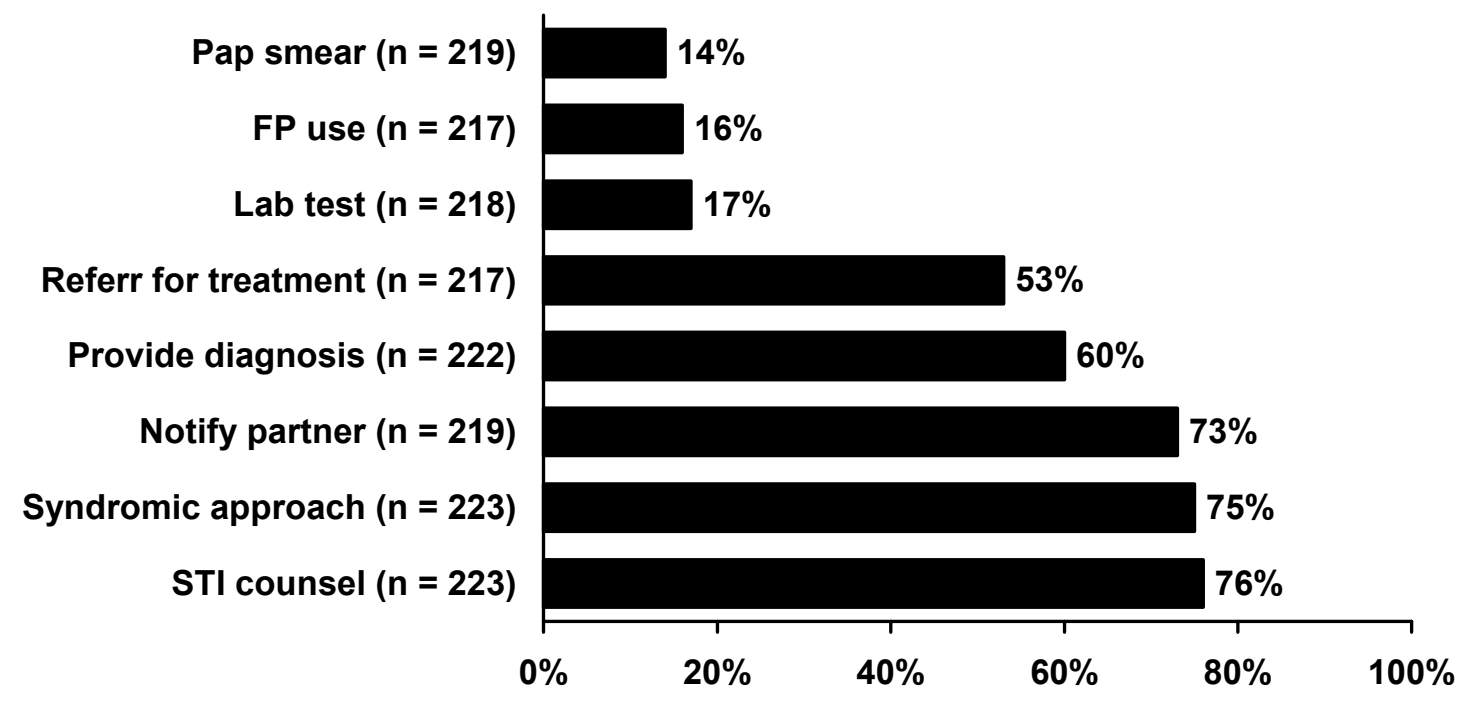

A similar question was asked providers about clients they suspected of having HIV/AIDS. Figure 3.2 shows that the vast majority of providers ( 87 percent) would provide counseling services. Just over half (51 percent) said they would provide treatment (what kind of treatment was unspecified). Other actions that providers said they would take include STI counseling and diagnosis (44 percent), encourage the client to notify partners (38 percent), and check on the risky behavior of clients (32 percent). A relatively large proportion (43 percent) of providers mentioned that they would take other actions that were not specified. 


\section{Figure 3.2 Percentage of staff indicating the services they would provide to a client} who has HIVIAIDS

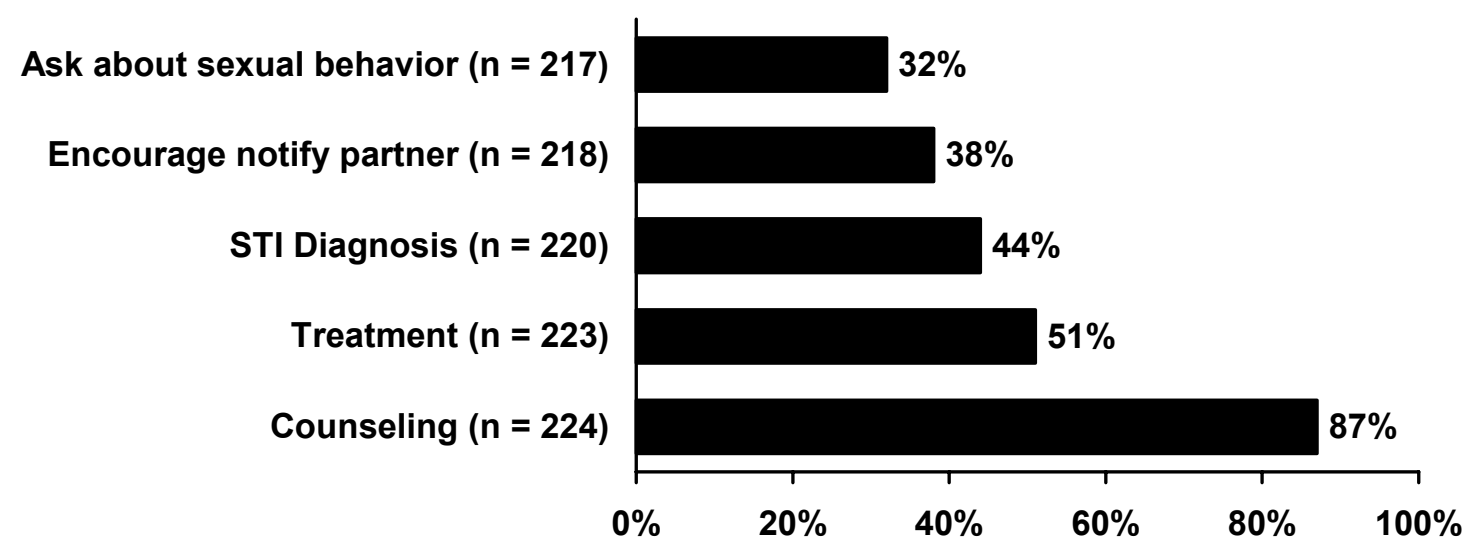

The KZN Department of Health has expanded reproductive health services to new areas. For example, facilities are encouraged to provide services to women who are victims of rape and domestic violence. In addition, staff are now encouraged to provide services related to menopause and infertility. While more could be done in these areas, many providers are making an effort to deliver these much needed new services (Figure 3.3). Providers themselves identified reasons for not providing some of the reproductive health services mentioned above. The most frequently mentioned reason is lack of training ( 83 percent) followed by lack of equipment or instruments (42 percent). The absence of facilities for services was mentioned by 38 percent of providers. Finally, one in five providers did not provide services "for personal reasons" which anecdotal information suggests is related to TOP and contraception. 


\section{H ${ }^{\text {rizons }}$}

Figure 3.3 Percentage of staff providing sexual and RH services

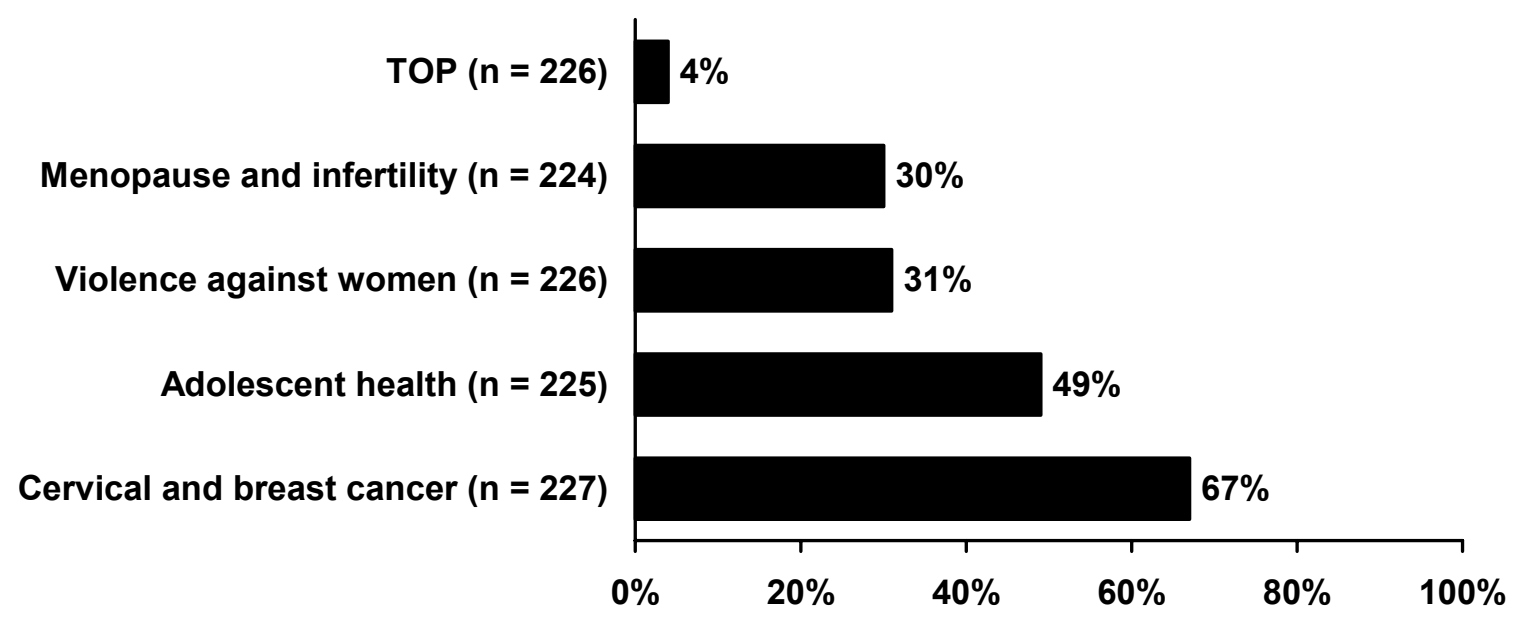

\section{Summary}

This chapter has presented findings about staff providing services at health facilities. It suggests that the Department of Health should embark on a more aggressive in-service reproductive health training program for service providers. It appears that a significant percent of health providers are providing reproductive health services without adequate recent in-service training. Of concern, however, is that a sizable proportion of health providers have never received in-service training in standard topics on family planning and sexually transmitted infections, although these topics are covered in basic training. Furthermore, when providers have received training, the training often took place more than three years ago, implying that the providers may not be up to date on developments in services they provide. Providers were even less prepared through in-service training to deal with less traditional topics of reproductive health such as termination of pregnancy and the prevention of the HIV/AIDS transmission from mother to child.

The government policy allows free provision of contraceptives to all women who request such services with no restriction based on age over 14 or other non-medical criteria. As with providers elsewhere in Africa, this study found that the prescription of some contraceptives usually is restricted for adolescents and women over 40 years of age. In South Africa, the restriction tends to be for contraceptives other than the injectables and male condoms, which suggests a lack of clarity for providers on how to deal with other contraceptive methods

In general, providers seem to be better trained to deal with clients presenting with sexually transmitted infections than with HIV/AIDS. It is not clear what providers meant when they said they would provide treatment for such clients. They may have been referring to treatment for opportunistic infections. Again, the fact that 43 percent of providers said they would take some 
other action that is not clearly defined may suggest some confusion about how to deal with clients with HIV/AIDS.

Finally, it is important to note that at least some staff are providing services in the nontraditional areas of reproductive health. For instance, they are screening women for cervical and breast cancer, engaging women on matters related to rape and violence, dealing with HIV/AIDS, and dealing with issues related to adolescents and youth health. However, lack of attention to TOP and inadequate training for this service suggests an unmet program need. 


\section{Herizons}

\section{Chapter 4 \\ Family Planning Services}

\section{KwaZulu Natal Family Planning Program}

Though a considerable amount of research shows that spacing births at least two to three years apart significantly decreases infant mortality (Blacker 1987; Trussell and Pebley 1984), recently debate has surfaced about the benefits of such spacing on maternal morbidity and mortality (Ronsmans and Campbell 1998). Furthermore, since the International Conference on Population and Development in Cairo in 1994 (ICPD 1994), emphasis has been placed on integrating the delivery of FP and other RH services. The DOH's standards and norms for PHC therefore indicate that women's reproductive health should be provided in an integrated and comprehensive manner, covering preventive, curative, and rehabilitative levels of care, including antenatal, postnatal, and family planning services (Department of Health 2000: 16). The DOH's National Contraception Policy Guidelines establish the protocol for providing contraceptives in family planning services.

This approach has made FP services widely available in KwaZulu Natal. In 2000, 87 percent of PHC facilities in South Africa offered family planning services every weekday. Because of the reported availability of FP services and relatively higher socioeconomic levels, contraceptive use in South Africa is high in comparison to other sub-Saharan countries. Fully 62 percent of women between 15 and 49 years old are using some form of contraception, with injectable methods being the most popular (Adar and Stevens 2000). In KZN, 95 percent of clinics offer family planning services daily, and 57 percent of women 15 to 45 years old are using a modern contraceptive method. Despite high overall levels of contraceptive availability and usage, the DOH has numerous questions about both the readiness of its SDPs to provide services and about the quality of services offered.

Several questions raised by the Sub-Directorate of $\mathrm{MCWH}$ and by previous researchers are addressed in this study:

- Are contraceptive methods, including female condoms, freely available in all health institutions on a regular basis?

- Is the injectable method popular as a result of fully informed choice by clients or because of provider bias, availability, and limited information?

- Are FP services that are integrated with other RH services and with providers promoting dual protection (which uses male or female condoms) providing counseling for STI and HIV/AIDS prevention, and screening for cervical cancer (Adar and Stevens 2000)?

- Are FP services youth-friendly, or do providers have judgmental attitudes?

- Is emergency contraception widely available and being promoted?

- Are males excluded from FP and RH services?

- What improvements in the delivery of MCWH should be recommended?

The Sub-Directorate of MCWH conducted this Situation Analysis study to help answer such questions. The study also aimed at providing an overall picture of the strengths and weaknesses of 
their FP services in KZN Province that would cover both the readiness of SDPs to deliver FP services and the quality of these services. As part of the KwaZulu Natal Situation Analysis study, 98 SDPs were visited and $93 \mathrm{FP}$ clients were observed as they received services from a provider. Subsequently, 89 clients were interviewed as they exited, using a structured interview schedule. All of the clients who were observed and interviewed were new FP clients, or clients restarting contraception, or clients wishing to switch methods. Four exit interviews were not possible because either the client said she didn't have the time for the interview or she refused. This chapter also uses data from 229 providers who were interviewed.

\section{Family Planning Client Characteristics}

As noted in Table 4.1, the 89 FP clients interviewed were all female, usually young (with onequarter 19 years old or younger, and a median age of 22), and single. They had less than a high school education and were mothers, the majority of whom did not want more children. Almost all speak Zulu. 


\section{${ }^{\text {Horizons }}$}

Table 4.1 Characteristics of 89 family planning clients

\begin{tabular}{|c|c|}
\hline Client characteristic & Percent \\
\hline \multicolumn{2}{|l|}{ Sex } \\
\hline Female & 100 \\
\hline \multicolumn{2}{|l|}{ Age $($ Median $=22)$} \\
\hline $10-14$ & 1 \\
\hline $15-19$ & 24 \\
\hline $20-24$ & 36 \\
\hline $25-29$ & 20 \\
\hline $30-34$ & 11 \\
\hline $35+$ & 7 \\
\hline \multicolumn{2}{|l|}{ Marital status } \\
\hline Single & 82 \\
\hline Married & 10 \\
\hline Living together with partner & 7 \\
\hline Widowed & 1 \\
\hline \multicolumn{2}{|l|}{ Educational level } \\
\hline No schooling & 5 \\
\hline Primary incomplete & 14 \\
\hline Primary complete & 5 \\
\hline High school incomplete & 48 \\
\hline High school complete & 28 \\
\hline Postmatriculation & 1 \\
\hline \multicolumn{2}{|l|}{ Number of children } \\
\hline 0 & 12 \\
\hline 1 & 49 \\
\hline 2 & 14 \\
\hline 3 & 9 \\
\hline $4+$ & 16 \\
\hline \multicolumn{2}{|l|}{ More children wanted } \\
\hline Yes & 32 \\
\hline No & 60 \\
\hline Depends (on God or husband) & 2 \\
\hline Not sure & 6 \\
\hline \multicolumn{2}{|l|}{ Language } \\
\hline Zulu & 98 \\
\hline Xhosa & 2 \\
\hline
\end{tabular}




\section{Readiness to Deliver FP Services}

\section{Health facilities and FP services}

Family planning services were available in nearly all of the SDPs visited (99 percent), except for one clinic (see Chapters 1-3 for further discussion of readiness and the functioning of various subsystems - records, training, etc.). KZN facilities are serving a large number of clients every month. In August 2002 (the last complete month before field research for this study began), the majority of SDPs served both new clients (87 percent) and continuing clients (70 percent). It is not clear why substantially fewer facilities see continuing rather than new clients. Ninety-one percent of urban facilities have a record of seeing continuing clients compared with 54 percent of peri-urban facilities and 72 percent of rural facilities. This could be attributable partially to migration (periurban clients may move around more than other clients); however, it could just as well reflect differences in the record-keeping practices in different environments. In the facilities reporting provision of FP services (including those that saw no clients in the past month), the median number of new FP clients seen in the past month was 27, and, as expected, the median number of continuing FP clients seen in the past month was higher, 91. Of the SDPs providing FP services in the previous month, Table 4.2 indicates that $\mathrm{CHCs}$ attended to the greatest number of new and revisiting family planning clients.

Table 4.2 Median and mean number of FP clients seen in the past month by SDPs providing FP services

\begin{tabular}{|c|c|c|c|c|c|}
\hline Type of facility & Median & Mean & $\begin{array}{l}\text { Standard } \\
\text { deviation }\end{array}$ & $\begin{array}{c}\text { Low } \\
\text { range }\end{array}$ & $\begin{array}{c}\text { High } \\
\text { range }\end{array}$ \\
\hline \multicolumn{6}{|l|}{ New FP clients } \\
\hline District hospitals (10) & 62 & 102 & 93 & 6 & 259 \\
\hline Community health centers (12) & 92 & 224 & 415 & 0 & 1,491 \\
\hline Clinics (75) & 16 & 52 & 84 & 0 & 495 \\
\hline \multicolumn{6}{|l|}{ Revisiting FP clients } \\
\hline District hospitals (10) & 137 & 163 & 160 & 0 & 538 \\
\hline Community health centers (12) & 688 & 550 & 514 & 0 & 1,224 \\
\hline Clinics (75) & 79 & 113 & 156 & 0 & 1,089 \\
\hline \multicolumn{6}{|l|}{ Total FP clients } \\
\hline District hospitals (10) & 218 & 265 & 193 & 142 & 797 \\
\hline Community health centers (12) & 851 & 774 & 493 & 0 & 1,491 \\
\hline Clinics (75) & 122 & 165 & 181 & 0 & 1,304 \\
\hline Urban (9) & 495 & 584 & 364 & 133 & 1,332 \\
\hline Peri-urban (12) & 222 & 404 & 455 & 0 & 1,491 \\
\hline Rural (46) & 106 & 251 & 311 & 0 & 797 \\
\hline
\end{tabular}




\section{Hgrizons}

\section{Infrastructure}

As has been noted in Chapters 2 and 3, KZN SDPs have a well-developed infrastructure that supports a high degree of readiness to deliver FP services. Despite the fact that the majority of the facilities visited are located in either rural or peri-urban areas, electricity, phone service, and working toilets for clients are available in more than 90 percent of the SDPs in the study. Virtually all of the examination areas were judged as "clean." However, the water supply was not judged to be adequate and safe in nearly one-fifth (19 percent) of the SDPs, and readiness to provide FP information and education materials was relatively weak compared to many other dimensions of the program (Figure 2.4 and Table 2.7).

Table 4.3 Percentage of 98 clinics with infrastructure components available for FP

\begin{tabular}{lc}
\hline Components & Percent \\
\hline Electricity & 94 \\
Telephone & 94 \\
Working toilets for clients & 90 \\
Designated area for examinations & 100 \\
Visual privacy for examinations & 97 \\
Auditory privacy for examinations & 91 \\
Visual privacy for counseling & 76 \\
Auditory privacy for counseling & 76 \\
Sufficient seating for waiting clients & 50 \\
Linens & 84 \\
Adequate safe water & 81 \\
Bare essential components (auditory and visual privacy for & 55 \\
examination and safe, adequate water supply) &
\end{tabular}

\section{Staff and training}

All staff providing FP services were female, and almost 90 percent of FP providers were professional nurses (Figure 4.1). 
Figure 4.1 Percentage of 88 staff at different levels observed providing FP services

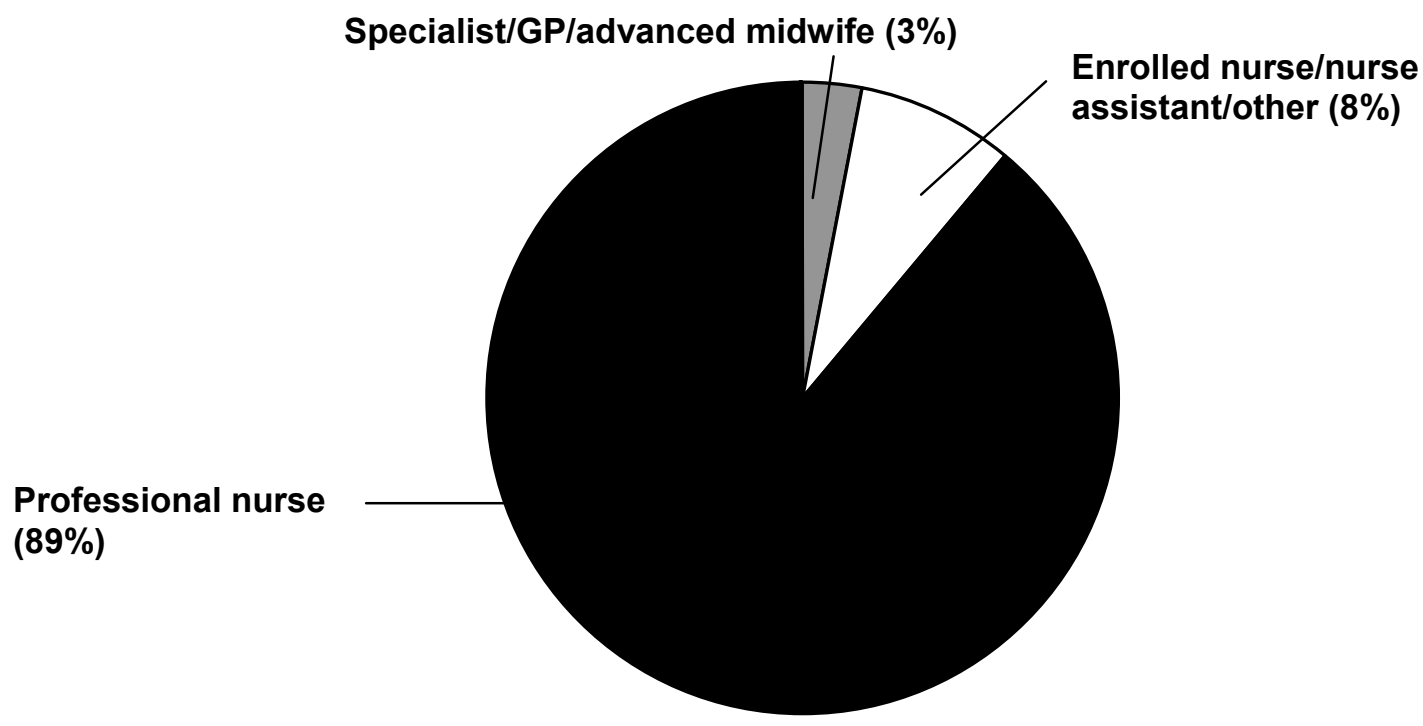

Staff providing RH services (not limited to FP) were interviewed about whether they had ever had in-service training on FP counseling or promotion. Because nearly 90 percent of the staff providing FP were professional nurses, the information is presented below on in-service FP training for the 170 professional nurses interviewed. Almost half of the professional nurses report never having had an in-service FP course, and of those who have had such a course, the majority report that they had taken it three or more years ago. This finding suggests that though professional nurses receive FP training in their basic nursing course, most of the professional nurses supplying FP services either have not had a recent course in FP counseling or promotion or have never had one (Figure 4.2). 


\section{Hgrizons}

Figure 4.2 Percentage of 170 professional nurses interviewed who had ever received in-service training on FP

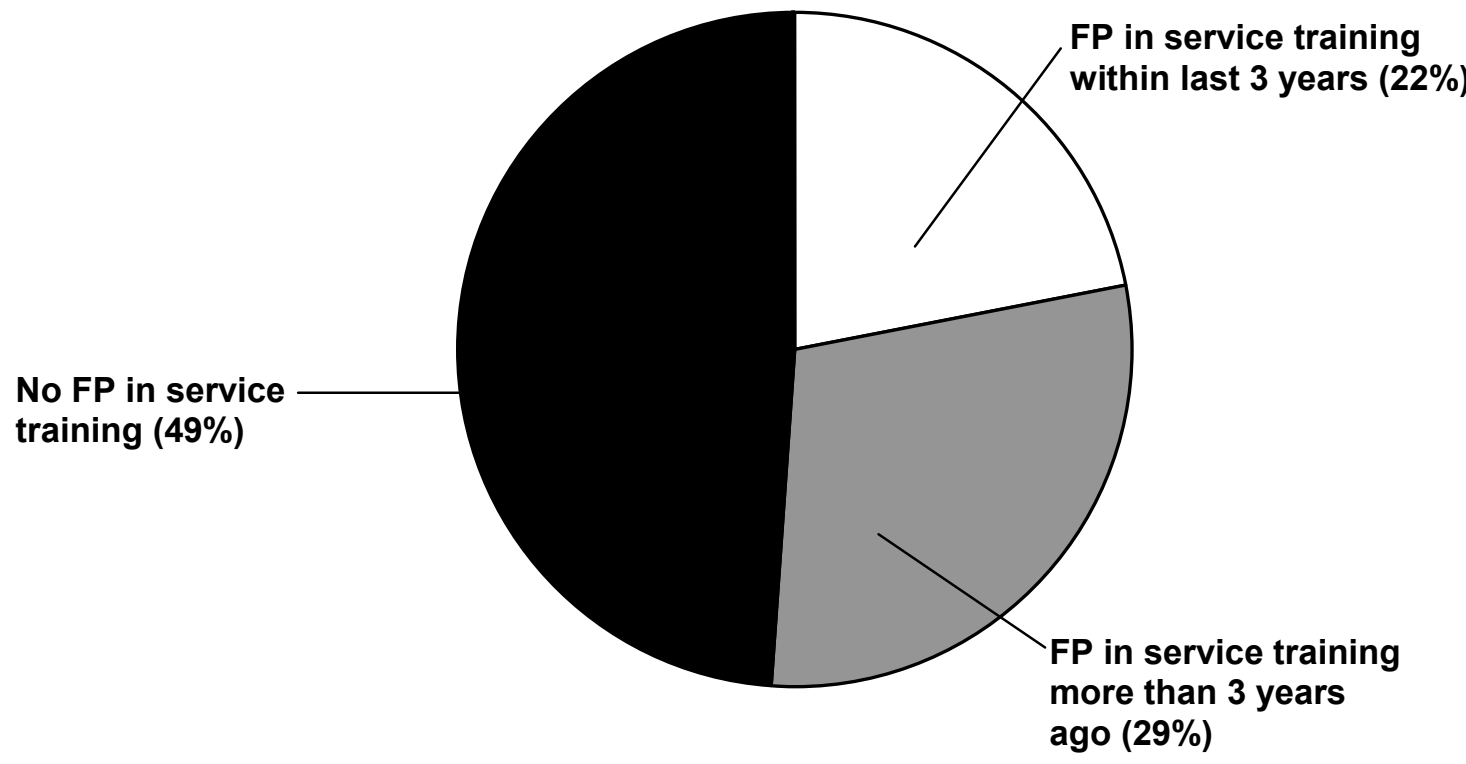

\section{Equipment}

Several basic equipment items for delivering FP services were almost always available (Table 4.4). However, penis models, gynecological exam tables, and microscopes were available much less frequently. Penis models have been found to aid understanding of effective condom use.

\section{Table 4.4 Percentage of 98 SDPs with basic FP equipment available}

\begin{tabular}{lc}
\hline Equipment & Percent \\
\hline Stethoscope & 100 \\
Blood pressure gauge & 99 \\
Disposable syringes & 99 \\
Disposable gloves & 100 \\
Speculum & 93 \\
Scale for adults & 98 \\
Penis model & 71 \\
Gynecological exam table & 45 \\
Microscope & 10 \\
Bare essential FP equipment (gynecologic table and speculum)* & 40
\end{tabular}

* The assessment did not include evaluation of homeostatic and ring forceps, scissors, or disinfecting bowls. 
Gynecological tables and working microscopes are usually considered important for STI detection and provision of IUDs. However, as noted earlier, IUDs are infrequently provided in KZN, and syndromic management of STIs is provincial policy. Seventy-eight percent of hospitals, 73 percent of CHCs, and 29 percent of clinics had both of the two items assessed (gynecological tables and speculums) considered to be "bare essentials" equipment for providing family planning services.

\section{Supervision}

Supervisory visits were common in the majority of SDPs, but there appears to be considerable room for improving the helpfulness of these visits. About three-quarters of the SDPs (76 percent) received one or more supervisory visits during the previous six months, and more than half of the SDPs receiving a visit reported that they received two or more supervisory visits in that period. (Five percent of the SDPs reported 30 supervisory visits in that period.) During these visits, supervisors most often ask about problems in the facility ( 78 percent), and check all of the services that are provided ( 65 percent). Supervisors less frequently check on the recording and reporting of information (50 percent), provide encouragement and motivation (44 percent), or provide recommendations for improving the quality of service (40 percent) (Figure 4.3).

\section{Figure 4.3 Reports on supervisors' behavior}

\section{Recommend improvements to quality}

\author{
Provide encouragement \\ Check recording and reporting of \\ information
}

Check all services

Ask about problems

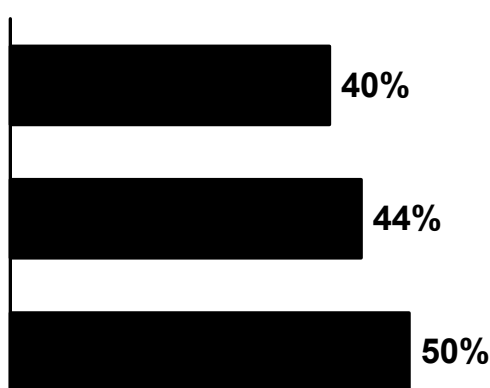

$50 \%$

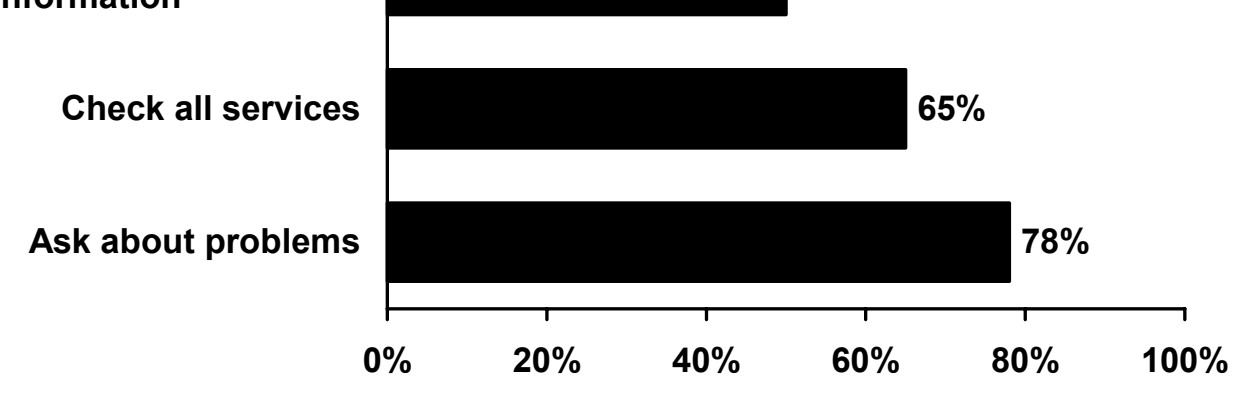




\section{Hgrizons}

\section{Contraceptives}

A wide variety of family planning methods are available at the SDPs visited (Figure 4.4). Five methods of contraception, including two kinds of injectables (2-month and 3-month), combined oral pills, POPs, and male condoms are available in almost all SDPs, (>95 percent). In addition, emergency contraception is available in more than 80 percent of SDPs. However, two methodsIUDs and female condoms - are rarely available (4 percent, and 10 percent of SDPs, respectively). Female condoms are rarely provided because at the time of the study, they were supplied only as part of a pilot program. This assessment did not directly evaluate the reason for the rare provision of IUDs. However, clinicians and/or policymakers may disdain the provision of IUDs in this environment, where the prevalence of STIs and HIV is high and where there is limited ability (diagnostic tests and equipment) to adequately identify STIs, to avoid iatrogenic infection (Walsh et al. 1998). Because of the rare availability of IUDs, only 2 percent of 229 service providers reported that they delivered IUD services in the past three months, while 84 percent reported that they delivered other FP services in the last three months (not shown in Figure 4.4).

\section{Figure 4.4 Availability of contraceptive methods at 98 facilities on the day of the fieldworker visit}

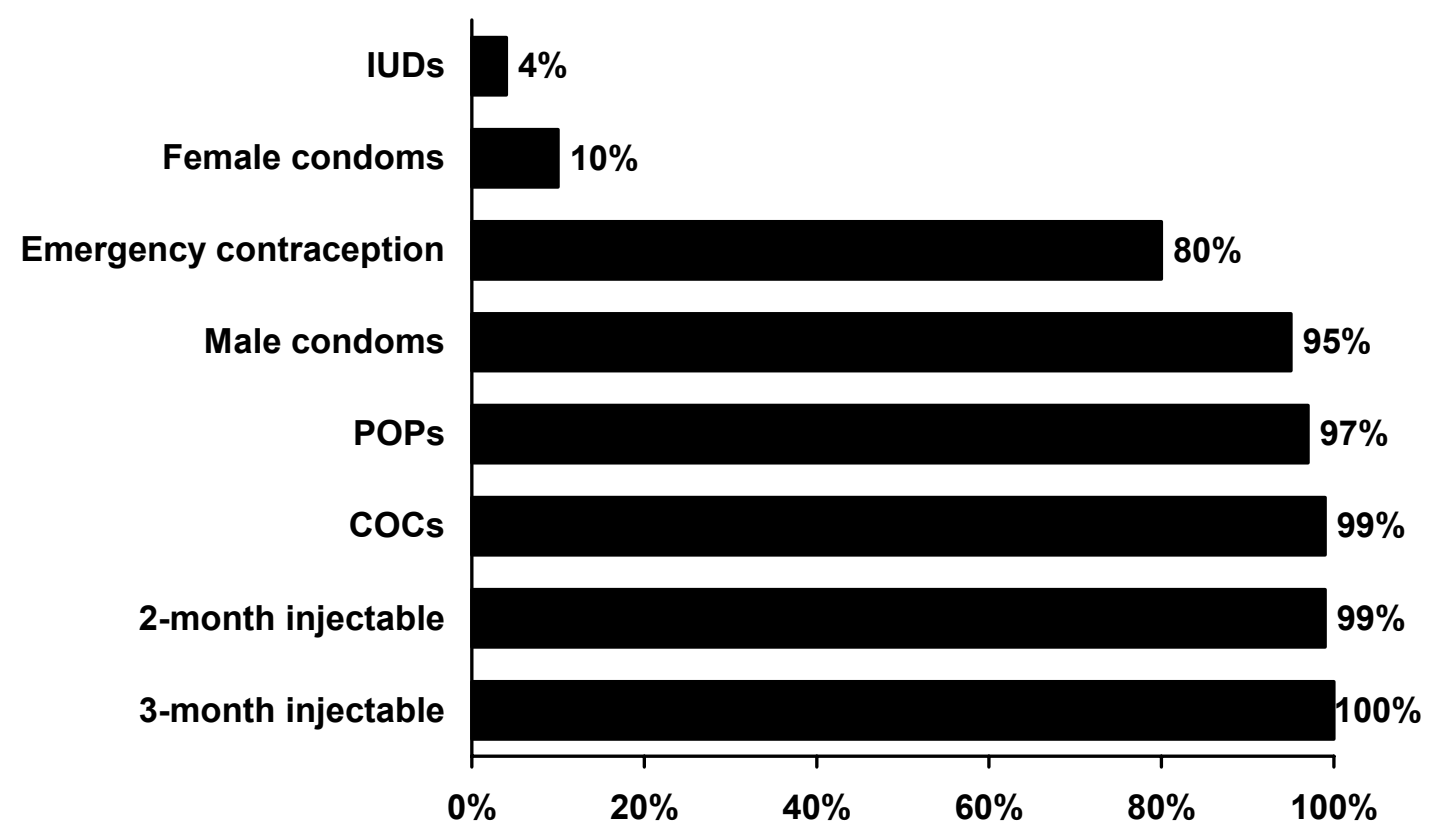

In addition, 95 percent of the SDPs providing FP services in the past month were distributing condoms to protect against STI and HIV infections and to provide dual protection. The median number of condoms distributed by these SDPs in the past month was 1,000. Table 4.5 indicates that there is a large variation in male condom distribution, even within the same types of SDPs. Indeed, 
two district hospitals and four clinics distributed no male condoms in the previous month. Three hospitals, one $\mathrm{CHC}$, and 13 clinics reported stock-outs of male condoms, and one additional $\mathrm{CHC}$ reported no regular supply of male condoms in the past six months.

Although female condoms are distributed only as part of a pilot program and are therefore rarely available at KZN SDPs (only at two district hospitals and five clinics), a few (four) SDPs distributed a large number of female condoms in the previous month. At two hospitals, 372 (at a peri-urban center) and 600 (at a rural center) female condoms were distributed in the previous month, respectively, suggesting that female condoms may become popular when available in a supportive environment.

Table 4.5 Median and mean number of FP clients given condoms in the past month at 97 SDPs providing FP services

\begin{tabular}{lrrrrr}
\hline Type of facility & Median & Mean & $\begin{array}{c}\text { Standard } \\
\text { deviation }\end{array}$ & $\begin{array}{c}\text { Low } \\
\text { range }\end{array}$ & $\begin{array}{c}\text { High } \\
\text { range }\end{array}$ \\
\hline Male condoms & & & & & \\
$\quad$ District hospitals (10) & 1,220 & 1,743 & 1,995 & 0 & 6,980 \\
$\quad$ Community health centers (12) & 4,858 & 5,454 & 4,799 & 0 & 16,420 \\
$\quad$ Clinics (75) & 800 & 1,360 & 1,923 & 0 & 13,180 \\
Female condoms & & & & & \\
$\quad$ District hospitals (10) & 0 & 97 & 212 & 0 & 600 \\
Community health centers (12) & 0 & 0 & 0 & 0 & 0 \\
Clinics (75) & 0 & 0 & 2 & 0 & 20
\end{tabular}

Though several types of contraception are widely available in KZN, study findings also indicate some difficulties with the logistical system. Stock-outs in the previous six months were reported for all major methods of contraception in 12 to 18 percent of the SDPs. Of particular concern in this environment where the prevalence of HIV is high is that the male condom was the method most frequently stocked-out.

\section{Family planning services for youth}

As can be seen in Table 4.1, with a quarter of the FP clients 19 years old or younger, youthfriendliness in FP services is very important in KZN. About three-quarters of the $229 \mathrm{RH}$ service providers interviewed indicated that they would be willing to prescribe FP methods for women under 16 years of age. However, 13 percent said definitively that they would not prescribe FP for women under age 16, and an additional 12 percent indicate that their willingness to prescribe FP 


\section{Hgrizons}

depended on the situation. In fact, only one of the 89 FP clients interviewed reported that she was under 16 (she was 12 years old).

This finding may reflect the low incidence of sexual intercourse in girls before the age of 16 . However, it more likely suggests that providers are reporting greater friendliness toward youth than they actually feel and that younger girls, if interested in FP, are therefore seeking it elsewhere (though private pharmacies and other resources) or are not seeking it. Other factors, e.g. being seen attending FP services by persons in the girl's community who may know her friends or family, may also account for the near-absence of very young women among the clients.

Staff who say they would prescribe FP for youth (see Figure 3.3) indicate they would most often prescribe two-month injectables (87 percent) and male condoms (44 percent). Other methods, except emergency contraception and IUDs, were mentioned by one-quarter to one-half of the providers. In light of the potential suitability of EC to very young women who have infrequent sexual intercourse and who may lack more mature planning ability and judgment, it is interesting that only 17 percent of providers indicate they would prescribe emergency contraception to women under age 16. Eighty-three percent of providers indicated that they would not prescribe EC for women under 16. Furthermore, managers of SDPs indicated that few of the SDPs have been designated as "Youth-Friendly," and only 15 percent of facilities have "adolescent or youth health policy guidelines" available.

\section{Client-Provider I nteraction and the Quality of FP Service Delivery}

Information on quality comes mostly from observations of the actual delivery of FP services, supplemented with information from provider interviews and client exit interviews. The Bruce-Jain model of six dimensions of quality that is widely used in the field of FP provides conceptual guidance for the review of quality (Bruce 1990). These critical dimensions are client-provider relations, information exchange, choice of method, provider competence, follow-up mechanisms, and an appropriate constellation and integration of services. Observations are limited to clients who are new, restarting, or switching methods because the Bruce-Jain model is more clearly relevant to these clients, who are expected to have full counseling. (The evaluation of services to continuing clients is more complex and difficult to compare to a standard. This is because these clients' counseling needs vary greatly, since services to them depend on how long they have been using services, whether they have had problems with their contraceptive method, whether they may want to switch or stop their method, or whether they only want a resupply of their method.)

\section{Provider-client relations}

Fieldworkers observed that providers engaged in a wide variety of behaviors believed to promote high-quality provider-client relations. As indicated in Table 4.6, nearly all providers gave a friendly, respectful greeting and listened to clients. The vast majority provided emotional support and encouraged clients to ask questions. Only 5 percent appeared to have a judgmental attitude. 
However, even though all of these attributes are considered critical to good provider-client relations, only 60 percent of providers (55 percent in hospitals, 72 percent in CHCs, and 54 percent in clinics) met all of these behavioral criteria.

\begin{tabular}{lc}
$\begin{array}{l}\text { Table 4.6 } \\
\text { Percentage of providers with behavioral indicators } \\
\text { relations }\end{array}$ & Percent \\
\hline Providers' behavioral indicator & 99 \\
\hline Provides friendly, respectful greeting & 97 \\
Listens to client & 81 \\
Provides client with emotional support & 75 \\
Encourages client to ask questions & 5 \\
Has a judgmental attitude & 60 \\
All of the above, except for a judgmental attitude &
\end{tabular}

\section{Provider-client information exchange}

It is important for providers and clients to share substantial information on a variety of subjects, including medical, demographic, sexual partners, and HIV details during counseling. This information is necessary to determine the client's educational needs and to arrive at a good decision for a family planning method, including taking into account the client's risk of STI or HIV infection.

Surprisingly little information was obtained by staff from family planning clients beyond their age and the date of their last menstrual period (Table 4.7). Only 64 percent of new clients were asked about their medical history, only 50 percent were asked about their obstetric history and breastfeeding, and only 57 percent were asked about the age of their youngest child, all critical to understanding whether these clients should receive hormonal contraception. 


\section{${ }^{\text {Hrizons }}$}

Table 4.7 Percentage of 93 new, switching, or restarting FP clients with whom various medical, demographic, and partnership issues are discussed during counseling

\begin{tabular}{|c|c|c|c|c|}
\hline \multirow[t]{2}{*}{ FP issue } & \multicolumn{4}{|c|}{ Percent of provider-client interactions included } \\
\hline & $\begin{array}{c}\text { New } \\
(n=44)\end{array}$ & $\begin{array}{l}\text { Switching } \\
\quad(n=7)\end{array}$ & $\begin{array}{l}\text { Restarting } \\
(n=39)\end{array}$ & $\begin{array}{c}\text { Total } \\
(n=90)\end{array}$ \\
\hline \multicolumn{5}{|l|}{ Medical background } \\
\hline Date of LMP & 89 & 57 & 87 & 86 \\
\hline Obstetrical history & 50 & 43 & 51 & 50 \\
\hline Medical history & 64 & 57 & 72 & 67 \\
\hline Previous use of FP & 73 & 100 & 87 & 86 \\
\hline Currently breastfeeding & 50 & 43 & 36 & 43 \\
\hline \multicolumn{5}{|l|}{ Demographics } \\
\hline Age & 86 & 57 & 85 & 83 \\
\hline Number of children alive & 66 & 86 & 72 & 70 \\
\hline Age of youngest child & 57 & 86 & 69 & 64 \\
\hline Desired number of children & 16 & 14 & 31 & 22 \\
\hline \multicolumn{5}{|l|}{$\begin{array}{l}\text { Sexual partnership and HIV- } \\
\text { related issues }\end{array}$} \\
\hline Marital status & 48 & 43 & 59 & 52 \\
\hline $\begin{array}{l}\text { History of symptoms of } \\
\text { RTI/STI }\end{array}$ & 21 & 29 & 31 & 26 \\
\hline $\begin{array}{l}\text { Client has single or } \\
\text { multiple sexual partners }\end{array}$ & 14 & 14 & 15 & 14 \\
\hline $\begin{array}{l}\text { Partner has single or } \\
\text { multiple sexual partners }\end{array}$ & 7 & 0 & 10 & 8 \\
\hline $\begin{array}{l}\text { Discussed cooperation of } \\
\text { sexual partner }\end{array}$ & 18 & 29 & 41 & 29 \\
\hline HIV risk & 34 & 57 & 28 & 33 \\
\hline VCT & 11 & 14 & 10 & 11 \\
\hline Dual protection & 50 & 29 & 44 & 46 \\
\hline HIV serostatus & 0 & 14 & 5 & 3 \\
\hline $\begin{array}{l}\text { Use of vaginal inserts, } \\
\text { cleaning, and drying }\end{array}$ & 2 & 0 & 3 & 2 \\
\hline
\end{tabular}




\section{KZN Situation Analysis}

Almost no clients were asked about the number of children they wanted to have, which is another important factor in considering short-term versus long-term contraceptive choices. The low proportion of providers who asked about breastfeeding and the desired number of children may indicate that providers prefer a particular method, such as injectables, and/or assume clients want that method, unless clients ask for a different method.

Other important topics are not discussed/mentioned with many clients. For example, providerclient discussions most frequently tend to exclude issues related to sexual partners or HIV. The low proportion of providers discussing sexual partnership and other HIV-related issues in this environment with its high prevalence of HIV/AIDS is a serious weakness in provider-client exchanges. It may indicate that providers and clients are uncomfortable with these topics and/or do not fully understand and accept their importance. Interestingly, partner relations other than marital status, as well as issues surrounding STIs and HIV, are more commonly discussed with clients who are switching or restarting contraceptive methods than with new clients.

Clients who are new to FP, switching contraceptive methods, or restarting FP after a period of nonuse, are expected to have comprehensive FP counseling, and new clients are expected to have the most comprehensive FP counseling. This counseling normally provides information on several contraceptive methods and covers such issues as how the method works; how to use it; its effectiveness; its contraindications, advantages, and disadvantages; the possibility of side effects and how to manage them; switching methods if the client is not satisfied with the method; and where to obtain the method.

As noted in Figure 4.5, the majority of clients have only three methods mentioned to theminjectables, COCs, and male condoms - and these are the methods prescribed for the vast majority of clients. About a third of the clients hear about POPs, but only about 20 percent hear about IUDs, female condoms, and sterilization, and only 10 percent or less hear about vasectomy and emergency contraception. It is significant that, as shown in Figure 4.5, substantially fewer clients hear about how the method works and how to use it, that advantages tend to be discussed more than disadvantages, and that side effects and the management of side effects are frequently not discussed with clients. In addition, issues other than age and marital status are more fully discussed with clients who are switching or restarting. This finding suggests there may be a tendency for providers to more fully discuss these issues with clients with whom they are already familiar. 


\section{${ }^{\text {Hrizons }}$}

Figure 4.5 Percentage of 93 new, switching, and restarting FP clients to whom FP methods are mentioned during counseling

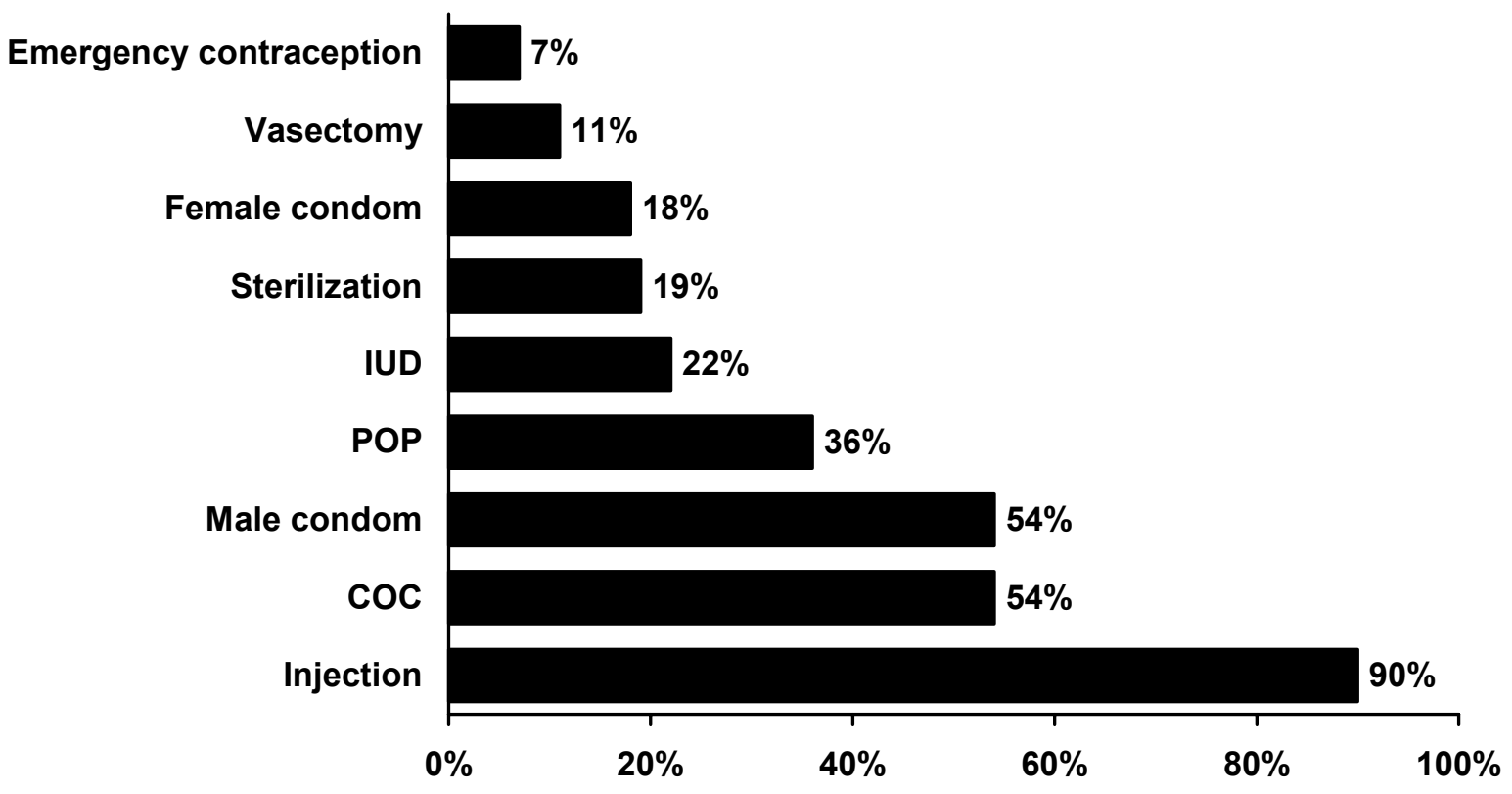


Table 4.8 Percentage of all 93 FP clients to whom specific methods were mentioned and percent told about various aspects of the method

\begin{tabular}{|c|c|c|c|c|c|c|c|c|c|}
\hline & \multicolumn{9}{|c|}{ Method (n) } \\
\hline & \multirow{2}{*}{$\begin{array}{l}\text { COC } \\
(50)\end{array}$} & \multirow{2}{*}{$\begin{array}{l}\text { POP } \\
\text { (33) }\end{array}$} & \multirow{2}{*}{$\begin{array}{l}\text { IUD } \\
(20)\end{array}$} & \multicolumn{2}{|c|}{ Condom } & \multirow{2}{*}{$\begin{array}{l}\text { Injectable } \\
\text { (84) }\end{array}$} & \multirow{2}{*}{$\begin{array}{l}\text { Sterilization } \\
\text { (18) }\end{array}$} & \multirow{2}{*}{$\begin{array}{l}\text { Vasectomy } \\
\text { (10) }\end{array}$} & \multirow{2}{*}{$\begin{array}{l}\text { EC } \\
(6)\end{array}$} \\
\hline & & & & $\begin{array}{c}\text { Male } \\
(50)\end{array}$ & $\begin{array}{c}\text { Female } \\
\text { (17) }\end{array}$ & & & & \\
\hline $\begin{array}{l}\text { Percent to } \\
\text { whom method } \\
\text { mentioned }\end{array}$ & 54 & 36 & 22 & 54 & 18 & 90 & 19 & 11 & 7 \\
\hline \multicolumn{10}{|c|}{ Percent of above who were told } \\
\hline how it works & 74 & 61 & 38 & 45 & 53 & 82 & 39 & 40 & 83 \\
\hline how to use it & 59 & 61 & 24 & 28 & 53 & 59 & 17 & 20 & 67 \\
\hline effectiveness & 38 & 33 & 5 & 30 & 29 & 56 & 17 & 20 & 33 \\
\hline $\begin{array}{l}\text { contra- } \\
\text { indications }\end{array}$ & 11 & 3 & 10 & 2 & 6 & 11 & 0 & 0 & 0 \\
\hline advantages & 26 & 30 & 14 & 30 & 24 & 56 & 0 & 0 & 0 \\
\hline disadvantages & 26 & 21 & 5 & 2 & 6 & 35 & 0 & 0 & 0 \\
\hline $\begin{array}{l}\text { side } \\
\text { effects }\end{array}$ & 30 & 21 & 5 & 6 & 18 & 63 & 0 & 0 & 0 \\
\hline $\begin{array}{l}\text { about } \\
\text { management } \\
\text { of side effects }\end{array}$ & 13 & 6 & 5 & 2 & 6 & 34 & 0 & 0 & 0 \\
\hline $\begin{array}{l}\text { about } \\
\text { possibility of } \\
\text { switching }\end{array}$ & 17 & 6 & 5 & 2 & 6 & 17 & 0 & 0 & 0 \\
\hline $\begin{array}{l}\text { where to } \\
\text { obtain method }\end{array}$ & 34 & 27 & 29 & 21 & 29 & 57 & 6 & 0 & 17 \\
\hline $\begin{array}{l}\text { Percent } \\
\text { accepted } \\
\text { method }\end{array}$ & 26 & 9 & 10 & 8 & 12 & 80 & 11 & 0 & 33 \\
\hline
\end{tabular}

As can readily be seen in Table 4.8, FP clients are usually not provided with detailed information on the three most popular FP methods so that they can make an informed decision (and much less information is provided on the less popular methods). Effectiveness, contraindications, advantages, disadvantages, possible side effects, and the management of side effects are frequently not discussed with clients during FP counseling. More information is provided on advantages than on disadvantages, and less is provided on the management of side effects than on actual side effects.

An analysis of type of facilities and a comparison of urban versus rural areas indicated that only a few marginally significant differences existed in the types of contraceptives mentioned to clients. POPs were more likely to be mentioned to clients in urban and peri-urban SDPs than in rural SDPs. 


\section{${ }^{H}{ }^{\text {rizons }}$}

Male condoms and EC were most likely to be mentioned in CHCs and least likely to be mentioned in hospitals. In addition, though female condoms were significantly more likely to be mentioned in CHCs than in clinics and hospitals, this may be caused by the purposeful selection of CHCs to participate in the female condom pilot program.

\section{Choice of methods}

Figure 4.5 indicates that providers do not mention the full range of contraceptives that are available to clients. Also, Table 4.8 shows that complete information on methods is not made available to clients. However, the minimum definition of choice used in Situation Analysis studies is whether or not the providers mention two or more FP methods to the clients during counseling (Table 4.9) . Observers report that three-quarters of the clients heard about two or more methods, and almost two-thirds of clients heard about three or more methods. (Slightly more clients -85 percentreported that the provider mentioned other methods than the one they adopted.) Thus, most clients received the minimum definition of "choice."

However, another issue related to choice is whether providers are promoting or emphasizing one or more methods in particular. Observers noted that providers were promoting methods with almost half the clients (47 percent). Providers promoted the three-month injectable most often. About onethird as often, providers promoted the two-month injectable or condoms.

Although providers are promoting injectable contraceptives, they are also asking about half the clients whether they have a preference, and about half the clients are also telling providers spontaneously that they have a preference. Since almost all clients ( 96 percent) received their preferred method (and three-quarters received injectables), fieldworkers concluded that clients also prefer injectable methods. Thus, it can be seen that a number of factors are responsible for the large proportion of clients receiving injectables. Injectables are the most widely available method, and providers are promoting that method. Many women attending the SDPs prefer this method to begin with, and more chose it after receiving less than adequate information about all methods and after providers made a presentation often biased in favor of injectables. 


\section{Table 4.9 Number of methods mentioned to 93 FP clients}

\begin{tabular}{lc}
\hline Number of methods mentioned & Percent \\
\hline 1 & 26 \\
2 & 16 \\
3 & 23 \\
4 & 12 \\
5 & 11 \\
$6+$ & 13
\end{tabular}

More than three-quarters (78 percent) of the 93 clients accepted injectable contraceptives (the proportion accepting three-month injectables was twice that accepting two-month injectables). Combined pills were accepted by 16 percent of clients, and male condoms were accepted by 5 percent. One client accepted sterilization.

\section{Provider competence}

The Situation Analysis methodology relies on examining whether providers are in compliance with recommended procedures. In Table 4.10, provider compliance is reviewed for conducting pelvic examinations and providing injectable contraceptives. Providers comply with about three-quarters of the recommended procedures, on average. In the pelvic examinations, providers did well at explaining and carrying out the procedure - using sterile gloves, inspecting external genitalia, and using a sterile speculum (if a speculum was used). Providers did relatively poorly by not performing bimanual examinations, not washing hands, and not using a speculum. In the case of injectables, providers were in compliance with many recommended procedures, but were not compliant with asking about smoking and breastfeeding and with explaining the need for HIV/AIDS protection. 


\section{Hgrizons}

Table 4.10 Percentage of providers observed to be technically competent in the provision of pelvic examinations and injectable contraceptive services

\begin{tabular}{lr}
\hline Service & Percent \\
\hline Pelvic examination ( $\mathbf{n}$ 15) & 100 \\
Explains the procedure to client & 100 \\
Puts on clean, sterile gloves before exam & 87 \\
Inspects external genitalia & 40 \\
Performs bimanual exam & 47 \\
Washes hands before exam & 27 \\
Uses speculum & 100 \\
Uses sterile speculum & \\
Injectable contraceptive services ( $\mathbf{n}$ 77) & 90 \\
Checks blood pressure & 91 \\
Asks about menses & 46 \\
Asks about breastfeeding & 75 \\
Weighs client & 81 \\
Discusses changes in menstrual cycle & 71 \\
Shakes vial & 55 \\
Wipes top of vial with disinfectant & 96 \\
Uses a sterile syringe and needle & 91 \\
Disinfects injection site with antiseptic & 94 \\
Disposes syringe and needle in sharps container & 48 \\
Explains need for STI and HIV protection &
\end{tabular}




\section{Recontact and follow-up mechanisms}

The most general indications that providers are attending to follow-up procedures are that almost all clients were given a written reminder of when to return, and that all 73 injectable clients report being told how often to obtain their injection. Furthermore, almost all of the injectable clients reported that they were told they should return to the clinic if they experienced certain problems. However, clients had difficulty in spontaneously mentioning problems for which they should return, except for "irregular bleeding or spotting," which is the most common problem experienced with injectables. (Almost three-quarters of the injectable clients mentioned having this problem.)

\section{Table 4.11 Percentage of FP clients given follow-up encouragement} (from observations and exit interviews)

\begin{tabular}{lr}
\hline & Percent \\
\hline Indicator of follow-up encouragement & 98 \\
Clients given a written reminder of when to return (observation, $\mathrm{n}=90)$ & 69 \\
Clients told where else they can get method (exit, $\mathrm{n}=89)$ & 100 \\
Injectable clients told how often to get injection (exit, $\mathrm{n}=73)$ & 95 \\
Injectable clients told to return if they experience certain problems (exit, $\mathrm{n}=73)$ ) & \\
Reports by 71 injectable clients (without prompting) on what problems & 73 \\
require return (exit) & 21 \\
Irregular bleeding or spotting & 20 \\
Increased discharge & 18 \\
Excessive weight gain & 18 \\
Regular or severe headaches & \\
Other problems &
\end{tabular}

\section{Clients' Experience With and Views About Service Provision}

Client responses to questions about satisfaction with services are generally believed to be influenced by courtesy biases, that is, they tend to give positive responses to questions in order not to offend the providers. However, the long list of positive responses to a number of questions suggests that FP clients are relatively satisfied with FP services at MCHW SDPs in KwaZulu Natal. Indeed, about 95 percent of FP clients say they are fully satisfied (and the rest are partially satisfied). While only about a third of clients had concerns they wanted to discuss with providers, the vast majority were able to discuss their concerns, felt the provider listened, and were satisfied by the provider's response. 


\section{Hgrizons}

Table 4.12 Percentage of 89 clients indicating satisfaction with FP services

\begin{tabular}{lc}
\hline Indicator of client satisfaction & Percent \\
\hline Waiting time was reasonable (or none) & 63 \\
Never been turned away during open hours & 90 \\
Had FP concerns you wanted to discuss & 33 \\
Provider let you express concerns & 90 \\
Provider listened to your concerns & 100 \\
Provider responded to your concerns & 100 \\
Had enough privacy & 92 \\
Provider spent enough time with you & 99 \\
Fully satisfied & 94
\end{tabular}

\section{Client Awareness and Knowledge of HIV/ AI DS}

The most important issue related to an appropriate constellation of services in KZN, which has high HIV prevalence, is the integration of STI and HIV/AIDS services. This includes counseling on condom use and dual protection, education on strategies for preventing STI and HIV transmission, and referral for STI treatment and VCT. One of the main motivations of the Subdirectorate of MCWH in carrying out this study was to obtain data on how extensively FP services was promoting condom use and dual protection, that is, the simultaneous prevention of pregnancy and STI /HIV transmission.

Data from the observation of services provided to 89 new family planning clients in 58 SDPs indicate that providers are encouraging condom use. About 70 percent of FP clients were encouraged to use condoms for protection against STIs/HIV (that is, the percentage who were encouraged to use male condoms, plus the percentage who were encouraged to use female condoms, plus the percentage who were encouraged to use both male and female condoms). Fiftyfive percent were advised to use condoms for protection against pregnancy, and 44 percent received encouragement to use condoms for both STI and HIV and pregnancy prevention. However, providers and clients tended to discuss much less frequently such important topics as partner cooperation, how to actually use condoms, and other strategies of HIV prevention such as abstinence and monogamy, VCT, or the clients' actual serostatus. Less than a third of clients (28 percent) received information on how to use condoms. Twenty percent of FP clients actually received condoms. Nineteen percent of those receiving injectable contraceptives also received male condoms, as did 21 percent of those receiving oral contraceptives. However, none of the clients receiving IUDs received male contraceptives for dual protection. 
KZN Situation Analysis

Table 4.13 Percentage of 89 provider-client interactions in which HIV-related topics were discussed

\begin{tabular}{lc}
\hline HIV-related topics for discussion & Percent \\
\hline STI/HIV risk factors & 48 \\
Multiple partners & 14 \\
STIs & 39 \\
Unprotected sexual intercourse & 39 \\
Provider encourages male condoms for STI/HIV prevention & 52 \\
Provider encourages female condoms for STI/HIV prevention & 3 \\
Provider encourages both male and female condoms & 14 \\
Provider gives information on how to use a condom & 28 \\
Provider discusses abstinence & 13 \\
Provider discusses monogamy & 11 \\
Provider discusses partner's monogamy & 10
\end{tabular}

The data suggest that the majority of FP clients usually receive encouragement to use condoms and practice dual protection. However, generally less than a third of clients receive the more complete counseling, information, and supplies that would prepare them more fully to actually use condoms, or use other strategies to prevent HIV. Overall, providers do moderately well at promoting condoms and dual protection, but there is room for substantial improvement in counseling on HIV prevention.

\section{Travel and Waiting Times}

More than a third (37 percent) of the clients complained about waiting time, and the most common suggestion made by the clients for improving services was to increase the number of nurses providing services. The main way in which clients would like services to improve is to reduce waiting time.

Furthermore, about 10 percent of clients suggested important improvements in provider behavior or in SDP organization. For example, clients said that "nurses should stop scolding clients;" "nurses should treat clients with dignity," "nurses should stop chasing away teenagers," and "staff should increase privacy," even "in the waiting area so no one can see that the client has come for FP." 


\section{Hgrizons}

\section{Summary}

The Subdirectorate of MCHW services has developed substantial readiness to deliver FP services in terms of infrastructure, availability of contraceptives, equipment, logistics, staffing, records, and reporting. The infrastructure includes widespread availability of supportive elements such as electricity, telephone service, working toilets for clients, designated areas for examination, and relative privacy (especially visual privacy) for the delivery of service. However, a few weaknesses in infrastructure also exist, including inadequate seating for waiting clients and adequate amounts of safe water in a minority of SDPs. Contraceptives, including injectables, orals, and male condoms, are widely available, but stock-outs of all these methods were reported during the past six months from a minority of SDPs, and IUDs and female condoms are not widely available. Many items of basic equipment for delivering services are almost always available. A staff of professional nurses delivers FP services, but the nursing staff has had little in-service training in FP during the past three years, and almost half the nurses have never had in-service training on FP. There is supervision at most service delivery points, but there is room for improving the helpfulness of these supervisory visits. In contrast to the many strengths in readiness to deliver FP services, the information and education subsystem is comparatively weak. Signs about the availability of FP services were frequently not available and educational materials are generally not available for clients to take home.

An examination of the quality of FP services was organized around the Bruce-Jain model of six dimensions of quality. Providers usually do a better job of obtaining and providing information on the medical and demographic background of clients, but they avoid discussions about partnership and HIV-related issues. How to use a method, how it works, and its effectiveness are topics that are discussed more frequently with clients than are contraindications, disadvantages, and the possibility of switching methods if the client is not satisfied with her method. Clients usually receive a choice of two or more methods, but providers are positively biased toward injectables, the most commonly discussed method and the one accepted by about three-quarters of all new, restarting, and switching clients.

Providers were technically competent in providing pelvic exams and injectables with nearly all of the clients. For example, all of the providers explained the pelvic examination and put on clean, sterile gloves before the exam. Yet fewer providers performed bimanual examinations, washed hands before the exam, and used a speculum. Similarly, the vast majority of nurses provided injectables, checked blood pressure, asked about menses, used a sterile syringe and needle, and disposed of it properly. Yet fewer nurses asked about breastfeeding or explained the need for STI and HIV protection when using injectable contraceptives.

Providers are strong in the area of follow-up systems for FP, although they need to emphasize reasons for clients to return to the SDP. It is significant that nurses are promoting condom usage for preventing STIs, HIV/AIDS, and preventing pregnancies. Most important in this region where HIV/AIDS prevalence is high, about 70 percent of clients were encouraged to use male condoms. However, though condom usage was promoted, providers tended not to discuss with clients the specifics of how to use condoms, the sensitive issues of negotiating and gaining partner cooperation, and strategies of HIV prevention besides condom usage. 
In general, clients seemed to be quite satisfied with FP services. About 10 percent of the clients provided specific suggestions for improving services, especially about reducing waiting times. Although the clients were young and mostly unmarried, only 19 percent of the facilities classified themselves as youth-friendly, and only one of 89 clients said she was under 16 years of age. These findings, along with reports by providers of various restrictions on the provision of FP methods, suggest the need to examine the youth friendly nature of service provision. 


\section{Herizons}

\section{Chapter 5 Antenatal Care Services}

\section{KwaZulu Natal Antenatal Care Program}

Antenatal care has been promoted over the past two decades to identify and manage antenatal conditions that might affect labor and delivery and maternal and infant health and survival, and to identify and help plan for special obstetric care for women "at risk" of poor pregnancy outcome (Rooney 1992). Recent recognition of the ineffectiveness of many antenatal procedures, including risk screening for maternal and infant survival (Rooks 1989; Rooks and Winikoff 1990; Alexander 1989; Starrs 1998), has led researchers and managers to focus more on the elements of ANC proven to be effective rather than on the timing or quantity of ANC visits (Villar 2001).

Data from the Health Systems Trust indicates that in 1998, more than 94 percent of pregnant women in KwaZulu Natal Province received ANC services from a health professional. In addition, in 200070 percent of KZN clinics offered ANC services every weekday. ANC clients normally come late in their second trimester of pregnancy (approximately the 28th week) and often make only one ANC visit.

Although the 1997 DHS data have not yet been released to the public, KZN is believed to have the highest incidence of maternal deaths in South Africa (the national maternal mortality rate [MMR] is 230 per 100,000 live births) (WHO/UNICEF 1996). However, according to data in the "Saving Mothers 2 Report" (launched in March 2003), the MMR for KZN is 144 per 100,000 (Department of Health 2000). The national MMR is estimated to be 175 per 100,000. This figure is calculated on the basis of public institutional deaths and excludes community deaths and deaths occurring in private institutions. According to the "Saving Mothers 2 Report," the primary obstetric causes, final and contributory cases of death are shown in Figure 5.1: non-pregnancy-related infections (31 percent), complications of hypertension in pregnancy (21 percent), obstetric hemorrhage (14 percent), pregnancy-related sepsis (12 percent), and preexisting medical conditions ( 7 percent). The proportion of deaths due to non-pregnancy-related infections (including AIDS ) has dramatically increased from 23 percent in 1998 to 31.4 percent in the in the past three years? Many of these deaths are preventable. 
Figure 5.1 Maternal mortality in $\mathrm{KZN}^{*}$

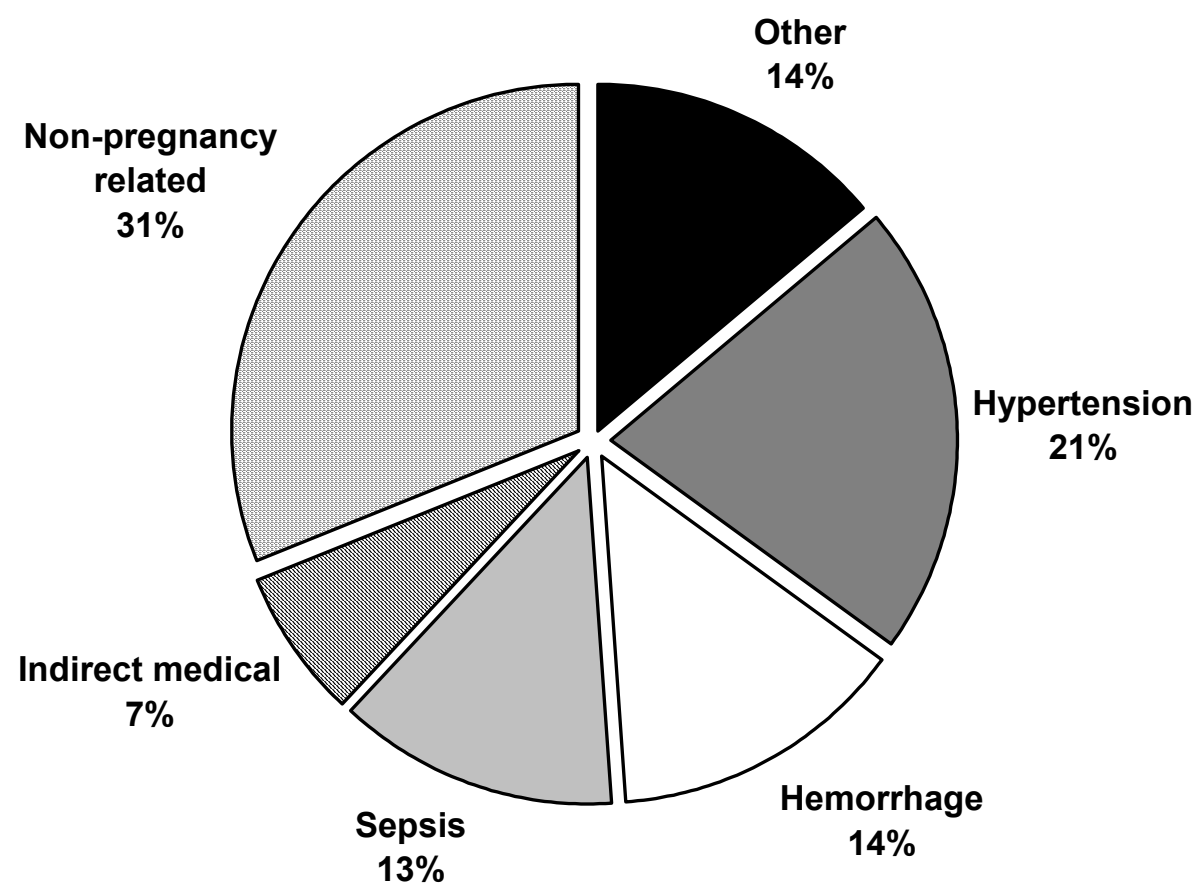

*Source: Department of Health and National Committee for Enquires into Maternal Deaths. 2000. Second Interim Report on Confidential Enquiries into Maternal Deaths in South Africa-Maternal Deaths in 1999, Pretoria.

In the past, it was believed that maternal mortality could be reduced by increasing the proportion of women receiving ANC, particularly by increasing the proportion presenting for this care early in gestation and by increasing their number of ANC visits. According to the "Saving Mothers 2 Report," ANC was attended by 57.2 percent of the women who died. The HIV test was performed in 36.4 percent of these cases, and in 76.1 percent of them it was positive. Other estimates that may be more representative indicate that approximately 36 percent of ANC clients are HIV-positive. This finding emphasizes the importance of integrating VCT services with ANC to determine the HIV status of pregnant women and thus ensure effective management of the pregnancy. Integrating VCT with ANC also will help determine the causes of death so that more information is available to appropriately restructure services. Recent research demonstrates that emphasis needs to be placed on components of ANC with known effectiveness, such as expanding the range of services for ANC clients to include counseling and testing for RTIs and HIV/AIDS, and improving the acceptability and quality of such services. The KZN Department of Health has prioritized all these components.

As part of the KZN Situation Analysis study, 98 SDPs were visited and 154 ANC clients were observed as they received services from a provider. Of these 154 clients, 151 were interviewed as 


\section{Hgrizons}

they exited, using a structured questionnaire. Three clients for whom clinical examination was observed were not interviewed. The assessment of ANC services was generally limited to basic indexes of care. Data on the infrastructure (such as running water, lights, windows, and toilets) are covered in Chapter 2.

\section{ANC Patient Characteristics}

\section{Sociodemographic characteristics}

Table 5.1 presents basic sociodemographic data on the 151 ANC clients who were interviewed at the conclusion of their ANC services. The median age for this group was $24.5 \pm 6.7$, years with an age range from 15 to 41 . The mean number of living children was $1.2 \pm 1.5$, with 43 percent having no children. Of the 151 ANC clients, 79 percent were single. Zulu was the native language for most of the clients. Seventy-five percent had had a post-primary education. In summary, the ANC clients are a relatively young population consisting mainly of single females with no or few children, and at least a primary school education. 
Table 5.1 ANC client characteristics

\begin{tabular}{|c|c|}
\hline Characteristics & Percent \\
\hline \multicolumn{2}{|l|}{ Age $(n=150)$} \\
\hline $15-19$ & 29 \\
\hline $20-24$ & 29 \\
\hline $25-29$ & 18 \\
\hline $30-34$ & 13 \\
\hline $35-39$ & 11 \\
\hline $40+$ & 1 \\
\hline \multicolumn{2}{|c|}{ Number of living children $(n=142)$} \\
\hline 0 & 43 \\
\hline 1 & 30 \\
\hline 2 & 11 \\
\hline $3+$ & 15 \\
\hline \multicolumn{2}{|l|}{ Marital status $(n=151)$} \\
\hline Single & 79 \\
\hline Married & 15 \\
\hline Living with partner & 7 \\
\hline \multicolumn{2}{|c|}{ Language used at home $(n=150)$} \\
\hline Zulu & 94 \\
\hline Xhosa & 2 \\
\hline English & 3 \\
\hline Other & 1 \\
\hline \multicolumn{2}{|c|}{ Education, highest level $(n=151)$} \\
\hline No schooling & 2 \\
\hline Primary incomplete & 18 \\
\hline Primary complete & 5 \\
\hline High school incomplete & 55 \\
\hline High school complete & 19 \\
\hline Post-matriculate & 1 \\
\hline
\end{tabular}

\section{Pregnancy trimester of ANC clients on first ANC visit}

The pregnancy trimester at the first visit of ANC clients has been of interest in the past to managers so that manageable conditions could be detected early in the pregnancy. 


\section{Hgrizons}

Figure 5.2 Trimester of pregnancy of clients making their first or subsequent ANC visits

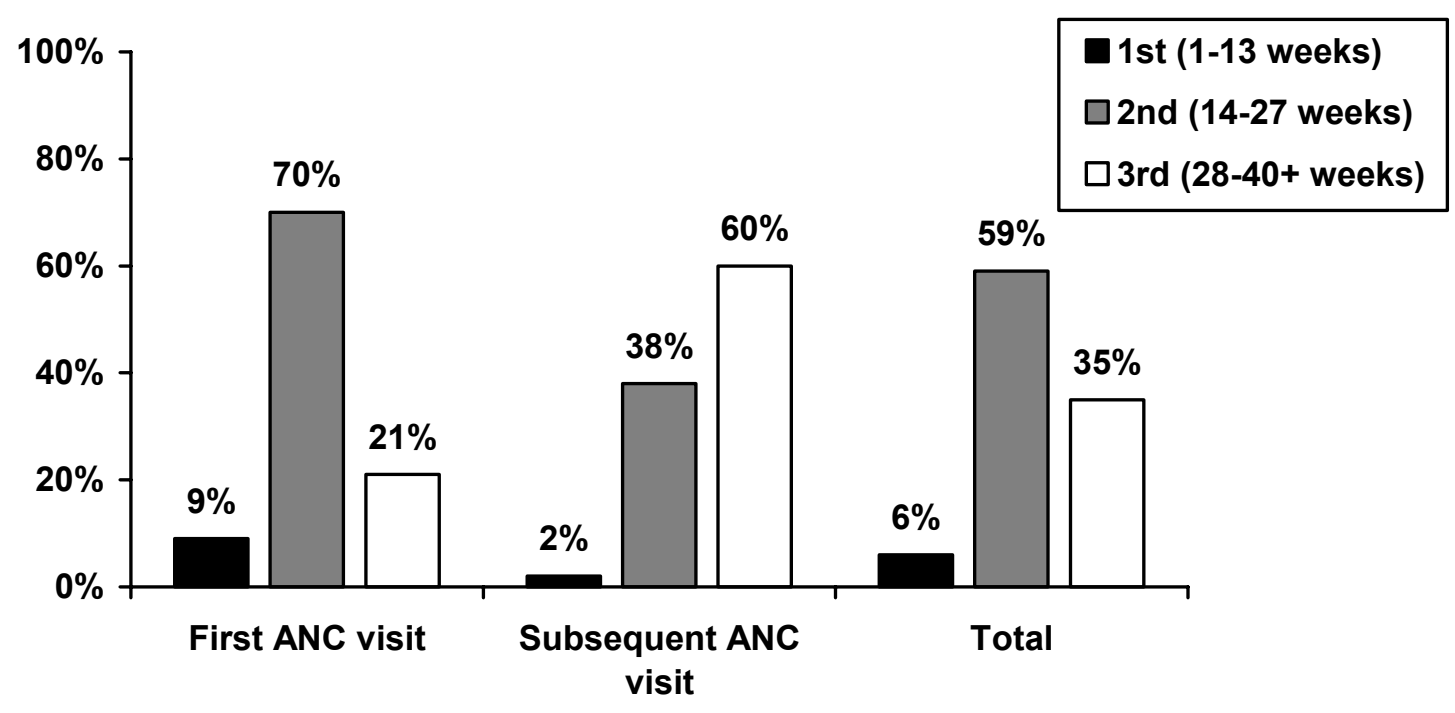

ANC clients usually come for care late in their second trimester of pregnancy ( $25 \pm 7$ weeks gestation), with 6 percent and 68 percent first presenting in the first and second trimesters, respectively (Figure 5.2). The mean gestation in weeks among 93 clients making their first ANC visit was $24 \pm 6$. Women in this study first presented one month earlier than the 28 weeks at first presentation reported by the Health Systems Trust in 1998.

\section{Readiness of Facilities to Provide ANC Services}

\section{Health facilities and ANC services}

The 154 ANC observations and 151 client interviews were obtained at 52 SDPs where ANC clients were found on the day of the research visit. Only seven SDPs reported that they were not offering ANC services on the week of the research visit. All but two SDPs were open at least five days a week, and only one was open less than eight hours per day. Twenty-five percent of SDPs were open seven days a week, and 11 percent were open 24 hours a day.

Seven SDPs reported that they were not providing ANC services. The following analyses include SDPs reporting no ANC clients, but exclude SDPs not providing ANC services. Thus, among the SDPs included in the analyses, the reported means and medians may be upwardly biased.

Community health centers, which are mostly located in urban or peri-urban areas and are usually larger than clinics, attended the largest number of ANC clients (Table 5.2), followed by district hospitals (55 percent of which are rural) and clinics ( 74 percent of which are rural). 
KZN Situation Analysis

Table 5.2 Median and mean number of ANC clients in the last month before fieldworker visit by type of facility

\begin{tabular}{lccccr}
\hline Type of facility & Median & Mean & $\begin{array}{c}\text { Standard } \\
\text { deviation }\end{array}$ & $\begin{array}{c}\text { Low } \\
\text { range }\end{array}$ & $\begin{array}{c}\text { High } \\
\text { range }\end{array}$ \\
\hline District hospital (9) & 276 & 362 & 297 & 0 & 868 \\
Community health center (12) & 547 & 647 & 490 & 0 & 1,499 \\
Clinic (70) & 65 & 107 & 119 & 0 & 495 \\
Urban (11) & 405 & 544 & 374 & 83 & 1,121 \\
Peri-urban (22) & 185 & 290 & 381 & 0 & 1,499 \\
Rural (58) & 59 & 106 & 141 & 0 & 800
\end{tabular}

\section{ANC basic equipment and supplies}

As noted in Chapter 2, the readiness of KZN SDPs to provide ANC services is good, possibly because of the emphasis placed on improving ANC in KZN over the past decade. Eighty-nine percent of hospitals have all the basic essential ANC equipment), as do 83 percent of community health centers and 79 percent of clinics.

The equipment most frequently missing, as shown in Figure 5.3, is urine testing equipment (to identify proteinuria and pre-eclampsia) and tape measures (to measure fundal height). Further attention needs to be given to ensuring that adult weighing scales are not simply bathroom scales. Such spring scales are known to be inaccurate, and the more they are used, the more they tend to indicate that clients are heavier than they really are, even when these scales are periodically reset to zero. Pregnancy tests are available at 78 percent of hospitals, 83 percent of community health centers, and 74 percent of clinics. Sixty-eight percent of hospitals have ultrasounds, but only 33 percent of CHCs and none of the clinics have ultrasound scanners. Only 46 percent have gynecological tables, including 67 percent of hospitals, 67 percent of CHCs, and 40 percent of clinics. 


\section{Hgrizons}

Figure 5.3 Percentage of facilities with essential ANC equipment*

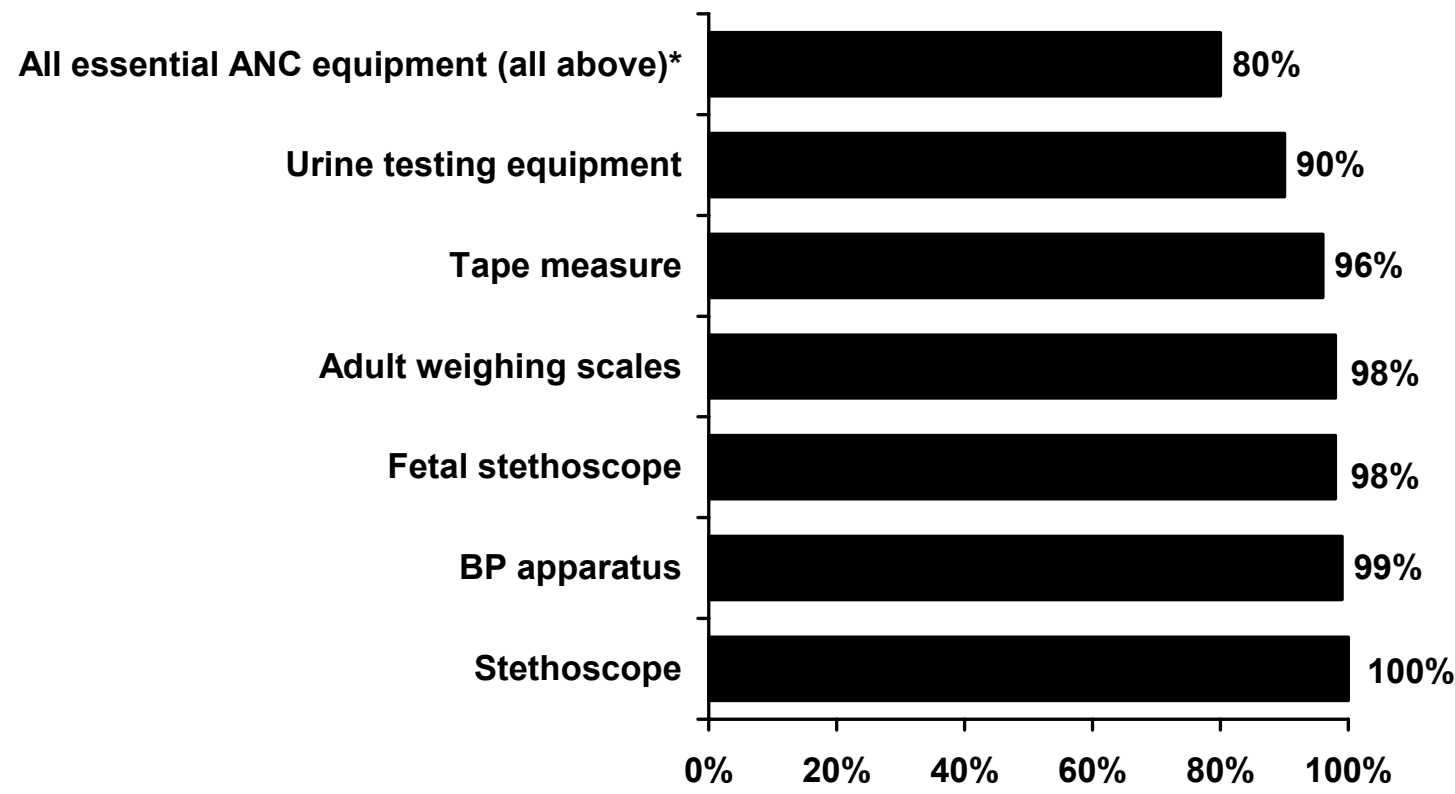

* Hand and instrument washbasins and hemoglobin testing equipment were not specifically assessed and are considered optional essential items because alternative sources for washbasins are acceptable, and the usual tests (hemoglobin and hematocrit) for anemia do not include definitive tests for iron deficiency, namely, serum ferritin.

Figure 5.4 Percentage of facilities with essential ANC supplies*

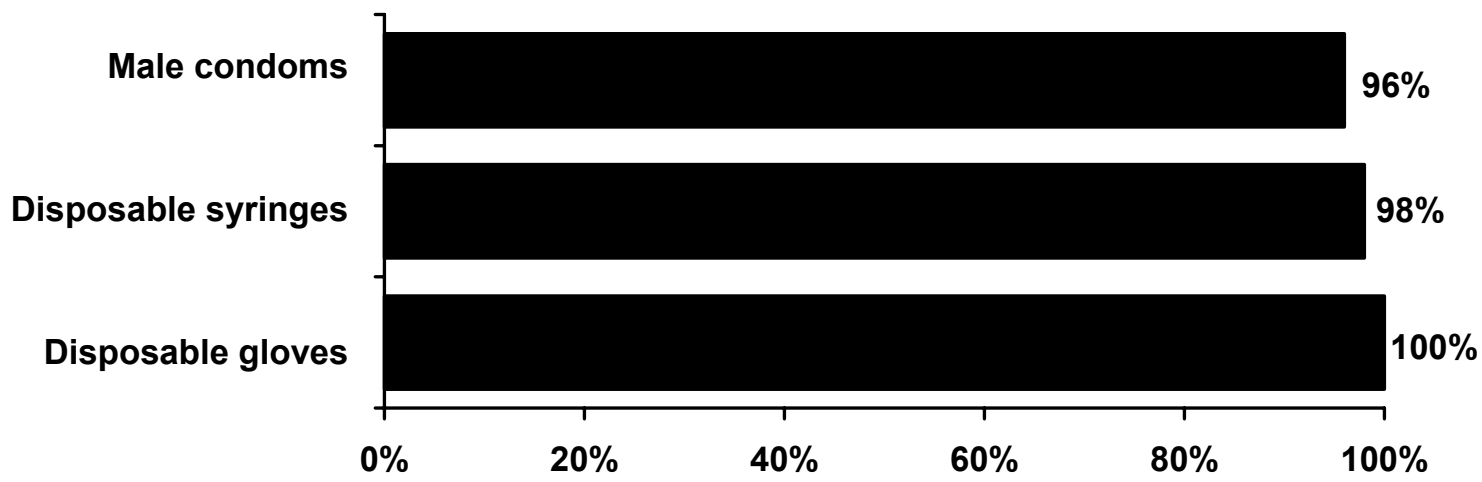

\footnotetext{
* Information was not collected on antibacterial soap, chlorine solution, partographs, or intravenous (IV) kits.
} 
Nearly all facilities have disposable gloves, syringes and male condoms available (Figure 5.4). Male condoms were available in all facilities except three clinics.

\section{ANC Medications}

The inventory collected information on anti-hypertensive, anti-infection medications and labor inducers listed in Table 5.3. Anti-hypertensive and anti-infective medications were available at nearly all SDPs. However, only 78 percent of SDPs had labor inducers. Information on the availability of iron or iron-folate tablets, antimalarials, and tetanus toxoid are presented below in the sections on observation of ANC exam (Table 5.11) and patient exit interviews. All hospitals and all but one clinic had anti-hypertensives, while only 75 percent of CHCs had these drugs available. This finding is surprising because one would expect the larger $\mathrm{CHC}$ facilities to be better stocked than clinics. All hospitals and clinics had anti-infection drugs, as did all CHCs except one. Fewer facilities had injectable labor inducers; interestingly, 83 percent of clinics had these drugs, while only 56 percent of hospitals and 67 percent of CHCs did.

Table 5.3 Percentage of facilities with selected ANC medications

\begin{tabular}{lcccc}
\hline Medications & $\begin{array}{c}\text { Hospitals } \\
(\mathbf{n}=\mathbf{9})\end{array}$ & $\begin{array}{c}\text { CHCs } \\
(\mathbf{n}=\mathbf{1 2})\end{array}$ & $\begin{array}{c}\text { Clinics } \\
(\mathbf{n}=\mathbf{7 0})\end{array}$ & $\begin{array}{c}\text { Total } \\
\text { (n= 91) }\end{array}$ \\
\hline $\begin{array}{l}\text { Anti-hypertensive (methydopa tablets, } \\
\text { injectable magnesium sulphate) }\end{array}$ & 100 & 80 & 99 & 96 \\
$\begin{array}{l}\text { Anti-infectives, tablets or injectable } \\
\text { (amoxycillin, erythromyacin, penicillin) }\end{array}$ & 100 & 92 & 100 & 99 \\
Labor inducers (oxytocin) & 56 & 67 & 83 & 78
\end{tabular}

\section{Availability of Supportive ANC Materials}

Table 5.4 indicates that educational materials on ANC and related care (such as postpartum, newborn, breastfeeding, and family planning services) are usually not available for ANC clients, and are rarely available for postpartum care. However, 71 percent of staff have access to "Guidelines for Management of Pregnancies," and most staff have registries. Still, the fact that 15 percent of facilities do not have logbooks and that 29 percent do not have "Guidelines for Management of Pregnancy" are of some concern. 


\section{Hgrizons}

Table 5.4 Percentage of facilities with availability of supportive ANC materials

\begin{tabular}{lc}
\hline Materials supporting ANC services & Percent \\
\hline ANC educational materials for clients to take & 17 \\
Educational material subjects & \\
Postpartum care & 6 \\
Newborn care & 23 \\
Breastfeeding & 34 \\
Family planning & 25 \\
STIs and/or HIVIAIDS & 58 \\
"Guidelines for Management of Pregnancies" & 71 \\
Logbook or registry & 85
\end{tabular}

\section{Readiness to manage emergency obstetric conditions}

Although antenatal care facilities are not necessarily capable of firsthand management of emergency obstetric conditions, recent thinking is that one of the most important components of ANC services is their ability to manage or refer and transport clients requiring emergency services, particularly cesarean deliveries and blood transfusions. All hospitals and CHCs had telephones and 91 percent of clinics had them. Clinics are the facilities with the least ability to provide firsthand management of emergency obstetric conditions and the greatest need to refer and transfer these cases (by ambulances, whose availability was not assessed, or to call for emergency assistance from a higher-level facility). No clinics and only 11 percent of hospitals and 8 percent of CHCs reported having full-time specialist physicians (namely, those who might have the capacity to perform a cesarean section), although these specialists may simply be available at the facility but do not actually provide antenatal or obstetric care. Twenty-two percent of hospitals, 25 percent of CHCs, and 14 percent of clinics have part-time medical specialists (who may not, however be obstetricians or surgeons). Similarly, 44 percent of hospitals, 41 percent of CHCs, and 19 percent of clinics have advanced midwives on their staff. Twenty-two percent of hospitals and 42 percent of CHCs have technicians, while no clinics have technicians (who are needed for blood typing before transfusions).

Seventy-eight percent of hospitals, 83 percent of CHCs, and 61 percent of the clinics surveyed provide maternity and delivery services. Sixty-seven percent of hospitals, 83 percent of CHCs, and 60 percent of clinics claim they currently provide care for emergency obstetric complications (although all hospitals purportedly provide emergency obstetric services, possibly reflecting a reporting bias). Nevertheless, hospitals have the greatest capacity for management of emergency obstetric conditions, but, as expected, clinics have limited capacity, and a significant proportion of CHCs lack the ability to provide essential emergency obstetric services. The availability of ambulances (or other government-owned vehicles that could compensate for any unavailability of ambulances) is critical to transporting emergency obstetric cases (for example, for women 
experiencing hemorrhaging) because private vehicles often refuse to do so. The survey did not assess the ability of these facilities to transport clients requiring emergency care or to arrange such transportation. Travel time from district hospitals to tertiary care averages approximately 45 minutes, whereas time from a $\mathrm{CHC}$ or clinic to a higher-level facility averages approximately half an hour. The availability of telephones or shortwave communications in ANC facilities has improved considerably over the past decade. For this reason, most women promptly presenting with an emergency obstetric condition or experiencing such a condition after arrival at hospitals can reach tertiary care if transportation is available when called on. This is less likely for women presenting at $\mathrm{CHCs}$ or clinics who require cesarean delivery or blood transfusion because of the limited ability of district hospitals and $\mathrm{CHCs}$ to provide these services.

Table 5.5 Percentage of facilities ready to provide or arrange for emergency obstetric care, by type of SDP

\begin{tabular}{|c|c|c|c|c|}
\hline Readiness indexes & $\begin{array}{c}\text { District } \\
\text { hospitals } \\
(n=9)\end{array}$ & $\begin{array}{c}\text { Community } \\
\text { health } \\
\text { centers } \\
(n=12)\end{array}$ & $\begin{array}{l}\text { Clinics } \\
(n=70)\end{array}$ & $\begin{array}{c}\text { Total } \\
(n=91)\end{array}$ \\
\hline Telephone & 100 & 100 & 91 & 93 \\
\hline Full-time specialist physicians & 11 & 8 & 0 & 3 \\
\hline Part-time specialist physicians & 22 & 25 & 14 & 16 \\
\hline Full-time other physicians & 33 & 33 & 3 & 10 \\
\hline Part-time other physicians & 44 & 33 & 37 & 37 \\
\hline Advanced midwives & 44 & 41 & 19 & 24 \\
\hline $\begin{array}{l}\text { Technicians } \\
\text { (including those doing blood typing) }\end{array}$ & 22 & 42 & 0 & 8 \\
\hline Maternity and delivery services & 78 & 83 & 61 & 66 \\
\hline $\begin{array}{l}\text { Management of emergency obstetric } \\
\text { condition }\end{array}$ & 67 & 83 & 60 & 64 \\
\hline \multicolumn{5}{|l|}{ Travel time (minutes) } \\
\hline Mean & 47 & 21 & 38 & 37 \\
\hline Minimum & 1 & 10 & 5 & 1 \\
\hline Maximum & 120 & 45 & 90 & 120 \\
\hline
\end{tabular}




\section{Herizons}

\section{Observation of General ANC Patient-Provider I nteractions}

\section{General counseling process with ANC clients}

Information is available on the interactions between providers and $154 \mathrm{ANC}$ clients who were observed, and from exit interviews with 151 clients. Providers were nearly all female ( 98 percent), and the fieldworkers judged that almost all of them (95 percent) greeted clients in a friendly and respectful manner, setting a sound foundation for good provider-client interactions. As shown in Table 5.6, fieldworkers noted that most of the ANC clients are receiving emotional support during their counseling. However, less than half the clients are encouraged to ask questions. Noted earlier in this report (Section 3) is the weakness of the IEC components, with inadequate supplies of materials for clients to take home. The fact that providers did not use audiovisual aids during counseling reinforces this view.

\section{Table 5.6 Percentage of 154 ANC clients who receive components of supportive} counseling

\begin{tabular}{lc}
\hline Components & Percent \\
\hline Greets clients in friendly, respectful manner & 98 \\
Encourages questions & 46 \\
Uses visual aids during consultation & 4 \\
Provides emotional support & 79
\end{tabular}

\section{History taking}

Table 5.7 provides information on the questions providers asked to obtain information on the background of the patient and her pregnancy. Providers ask most clients about their age, the date of their last menstrual period (LMP), the number of prior pregnancies, the number of living children, and whether they have felt the fetus move. About half the clients are asked about the age of their youngest child, prior stillbirths, and medications they are taking. Very few are asked about their HIV status, bleeding during the current pregnancy, postpartum hemorrhaging after prior deliveries, and history of RTIs or STIs. Only one patient was asked about gender-based violence. 
Table 5.7 Percentage of ANC clients asked routine history-taking questions

\begin{tabular}{lccc}
\hline Routine history-taking question & $\begin{array}{c}\text { First } \\
\text { visit } \\
\text { (n = 17) }\end{array}$ & $\begin{array}{c}\text { Subsequent } \\
\text { visit } \\
\text { (n = 135) }\end{array}$ & $\begin{array}{c}\text { Total } \\
\text { (n = 153) }\end{array}$ \\
\hline Patient's age & 95 & 75 & 77 \\
Date of LMP & 90 & 84 & 84 \\
Number of prior pregnancies & 90 & 79 & 80 \\
History of RTls or STls & 47 & 30 & 49 \\
HIV status & 26 & 15 & 16 \\
History of gender-based violence or abuse & 0 & 2 & 1 \\
Reproductive history & & & \\
$\quad$ Number of living children & 74 & 70 & 70 \\
$\quad$ Age of youngest child & 63 & 42 & 45 \\
$\quad$ Prior stillbirths & 69 & 50 & 31 \\
$\quad$ Prior infant deaths in first week after birth & 26 & 32 & 20 \\
$\quad$ Previous postpartum hemorrhage & 26 & 19 & 36 \\
$\quad$ Previous assisted delivery & 42 & 35 & \\
Current pregnancy conditions & & & 15 \\
$\quad$ Bleeding during current pregnancy & 16 & 15 & 47 \\
$\quad$ Medications woman is currently taking & 47 & 47 & 71 \\
$\quad$ Whether woman has felt fetus move & 68 & 71 & 48 \\
$\quad$ Self-reported pregnancy-related symptoms & 32 & 50 & \\
or problems & & &
\end{tabular}

In all of the facilities combined, service providers asked less than half of the essential historytaking questions, limiting the ability of the providers to adequately counsel and treat their clients. As expected, providers in hospitals asked a larger percentage of the essential history questions than did providers in CHCs, and providers in CHCs asked a larger percent of these questions than did providers in clinics. Providers usually asked more history questions at the subsequent than the first visits. 


\section{Hgrizons}

\section{Examination}

The ANC protocols of the KZN Subdirectorate of MCWH indicate that the physical examination of an ANC patient should contain all of the elements listed in Table 5.8. Almost all ANC clients have their weight and blood pressure measured, are checked for fetal presentation, and are checked for proteinuria by urinalysis. Providers in hospitals conduct 77 percent of these exams, compared with 68 percent in $\mathrm{CHCs}$ and 66 percent in clinics.

Only 20 percent of clients received a pelvic exam. Of those, 76 percent had the procedure explained to them. Only 30 percent were examined by providers who washed their hands, 84 percent were examined by providers who used gloves, and 36 percent received a bimanual exam. Only three clients were examined with a speculum, all with sterile instruments. Although pap smears for all ANC clients are required by Provincial policy, only 20 percent received a pap smear. This shortfall may be alleviated by new, sensitive, simple, affordable technology that simultaneously diagnoses and treats early cervical dysplasia.

Routine ANC procedures were conducted on most women, though only 21 percent of women were screened for HIV or referred for VCT services. The proportion of women measured or examined who were presenting for their first visit was similar to the proportion presenting for subsequent ANC visits (Table 5.8). However, the number of women presenting for a first visit was very limited. The Subdirectorate has been successful in training and supporting staff to conduct several components of a complete exam for an ANC patient. However, they may want to take steps to strengthen the completeness of these exams, and to improve such infection prevention behaviors as washing hands and using gloves. 
KZN Situation Analysis

\begin{tabular}{lccc} 
Table 5.8 Percentage of ANC client examinations containing particular components \\
\hline Examination components & $\begin{array}{c}\text { First } \\
\text { visit } \\
\text { (n = 17) }\end{array}$ & $\begin{array}{c}\text { Subsequent } \\
\text { visit } \\
\text { (n = 135) }\end{array}$ & $\begin{array}{c}\text { Total } \\
\text { (n = 153) }\end{array}$ \\
\hline Measures patient's height & 27 & 39 & 29 \\
Measures patient's weight & 94 & 96 & 96 \\
Takes blood pressure & 89 & 98 & 97 \\
Performs general exam including heart and lungs & 44 & 40 & 41 \\
Examines breasts & 78 & 64 & 65 \\
Palpates abdomen for fetal presentation & 100 & 99 & 99 \\
Palpates abdomen for fundal height & 89 & 86 & 86 \\
Listens for fetal heartbeat & 94 & 87 & 88 \\
Performs or refers for syphilis test & 83 & 71 & 73 \\
Screens for HIV or offers VCT & 22 & 22 & 21 \\
Conducts urine analysis & 89 & 96 & 95 \\
Conducts hemoglobin and blood test & 72 & 73 & 73 \\
Performs pelvic exam (n = 31) & 33 & 19 & 20
\end{tabular}

\section{Observed prophylactic care and treatment of ANC clients}

Most providers give out or prescribe iron and folic acid pills, and explain their purpose (Table 5.9). In the past, iron supplementation had been promoted to reduce maternal anemia. However, recent evidence indicates that prenatal folate supplementation is effective in preventing specific congenital malformations and may have a greater effect than iron supplements on reducing maternal anemia and low birth weight (Lumley 2003; Mahomed 2003). In addition, more than three-quarters of the clients either receive tetanus toxoid (TT) or have it prescribed, but fewer clients are told why they are receiving tetanus toxoid. Eighty-five percent of ANC primigravidas received a TT injection or referral for TT injections, compared to 72 percent of multigravidas.

Low-altitude areas of South Africa, including northeastern KZN, are listed as malarial zones by the Centers for Disease Control. However, almost no attention is given to antimalarial prophylaxis or treatment (the assessment did not distinguish between malaria services for Falciparum versus the other three forms of malaria). Although some recent evidence shows that prenatal consumption of low doses of vitamin A, beta-carotene, and zinc may be beneficial, further evidence is required before the benefit can be demonstrated (Sloan, Jordan, and Winikoff 2002). Accordingly, little emphasis has been placed on providing other vitamin and mineral supplements, and almost no women received these. 


\section{${ }^{\text {Hrizons }}$}

Table 5.9 Percentage of ANC clients receiving components of prophylactic care and treatment

\begin{tabular}{lccc}
\hline Components of prophylaxis & $\begin{array}{c}\text { First } \\
\text { visit } \\
\mathbf{n = 1 7}\end{array}$ & $\begin{array}{c}\text { Subsequent } \\
\text { visit } \\
\mathbf{n = 1 3 5}\end{array}$ & $\begin{array}{c}\text { Total } \\
\mathbf{n}=\mathbf{1 5 3}\end{array}$ \\
\hline Prescribes or gives iron pills and folic acid & 94 & 86 & 87 \\
Explains purpose of iron pills and folic acid & 94 & 66 & 69 \\
Explains how to take iron pills and folic acid & 100 & 78 & 80 \\
Prescribes or gives tetanus toxoid injection & 83 & 77 & 78 \\
Explains the purpose of tetanus toxoid injection & 53 & 50 & 53 \\
Prescribes or gives antimalarial prophylaxis & 0 & 2 & 2 \\
Explains the purpose of antimalarial prophylaxis & 0 & 2 & 2 \\
Prescribes or gives tonic or multivitamins & 6 & 2 & 3
\end{tabular}

\section{Counseling on pregnancy danger signs and symptoms, nutrition, delivery, and infant care}

In general, counseling on pregnancy danger signs and symptoms, nutrition, delivery, and infant care is weak. It has been demonstrated that danger signs are not particularly predictive of pregnancy complications (Fortney 1999), and thus the lack of attention given to this topic demonstrated in Table 5.10 is not a cause for concern. Nutritional advice is most warranted when women are malnourished. This study did not assess women's nutritional status and therefore cannot judge whether those requiring such counseling received it. However, counseling on hygiene, planning the location of delivery, planning for breastfeeding, and postpartum family planning when needed are all important issues that require full explanation. Only one woman received counseling on all of the delivery and care issues listed in Table 5.10.

An effort is being made to provide more counseling at the first antenatal care visit than at subsequent visits, even though the timing of discussing place of delivery, breastfeeding, and postpartum family planning might be more appropriate later in gestation. It may be that providers operate under the assumption that many women make only a single antenatal care visit, so that this visit may be the only opportunity to provide counseling (however, the number of first-visit clients was limited, thus limiting any inference in this area). 
KZN Situation Analysis

Table 5.10 Percentage of ANC clients counseled on pregnancy danger signs and symptoms, nutrition, delivery, and infant care

\begin{tabular}{lccc}
\hline & $\begin{array}{c}\text { First } \\
\text { visit } \\
\text { (n=17) }\end{array}$ & $\begin{array}{c}\text { Subsequent } \\
\text { visit } \\
(\mathbf{n}=\mathbf{1 3 5})\end{array}$ & $\begin{array}{c}\text { Total } \\
\text { (n = 153) }\end{array}$ \\
\hline Danger signs and symptoms & 22 & 37 & 35 \\
$\quad$ Vaginal bleeding & 0 & 7 & 6 \\
$\quad$ Fever & 1 & 10 & 9 \\
$\quad$ Excessive tiredness & 11 & 38 & 35 \\
$\quad$ Swollen hands or feet & 17 & 30 & 29 \\
$\quad$ Severe headache or blurred vision & & & 44 \\
Nutrition and hygiene & 22 & 47 & 24 \\
$\quad$ Provides nutritional food & 11 & 26 & 33 \\
$\quad$ Discusses personal hygiene & & & 21 \\
Delivery and infant care & 11 & 36 & 12 \\
$\quad$ Asks where patient will deliver & 11 & 22 & 22 \\
$\quad$ Advises exclusive breastfeeding up to 6 months & 11 & 12 &
\end{tabular}

\section{Clients' Experiences and Views About General ANC Services}

Almost all clients agreed to exit interviews. However, some information was collected only on a subset of clients responding to queries about services "other than the ANC received" on that date. This method biases the responses to include only clients who perceived they received a wider range of information or services than is offered in general ANC.

Client reports of the services they received indicate that clients are more likely to get tetanus toxoid, iron pills (both $p \leq 0.05)$, and gynecological exams $(p \leq 0.01)$ on the first ANC visit than at subsequent visits, though only about half of the clients received these services on their first ANC visit (Table 5.11). Regardless of the selection bias, these reports of receiving more care at the first ANC visit compared to subsequent ANC visits are nevertheless consistent with the observations of those services from all ANC clients. Slightly fewer women reported receiving tetanus toxoid and iron pills than were observed receiving TT and iron pills, possibly because the observation does not distinguish referral from receipt of these services. 


\section{${ }^{\text {Hrizons }}$}

Table 5.11 Percentage of ANC clients reporting receiving components of ANC service

\begin{tabular}{lc}
\hline Components of ANC services received & $\begin{array}{c}\text { Percent } \\
(\mathbf{n}=\mathbf{1 4 9})\end{array}$ \\
\hline Tetanus toxoid & 65 \\
Iron pills* & 82 \\
Pregnancy test & 14 \\
Gynecological exam ${ }^{* *}$ & 45 \\
${ }^{*} p \leq 0.05$ & \\
${ }^{*} p \leq 0.01$ &
\end{tabular}

Of the 92 women who indicated they had received associated services in addition to general ANC services, fewer than 10 percent reported receiving child immunization, growth monitoring, or counseling on oral rehydration therapy (ORT), breastfeeding, or gender-based violence (Table 5.12). One-quarter reported receiving breast cancer screening and nearly one-third reported receiving nutrition counseling. Fewer women reported receiving this information or these services than were observed receiving them. This likely reflects a biased subsample of women reporting on the services they perceived to be "other than ANC."

Table 5.12 Percentage of ANC clients reporting additional services received on today's visit

\begin{tabular}{lc}
\hline Additional services* & $\begin{array}{c}\text { Percent } \\
\text { (n = 92) }\end{array}$ \\
\hline Child immunization & 5 \\
Child growth monitoring & 7 \\
Oral rehydration therapy & 3 \\
Nutrition counseling & 31 \\
Gender-based violence and abuse counseling & 1 \\
Counseling on breastfeeding & 9 \\
Breast cancer screening & 25 \\
* Excluding RTI and HIV services that are described below. &
\end{tabular}


KZN Situation Analysis

\section{Associated Sexually Transmitted I nfection and HIV Services}

One of the most important advances in antenatal care services since the 1994 International Conference on Population and Development (ICPD) is the call for comprehensive approaches to reproductive health services and the integration of the identification and management of reproductive tract and sexually transmitted infections into these services. The World Health Organization estimates that, globally, 333 million new cases of curable sexually transmitted infections occur annually (WHO 1996). Eastern and southern Africa have the highest prevalence rates of RTIs and HIV in the world (Gerbase 1998). STIs increase the likelihood of transmission of HIV, prematurity, opthalmia neonatorum, and stillbirth (Wang 1989; Brunham, Holmes, and Eschenback 1984; Hauth 1995; Hillier 1995; Laga 1992; Martin 1982).

\section{Capability of providing RTI and HIV ANC-integrated services}

The prevalence of HIV in antenatal clients in KZN is approximately one-third. In response, 96 percent of facilities have condoms in stock, and 99 percent stock anti-infective medications. Pap smears and HIV tests are available at most hospitals and community health centers, but are available at less than half of clinics (Table 5.13). Because of the expense and inaccessibility of diagnostic tests, the government made a conscious decision to use syndromic management of STIs. Thus diagnostic tests such as wet mounts and gram stain tests for identifying trichomonas vaginales and Neisseria gonorrhea, respectively, are available at a minority of facilities, but were most available at larger facilities. The chapter on STI and HIV services further details the capacity to provide ancillary STI and HIV services.

\begin{tabular}{lcccc}
\multicolumn{3}{l}{ Table $\mathbf{5 . 1 3}$} & $\begin{array}{l}\text { Percentage of facilities able to conduct STI and HIV tests, by type of } \\
\text { facility }\end{array}$ \\
\hline Test & $\begin{array}{c}\text { District hospital } \\
(\mathbf{n}=\mathbf{9})\end{array}$ & $\begin{array}{c}\text { Community health } \\
\text { center } \\
(\mathbf{n}=\mathbf{1 2})\end{array}$ & $\begin{array}{c}\text { Clinic } \\
(\mathbf{n}=\mathbf{7 0})\end{array}$ & $\begin{array}{c}\text { Total } \\
(\mathbf{n}=\mathbf{9 1})\end{array}$ \\
\hline Pap test & 78 & 75 & 41 & 50 \\
HIV test & 78 & 75 & 24 & 36 \\
Wet mount & 33 & 33 & 11 & 17 \\
Gram stain & 11 & 25 & 1 & 6
\end{tabular}

Although 62 percent of facilities have educational materials on sexually transmitted diseases and/or HIV/AIDS, ANC providers in KZN discussed HIV, STIs, MTCT, and condom use with only about a third of clients (Table 5.14). Other HIV risk factors are discussed with few clients. Most important, even though condoms are almost universally available at the facilities, only 4 percent of ANC clients receive condoms. Thus, while a substantial beginning has been made to integrate HIV/AIDS issues into ANC counseling, two-thirds of the ANC clients are still not being counseled 


\section{Hgrizons}

on this important subject, and almost none are receiving condoms to protect themselves from STI and HIV exposure during pregnancy. In view of the high HIV prevalence rate in the province, the Subdirectorate of MCWH should establish a priority for SDPs to increase the extent of HIV/AIDSrelated counseling of ANC clients. It should also have the SDPs increase the condom-related knowledge and skills of ANC clients, as well as increase actual condom distribution to ANC clients.

Table 5.14 Percentage of ANC clients counseled on STI- and HIV-related issues

\begin{tabular}{lc}
\hline STI- and HIV-related issues & Percent \\
\hline Discuss HIV & 40 \\
Discuss STIs & 37 \\
Discuss condom use during pregnancy to prevent STIs and HIV & 30 \\
Provide patient with condoms & 4 \\
Refer for prevention of MTCT & 32 \\
Counsel on prevention of MTCT & 29 \\
Discuss other risk factors & 16
\end{tabular}

All hospitals provided nevirapine to mothers in the month before the survey, compared with 42 percent of CHCs and 17 percent of clinics. Hospitals and CHCs provided more clients with nevirapine than did clinics (Table 5.15). Yet, when this survey was conducted, very few women and newborns received the medication directly, and the proportion of women (and newborns) requiring this treatment was far greater than those receiving it (assuming approximately one-third of them are HIV-positive). However, in the past year the government has made a concerted effort to roll out the availability of nevirapine to prevent mother-to-child HIV transmission, and it is expected that the administration of this ARV is increasing. 
Table 5.15 Percentage of facilities providing nevirapine, and mean number of ANC clients and newborns receiving nevirapine for PMTCT

\begin{tabular}{|c|c|c|c|c|}
\hline & Hospitals & CHCs & Clinics & Total \\
\hline Facilities providing ANC & $(n=9)$ & $(n=12)$ & $(n=70)$ & $(n=91)$ \\
\hline $\begin{array}{l}\text { SDPs reporting they provide } \\
\text { nevirapine to mothers }(\%)\end{array}$ & $100 \%$ & $42 \%$ & $17 \%$ & $29 \%$ \\
\hline Mean number of ANC patients* & 362 & 647 & 107 & 203 \\
\hline $\begin{array}{l}\text { Facilities providing nevirapine to } \\
\text { mothers in the month prior to } \\
\text { survey }\end{array}$ & $(n=8)$ & $(n=5)$ & $(n=38)$ & $(n=51)$ \\
\hline $\begin{array}{l}\text { Mean number of mothers } \\
\text { receiving nevirapine }{ }^{* *}\end{array}$ & 10 & 26 & 2 & 5 \\
\hline $\begin{array}{l}\text { Facilities providing nevirapine to } \\
\text { infants in the month prior to } \\
\text { survey }\end{array}$ & $(n=7)$ & $(n=5)$ & $(n=36)$ & $(n=48)$ \\
\hline $\begin{array}{l}\text { Mean number of newborns } \\
\text { receiving nevirapine }{ }^{* *}\end{array}$ & 13 & 12 & 15 & 3 \\
\hline
\end{tabular}

Of the 92 women reporting receipt of services other than ANC (Table 5.16), only 21 percent received services (including counseling and nevirapine) for prevention of mother-to-child transmission. Fewer women reported receiving STI services (19 percent) or HIV tests (11 percent). Even fewer reported receiving non-ANC counseling related to RTIs and HIV. Furthermore, the information that only 11 percent of ANC clients are tested for HIV (Table 5.16) indicates that a substantial opportunity is missed to provide STI/HIV services to ANC clients in a population where the local prevalence of HIV in ANC clients ( $\sim 33$ percent) is high and the need for these services is great. It is essential to identify HIV status to effectively manage pregnancy. 


\section{Herizons}

Table 5.16 Percentage of ANC clients who report receiving additional services on today's visit

\begin{tabular}{lc}
\hline Services received in addition to ANC & Percent \\
\hline STI services & 19 \\
HIVIAIDS test & 11 \\
Precounseling and postcounseling on HIVIAIDS & 14 \\
Counseling on how to negotiate condom use & 11 \\
Counseling on supplementary breastfeeding issues & 9 \\
Pap test & 5 \\
PMTCT & 21
\end{tabular}

\section{Knowledge of STIs and HIV/AIDS reported by ANC clients}

Great efforts have been made in the past two decades to increase people's knowledge of sexually transmitted infections and of signs and symptoms thought to identify these infections. Over the years, it has been demonstrated that, except for genital warts and urethral discharge - which are signs of STIs in men - and observed weight loss, lesions, or sores, symptomatic identification of STIs in women has poor predictive ability (Dallabetta, Gerbase, and Holmes 1998; Sloan 2000; van Dam 1998). Despite the poor predictive ability of many signs and symptoms of STIs, the expense and inaccessibility of diagnostic tests for STIs has led to a government policy to use syndromic management of STIs as a more pragmatic, "second best" approach.

The vast majority of ANC clients indicated in exit interviews that they know that diseases can be sexually transmitted, and most say they know the common signs and symptoms of STIs. However, in unprompted questioning, only 30 percent to 40 percent could name lesions, sores, and/or loss of weight as a sign or symptom of STIs (Table 5.17). While all other symptoms were mentioned by very few clients (except for abnormal vaginal discharge), knowledge of these symptoms has not been demonstrated to increase the number of women seeking or receiving required services. 


\section{Table 5.17 Percentage of ANC clients with knowledge of STls and their signs and} symptoms

\begin{tabular}{lc}
\hline Patient's knowledge & Percent \\
\hline Knows diseases can be sexually transmitted & 86 \\
Knows common signs and symptoms of STls & 71 \\
(n= 151, unprompted responses) & \\
Abnormal vaginal discharge & 40 \\
Abnormal vaginal bleeding & 3 \\
Genital itching & 15 \\
Lesions or sores & 38 \\
Lower abdominal pain & 9 \\
Pain during intercourse & 2 \\
Painful urination & 16 \\
Genital warts & 5 \\
Urethral discharge & 9 \\
Loss of weight & 31 \\
Diarrhea of long duration & 9 \\
Other & 14
\end{tabular}

Similarly, the vast majority of ANC clients know that HIV/AIDS is sexually transmitted (Table 5.18). Almost all know that use of condoms prevents HIV/AIDS transmission. However, few clients indicate that they know about nonsexual means of transmission or about other strategies for preventing transmission besides using condoms. Education about sexual transmission of disease and the importance of using condoms for disease prevention has been successful at generating (unprompted) knowledge about these factors. Generating knowledge about staying faithful to partners and encouraging partners to stay faithful is less successful with ANC clients. 


\section{Hgrizons}

Table 5.18 Percentage of ANC clients with knowledge about HIVIAIDS and methods of protecting against STI and HIVIAIDS transmission

\begin{tabular}{lc}
\hline Knowledge components & Percent \\
\hline Knows the ways in which people can get HIVIAIDS (unprompted) & 91 \\
Sexual transmission & 86 \\
Blood transfusion & 47 \\
Sharing items like razor blades and needles & 36 \\
Mother-to-child transmission & 6 \\
Knows how to protect herself from STIs and HIVIAIDS & 93 \\
Stay faithful to one partner & 21 \\
Encourage partner to stay faithful & 13 \\
Use condoms & 89 \\
Avoid sharing needles or razor blades & 11 \\
Abstinence & 37
\end{tabular}

\section{Accessibility of Service Facility, Travel, and Waiting Times}

Most clients report that they walked to the SDP. About one-third of the clients used a taxi or minibus to get there. A few clients used other forms of transportation (Table 5.19).

Table 5.19 Percentage of ANC clients reporting various means of transport to SDP*

\begin{tabular}{lr}
\hline Means of transport & Perce \\
\hline Walking & 76 \\
Taxi or minibus & 34 \\
Car & 8 \\
Bus or train & 6 \\
Other & 1
\end{tabular}

*Total is more than 100 percent because multiple answers were possible.

Clients left home relatively early to travel to the SDP. More than half of them left home by 7:00 a.m., and a quarter of them arrived at the clinic by 7:00 a.m., the usual opening time. Clients are expected to arrive early for services and they do-90 percent of the clients arrived by 9:00 a.m., and only 3 percent arrived at 10:00 a.m. or later. This crowding of nearly all the clients in the first two hours of service creates long waiting times. A review of waiting times of 96 ANC clients who could remember their arrival time and the time they received service (Table 5.20) indicates that the 
median waiting time was 1.5 hours. While the SDPs attempt to efficiently use the available waiting time, including holding group counseling sessions in the morning, a sizable proportion (26 percent) reported waiting 2.5 hours or more, and 10 percent waited 3.5 hours or more. Long waiting times were mentioned frequently by clients as a reason for dissatisfaction, for not recommending the SDP, or for suggesting that this aspect of service be improved.

On average, ANC clients travel a longer time to get to rural clinics and district hospitals (about an hour) than they do to get to other facilities (about 40 minutes). A large number of clients traveled only about 30 minutes or less; however, a few clients reported traveling 2.5 to 5 hours to reach the SDP.

Table 5.20 ANC clients' reports on travel time (in minutes) to SDP, by SDP characteristic

\begin{tabular}{lcc}
\hline SDP type & Mean travel time & Median travel time \\
\hline Urban (26) & 42 & 30 \\
Peri-urban (23) & 37 & 30 \\
Rural (74) & 61 & 60 \\
District hospital (14) & 56 & 52 \\
Community health center (29) & 45 & 30 \\
Clinic (79) & 55 & 40
\end{tabular}

\section{Clients' Reactions to ANC Services}

As with similar surveys, most clients reported that they were satisfied with the services, that they would encourage others to use them, and that they received the services and information they sought. Nevertheless, a substantial proportion (Table 5.21) felt they had to wait too long to receive the services, and nearly one-fifth had been turned away from services at this facility on an earlier occasion because of overcrowding, limited hours of service, or another unspecified reason. 


\section{Hgrizons}

\begin{tabular}{lc} 
Table 5.21 Percentage of ANC clients with various reactions to ANC services \\
\hline Clients' reactions & Percent \\
\hline Said waiting time too long $(n=151)$ & 35 \\
Had been turned away from this facility $(n=150)$ & 18 \\
Was fully satisfied $(n=151)$ & 91 \\
Would encourage friend to come to this facility $(n=151)$ & 97 \\
Received desired service $(n=151)$ & 90 \\
Received desired information $(n=149)$ & 83
\end{tabular}

\section{Summary of ANC Services and Quality of Care}

On average, about 100 ANC clients a month are attended at KwaZulu Natal clinics, and about five times more are seen at community health centers and hospitals. Approximately 80 percent of these facilities possess all the essential ANC equipment, supplies, and medicines, which is a substantial improvement over the past decade. The exception is medication for labor induction, which is unavailable at about 15 percent of clinics. Educational materials other than those for HIV/AIDS are rarely available for clients to take home.

Nearly 30 percent of ANC clients in the sample are less than 20 years old. Most had at least some high school education and were unmarried. Forty percent had at least one living child. Early pregnancy is associated with dropping out of school, and contributes to limitations of later earning capacity. Women presented on average in their 24th week of gestation, which is late by traditional recommendations for ANC presentation. This late presentation may result in missing early management of conditions like preeclampsia, a condition that can precipitate toxemia. Hypertension is one of the major contributors to maternal mortality in KwaZulu Natal. Still, most obstetric conditions requiring management occur around labor and delivery, and recent evidence indicates that the timing and number of ANC visits is less critical than the content of care. However, where STI and HIV prevalence is high and adequate diagnostic capacity is available, earlier and more frequent presentation could lead to better detection and prompt treatment. While syndromic management of STIs leaves out substantial numbers of women who could benefit from treatment while unnecessarily treating substantial numbers of women not requiring medication, it is globally implemented by government policy as the accepted "second best" option to unaffordable diagnostics New, simple, inexpensive STI diagnostic tests require further examination because they may hold great promise for affordably and pragmatically improving diagnosis and treatment of ANC clients.

Facilities providing ANC are immunizing most of their clients with tetanus toxoid or referring them for this immunization. Although two TT injections are recommended, service providers are appropriately and proportionately focusing on providing TT immunization to primigravidas, usually on the first prenatal visit. Most women also receive iron-folate tablets at their first ANC visit. Some sections of Northeastern KZN are listed as malarial zones, but this study team found 


\section{KZN Situation Analysis}

that almost no attention is given to malaria prophylaxis or treatment. Falciparum malaria is more common in primiparous than multiparous women and may be fatal. Because new international recommendations include prophylactic treatment of primiparous women, caution should be taken to avoid concurrent folate supplementation that appears to undermine the efficacy of antimalarial prophylaxis.

Counseling and examination of ANC clients in KZN both have strengths and weaknesses. Almost all clients are greeted well and most receive emotional support from the providers. However, on average, providers asked less than half of the essential history-taking questions, and counseling on delivery and infant care was weak. A similar situation exists for physical examinations. Some exams, like weight, blood pressure, urinanalysis, and abdominal palpation for fetal presentation, are conducted for nearly all clients (and appropriately during both first and subsequent visits), while some tests, such as hemoglobin and HIV tests, are performed with far fewer clients. The need for hemoglobin assessment is debatable in areas where the prevalence of gestational and nongestational anemia is high. All but 25 percent of ANC clients are tested for syphilis, and while this figure could be improved it is relatively good compared to past figures for this service and compared to most international ANC services. Slightly more than 20 percent of ANC clients are tested for HIV or referred for HIV tests and VCT, and this area merits additional attention.

As is customary, an examination of clients' reports of services indicates that there were "missed opportunities" to provide clients with additional services at the time of their ANC visit. Fewer than 10 percent (of those who reported that they received services in addition to general ANC services) reported receiving child immunization, growth monitoring, counseling on ORT, breastfeeding, or gender-based violence counseling. Breastfeeding and gender-based violence are critical topics that need to be discussed in antenatal care, whereas topics on child care and growth may be more appropriately emphasized in the peripartum and postpartum period. Most important in this environment with high HIV prevalence rates, only about a third of women are counseled on HIV, STIs, MTCT, and condom use, and a low 4 percent actually receive condoms on their ANC visit.

Though nevirapine or referral for MTCT treatment (for the prevention of mother-to-child transmission of HIV) was provided at most hospitals, these services were provided at only 42 percent of CHCs and 17 percent of clinics at the time of this survey (2002). Thus, antiretroviral treatment was not available to the vast majority of ANC clients. However, even in the small number of facilities providing or referring for nevirapine, with an estimated HIV prevalence of approximately 36 percent in ANC clients, few women requiring this service received it during the study period. Even fewer facilities provided this service to newborns. Similarly, clients' reports indicate that only about one-fifth received STI services and approximately 1 in 10 clients received an HIV test (though nearly double this number may have been offered VCT, according to fieldworkers' reports). Since the survey, however, the government has begun to roll out nevirapine distribution, and it is expected that continued improvement will occur in the provision of VCT and PMTCT.

The vast majority of ANC clients indicate that they know that diseases can be sexually transmitted, and most say they know the common signs and symptoms of STIs. However, in response to unprompted questions, only 40 percent identified lesions or sores as signs of STIs. About 30 


\section{${ }^{H}$ rizons $^{\text {rizons }}$}

percent believed that loss of weight could be a symptom of STIs. This belief is a misperception because observable weight loss usually occurs in the terminal stages of sexually transmitted diseases such as HIV. Similarly, the vast majority of ANC clients know that HIV/AIDS is sexually transmitted and almost all know that use of condoms prevents HIV transmission. Few ANC clients know about nonsexual transmission and about prevention strategies other than condom use.

Most clients reported that they walked to the facility for ANC services. Clients left home early and arrived at the facility early (by 9:00 a.m.), thus creating crowded conditions and long waiting times, with a median of 1.5 hours, but with about a quarter reporting waits of 2.5 hours or longer. The long waiting time was a source of dissatisfaction among clients. Overall, however, most clients report being satisfied with services, a finding that is consistent with similar surveys.

ANC services can play an important role in detecting and managing conditions that could be detrimental to the expectant woman and the fetus. The Safe Motherhood Initiative currently recommends emergency obstetric care as the most effective mechanism to save women's lives, and most facilities in this survey claim to be providing such services. However, most ANC services lacked specialized, or indeed any, physicians and technicians, and, as expected, this was especially true in clinics. Therefore the facilities surveyed do not, for the most part, have the ability to provide firsthand management of cesarean delivery or blood transfusion - two critical emergency obstetric services. However, substantial improvements have been made in the past 10 years to improve ANC facility readiness, and most facilities are equipped with telephones. Thus, women requiring emergency obstetric services can be referred and transported to a district hospital in about half an hour, or to a tertiary care hospital in about an hour, where transportation is available. The availability of ambulances and other transport between referral facilities was not investigated in this study and has been reported by other studies to be sporadic and unreliable in rural areas.

In summary, ANC services could be improved by the redirection of resources and reprioritization of ANC services, particularly by improving critical counseling, ensuring referral and transportation for obstetric emergencies, providing HIV testing and VCT services, distributing condoms, and counseling women in how to negotiate their use with partners. There is some rational emphasis placed on the first antenatal care visit, which includes somewhat more detailed history taking, examination, diagnosis, provision of information, and counseling. Given the staff workload and the need for periodic new training and retraining, a great need exists to identify creative ways to most efficiently use staff and client time. One mechanism for achieving this goal might be improving the efficiency of services offered at the first ANC visit compared to subsequent ANC visits. For example, it might be possible to replace counseling subsequent to the first ANC visit on recognition of STI and HIV symptoms that should have been discussed at the first visit. Discussions that might be more appropriate are those concerning discussion of more gestationally timely topics such as birth planning or family planning and/or of topics that are important but rarely discussed, such as gender violence and condom negotiation.

The KZN Situation Analysis did not include assessment of labor and delivery services. However, it is important to note that according to the "Saving Mothers 2 Report," the major social factor associated with maternal mortality is delayed arrival for care at health institutions. This is most common in remote areas, where women have economic constraints and affordable transportation is 
not always available. Thus, women experiencing emergency obstetric conditions who have delays in arrival may present in relatively poor condition. A problem that can aggravate the situation is lack of prompt care upon arrival. This situation can be rectified by good triage systems and improved assessment, diagnosis, use of protocols and policy guidelines for care provision, and patient monitoring. While women's antenatal conditions poorly predict risk at the time of delivery (Rooks et al. 1989), improving the ability of primary health care facilities to promptly refer women and arrange transportation for them to the appropriate level of care is crucial for saving women's lives. 


\section{Hgrizons}

\section{Chapter 6 \\ Sexually Transmitted I nfections Services}

\section{STI Program in KZN}

In 1994, the International Conference on Population and Development (ICPD) called for comprehensive approaches to reproductive health services. This appeal was intended in part to integrate services for the identification and management of reproductive tract and sexually transmitted infections into family planning, antenatal care, and other services in response to the STI/HIV pandemic. WHO estimates that 333 million new cases of curable sexually transmitted infections worldwide occur each year (World Health Organization 1996). Eastern and Southern Africa have the highest prevalence rates of STIs and HIV in the world (Martin et al. 1982). STIs not only increase the transmission of HIV, but also cause prematurity, opthalmia neonatorum, and stillbirth (Wang and Smaill 1989; Brunham, Holmes, and Eschenback 1984; Hauth et al. 1995; Hillier et al. 1995; Laga 1992; Martin 1982). The Department of Health of KZN and the Population Council conducted this assessment to identify the status and outstanding needs of the quality of services in KZN and its readiness to provide integrated services. The goal was to provide data that could be used to strengthen provincial policies and program activities.

\section{STI Client Characteristics}

Table 6.1 presents basic sociodemographic data on the 92 clients who were interviewed. The median age for this group was 24 with a range from 16 to 48 , with little difference between the sexes (males were 27.4 years old compared to 26.6 years old for females). The mean number of living children was 1.8 with about 22 percent having no children. Approximately 70 percent of the clients were female and 30 percent were male. Of the 92 clients, 77 percent were single. Zulu was the native language for 92 percent. Sixty percent had a post-primary education and 42 percent had completed some high school. However, of the 87 clients for whom gender was identified, 70 percent were female, indicating that STI services in the SDPs visited may be perceived primarily as services for women. In summary, this is a relatively young, sexually active population consisting primarily of single females. 
Table 6.1 STI client characteristics

\begin{tabular}{|c|c|}
\hline Sociodemographic characteristics & Percent \\
\hline \multicolumn{2}{|l|}{ Age } \\
\hline $15-19$ & 14 \\
\hline $20-24$ & 39 \\
\hline $25-29$ & 13 \\
\hline $30-34$ & 11 \\
\hline $35-39$ & 12 \\
\hline $40+$ & 9 \\
\hline Don't know & 2 \\
\hline Mean age & 27 \\
\hline Median age & 24 \\
\hline \multicolumn{2}{|l|}{ Number of living children } \\
\hline 0 & 22 \\
\hline 1 & 30 \\
\hline 2 & 20 \\
\hline $3+$ & 28 \\
\hline Mean number & 1.8 \\
\hline \multicolumn{2}{|l|}{ Sex } \\
\hline Male & 30 \\
\hline Female & 70 \\
\hline \multicolumn{2}{|l|}{ Marital status } \\
\hline Single & 77 \\
\hline Married & 10 \\
\hline Living together & 11 \\
\hline Widowed & 2 \\
\hline \multicolumn{2}{|l|}{ Native language } \\
\hline Zulu & 92 \\
\hline Afrikaans & 2 \\
\hline Other & 6 \\
\hline \multicolumn{2}{|l|}{ Highest level of education } \\
\hline No schooling & 3 \\
\hline Primary incomplete & 20 \\
\hline Primary complete & 17 \\
\hline High school incomplete & 42 \\
\hline High school complete & 15 \\
\hline Post-matriculate & 1 \\
\hline No response & 1 \\
\hline
\end{tabular}




\section{Hgrizons}

\section{Capacity of Facilities to Provide STI Services}

This section summarizes the data on the use of STI services by clients and on the equipment, supplies, and staff available to deliver STI services.

\section{Health facilities and STI services}

Among the 98 health facilities visited, STI services were provided at 97 facilities. Among facilities with available service statistics (92 facilities), 11,522 clients received STI services during August 2002. Table 6.2 shows that the average number of STI clients seen by each facility during August 2002 was 125, and the median number was 52. Community Health Centers and urban clinics had the highest client load. Only family planning and antenatal care services received more client visits.

Table 6.2 Number of STI patients seen in the last month, by type of facility

\begin{tabular}{lrrcrr}
\hline Type of facility & Median & Mean & $\begin{array}{c}\text { Standard } \\
\text { deviation }\end{array}$ & $\begin{array}{c}\text { Low } \\
\text { range }\end{array}$ & $\begin{array}{c}\text { High } \\
\text { range }\end{array}$ \\
\hline Total & 52 & 125 & 313 & 4 & 2,863 \\
District hospitals (8) & 61 & 82 & 64 & 8 & 193 \\
Community health centers (11) & 274 & 500 & 813 & 17 & 2,863 \\
Clinics (73) & 45 & 74 & 87 & 4 & 446 \\
Urban (11) & 209 & 444 & 812 & 17 & 2,863 \\
Peri-urban (20) & 136 & 185 & 191 & 20 & 799 \\
Rural (61) & 36 & 48 & 39 & 4 & 177
\end{tabular}

\section{Infrastructure}

As noted earlier, the majority of the facilities had electricity (94 percent) and telephone service (93 percent), and 80 percent had safe water in the examination rooms. The fieldworkers judged the examination area to be clean (98 percent) and linen was available in 83 percent of the facilities. All but one facility had seats available for clients, but in 50 percent of the these facilities the number of seats were inadequate given the number of clients attending services. One area of concern is that only 52 percent of the facilities had an area specifically designated for STI counseling. However, in 97 percent of the facilities, examinations took place in a private room where other clients could not see the client being examined.

In approximately half of the facilities (48 percent), a sign or poster advertised the availability of STI services. Written material about STI prevention was often not available for clients to take home. Only 50 percent of hospitals, 33 percent of CHCs, and 25 percent of clinics had such materials available. Although 60 percent of the facilities had written materials for the clients to take 


\section{KZN Situation Analysis}

home on HIV/AIDS and 34 percent had materials available on breastfeeding, less than a third of the facilities (29 percent) had written material on STIs available for clients to take home.

\section{Staff}

Almost all STI service delivery is provided by nurses. As noted in Chapter 3, very few physicians are available, particularly at the clinic level, even on a part-time basis. A total of 229 service providers were interviewed at the 98 facilities visited by the Situation Analysis nurse research teams. Of these providers, 209, or 91 percent, said that they provided STI counseling, diagnosis, and treatment to clients in the past three months. However, more than a third ( 35 percent) of those who said they were providing STI services also said that they had never had a specific in-service training course on STI counseling, diagnosis, and treatment. Clearly, improvements can be made in this area by providing training for those who need it.

\section{Equipment and supplies}

Most of the 97 facilities providing STI services have basic equipment necessary for providing services, such as a stethoscope (100 percent), a blood pressure gauge (98 percent), a thermometer (99 percent), syringes and needles (98 percent), an adult weighing scale (98 percent), and disposable gloves (100 percent). As has been noted earlier, because of the government policy to use syndromic management, microscopes are not relied on for STI identification and many facilities do not have them. However, as can be seen in Table 6.3, an area for concern is that only 44 percent of the facilities have sterilization equipment. This situation is worse among the 75 clinics where only 32 percent have any sterilization equipment.

With regard to condoms, 96 percent of the facilities had male condoms available, but only 11 percent provided female condoms which were being introduced on a pilot basis in selected facilities at the time of the Situation Analysis. A large number of male condoms were distributed in the month before the survey. However, in the six months before the research team visit to the facilities, 18 percent of facilities had experienced a stock out of male condoms and 4 percent had experienced a stock out of female condoms. Only one facility claimed no regular supply of male condoms (while 65 percent of facilities claimed no regular supply of female condoms, again because of the limited distribution as part of the roll-out campaign). Stock outs of male condoms in nearly one out of five facilities is an area of concern for the control of STIs as well as the transmission of HIV. 


\section{Hgrizons}

Table 6.3 Percentage of facilities with essential STI equipment and supplies

\begin{tabular}{|c|c|c|c|c|}
\hline & $\begin{array}{c}\text { District } \\
\text { hospital } \\
(n=10)\end{array}$ & $\begin{array}{c}\mathrm{CHC} \\
(n=12)\end{array}$ & $\begin{array}{c}\text { Clinic } \\
(n=75)\end{array}$ & $\begin{array}{c}\text { Total } \\
(n=97)\end{array}$ \\
\hline \multicolumn{5}{|l|}{ Equipment } \\
\hline $\begin{array}{l}\text { Percent with sterilizer/dry heat } \\
\text { sterilizer/autoclave }\end{array}$ & 90 & 83 & 32 & 44 \\
\hline Speculum & 90 & 92 & 93 & 93 \\
\hline Microscope & 40 & 42 & 1 & 10 \\
\hline \multicolumn{5}{|l|}{ Supplies* } \\
\hline Disposable gloves & 100 & 100 & 100 & 100 \\
\hline Disposable or reusable syringes & 100 & 100 & 97 & 98 \\
\hline Male condoms & 100 & 100 & 95 & 96 \\
\hline Female condoms & 22 & 30 & 7 & 11 \\
\hline $\begin{array}{l}\text { Mean number of clients receiving } \\
\text { male condoms in the month before } \\
\text { survey }\end{array}$ & 1,743 & 5,545 & 1,360 & 1,906 \\
\hline
\end{tabular}

\section{STI medications}

The availability of essential drugs for treating STIs is extremely good as can be seen in Table 6.4. More than 96 percent of all 98 facilities and 96 percent of all 76 clinics had amoxicillin, ciprofloxacin, doxycycline, erythromycin, and penicillin available. All but one SDP, a community health center, had at least one of the essential antibiotics.

Table 6.4 Percentage of facilities with essential STI medications

\begin{tabular}{ll}
\hline Medications & Percent \\
$(\mathrm{n}=97)$
\end{tabular}

\begin{tabular}{ll}
\hline Amoxycillin & 96 \\
Ciprofloxacin & 97 \\
Doxycycline & 99 \\
Erythromycin & 98 \\
Penicillin & 95 \\
Any of the above & 99
\end{tabular}




\section{Diagnostic ability}

Table 6.5 indicates that 80 percent of hospitals and 75 percent of CHCs provided HIV and pap smear tests, but less than one-quarter of clinics were able to conduct HIV tests and only 40 percent of clinics were able to conduct pap smears. About three-quarters of the health facilities (76 percent) used the syndromic approach to diagnose and treat STI clients, which reflects the government's promotion of this approach. This approach was used most often in CHCs (93 percent) and clinics (75 percent), compared with district hospitals (52 percent), presumably because district hospitals have greater laboratory diagnostic capacity. The use of the syndromic approach, coupled with the fact that 92 percent of all the facilities (and 100 percent of the clinics) had no laboratory technicians on site, is likely the reason that only 17 percent of all facilities conducted wet mount tests and only 6 percent conducted gram stain tests. Symptomatic identification of syphilis, gonorrhea, and chancroid (the genital ulcer caused by the bacterium haemophilus ducreyi) has been found to be adequate for the detection and treatment of men (van Dam et al. 1998). However, syndromic identification of gonorrhea, chlamydia, and other STIs has been demonstrated to be questionable for women (Dallabetta, Gerbase, and Holmes 1998; Sloan 2000). Few facilities are able to identify bacterial vaginosis, trichomonas, gonorrhea, syphilis, or chlamydia in women using gold-standard diagnostic tests (World Health Organization 1999; WPRO 1999).

Table 6.5 Percentage of facilities with essential laboratory diagnostics

\begin{tabular}{lcccc}
\hline Diagnostic tests* & $\begin{array}{c}\text { District } \\
\text { hospital } \\
(\mathbf{n}=\mathbf{1 0})\end{array}$ & $\begin{array}{c}\text { CHC } \\
(\mathbf{n}=\mathbf{1 2})\end{array}$ & $\begin{array}{c}\text { Clinic } \\
(\mathbf{n}=\mathbf{7 6})\end{array}$ & $\begin{array}{c}\text { Total } \\
(\mathbf{n}=\mathbf{9 7})\end{array}$ \\
\hline HIV test & 80 & 75 & 24 & 36 \\
Pap smear (human papilloma virus) & 80 & 75 & 40 & 49 \\
$\begin{array}{l}\text { Microscope (trichomonas vaginalis, } \\
\text { treponema pallidum/ syphilis) }\end{array}$ & 40 & 42 & 1 & 10 \\
$\begin{array}{l}\text { Gram stain (candida albicans) } \\
\text { Vaginal discharge smear and wet }\end{array}$ & 20 & 25 & 1 & 6 \\
mount (bacterial vaginosis and N. & 40 & 33 & 11 & 17 \\
gonorrhea*) & & & &
\end{tabular}

*Data were not collected on cell culture for C. trachomatis and N. gonorrhea.

\section{Client-Provider I nteraction and the Quality of STI Service Delivery}

As part of the KZN Situation Analysis study, in 59 of the 98 facilities visited, the interaction between providers and 96 clients with a RTI was observed and most of the clients were subsequently interviewed. For four clients, exit interviews were not possible either because the client did not have the time for the interview or refused to be interviewed. This section examines the experience of the STI clients as well as the type and quality of services they received. 


\section{Hgrizons}

\section{Topics discussed during provider-client interaction}

During the consultation between the provider and the client, trained nurse-midwives were present and observed the interaction. They used an observation guide to record the topics discussed between the provider and the client.

In 95 percent of the 96 interactions, the observer judged that the provider greeted the client in a friendly and respectful manner, and in 62 percent of the interactions, the provider informed the client that information the client shared would be kept confidential.

In general, most consultation sessions covered a fairly large number of topics. The four figures below show the percent of the 96 interactions during which a particular topic was discussed. Not surprisingly for this population of STI clients, Figure 6.1 reveals that in approximately 88 percent of the interactions, the general topic of STIs was discussed, in 80 percent the risk factors associated with acquiring an STI infection were discussed, and in 65 percent of the interactions the specific information and risk factors associated with HIV/AIDS were discussed. Condom use as a means to prevent STI infections was mentioned in 85 percent of the interactions. However, condom negotiation skills were discussed in only 24 percent of the interactions and the method for using a condom was discussed or demonstrated using a penis model in only about 14 percent of the interactions. Considering that penis models are available in 68 percent of all 98 health facilities, certainly more opportunities exist to demonstrate proper condom use.

Figure 6.1 Percentage of provider-client interactions in which condom-related issues discussed or information given to 65 female and 31 male STI clients

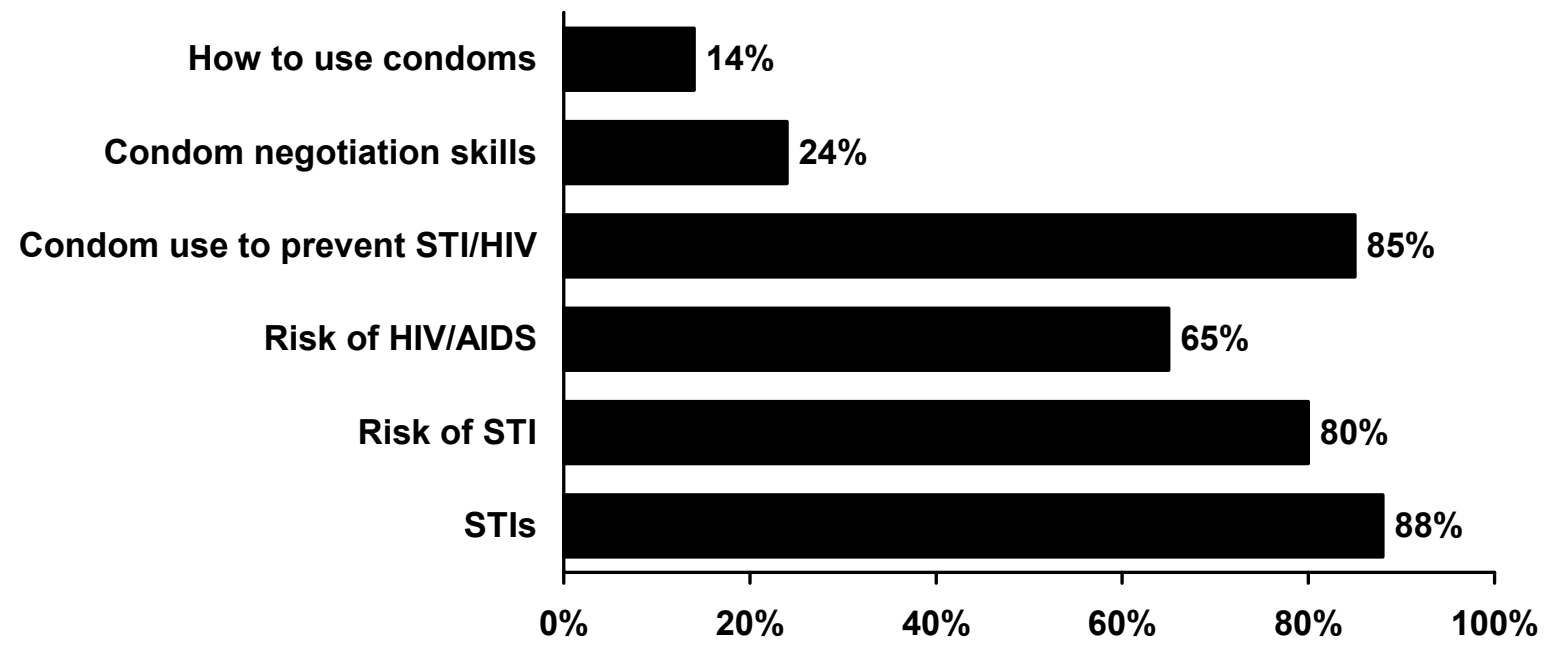


Figure 6.2 shows other topics related to sexual partner and risk behaviors that were discussed. In the 96 interactions between a provider and a client, 70 percent of these interactions covered the need for the client's partner to seek STI diagnosis and treatment, and 44 percent covered the need for abstinence during treatment. Much less frequently discussed as a prevention strategy were the topics of reducing the number of sexual partners or abstinence, 45 and 19 percent respectively.

\section{Figure 6.2 Percentage of provider-client interactions in which partner and risk factors discussed or information given to 65 female and 31 male STI clients}

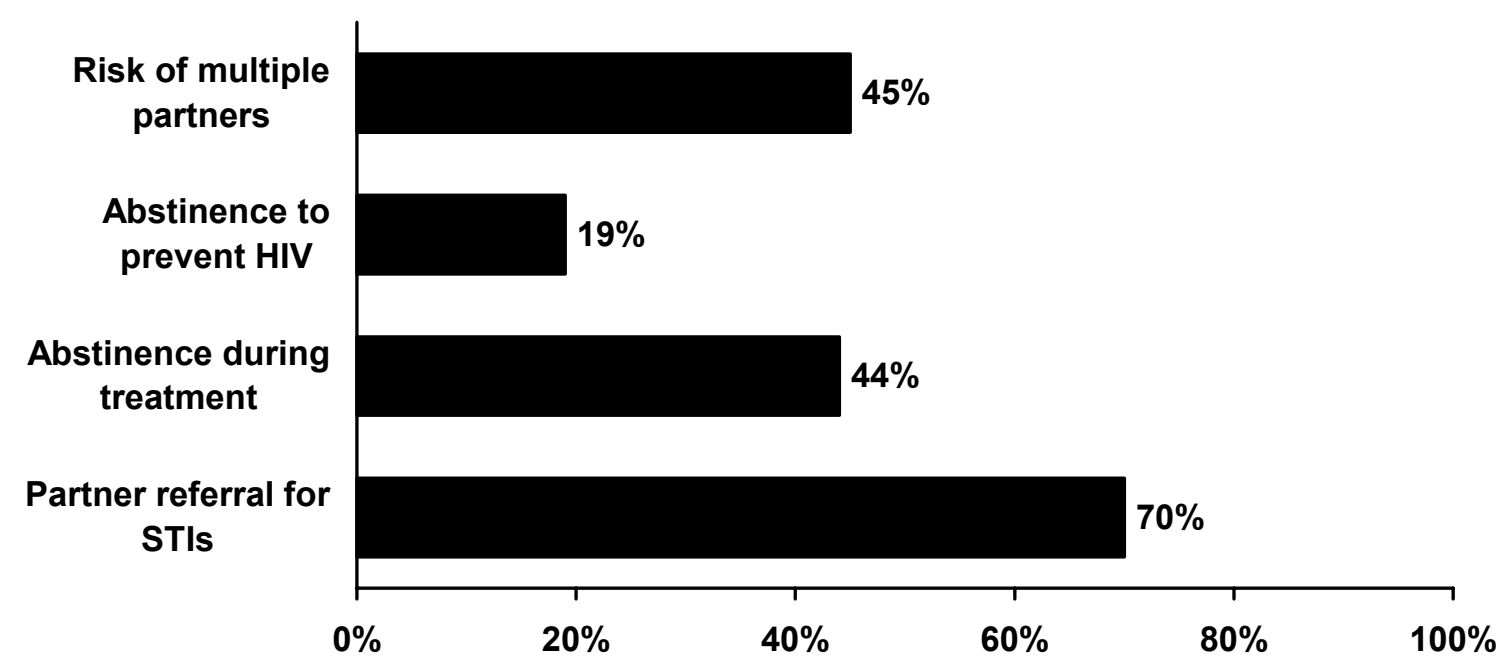

Figure 6.3 shows some of the least frequently discussed topics. Some of these topics are certainly related to the transmission or presence of an STI, such as PMTCT and pap smears. However, all of the topics in Figure 6.3 is related to broader issues of reproductive health and indicate the extent to which a variety of issues are integrated into the discussions between the provider and the client. 


\section{Hgrizons}

Figure 6.3 Percentage of provider-client interactions in which other health topics discussed or information given to 65 female and 31 male STI clients

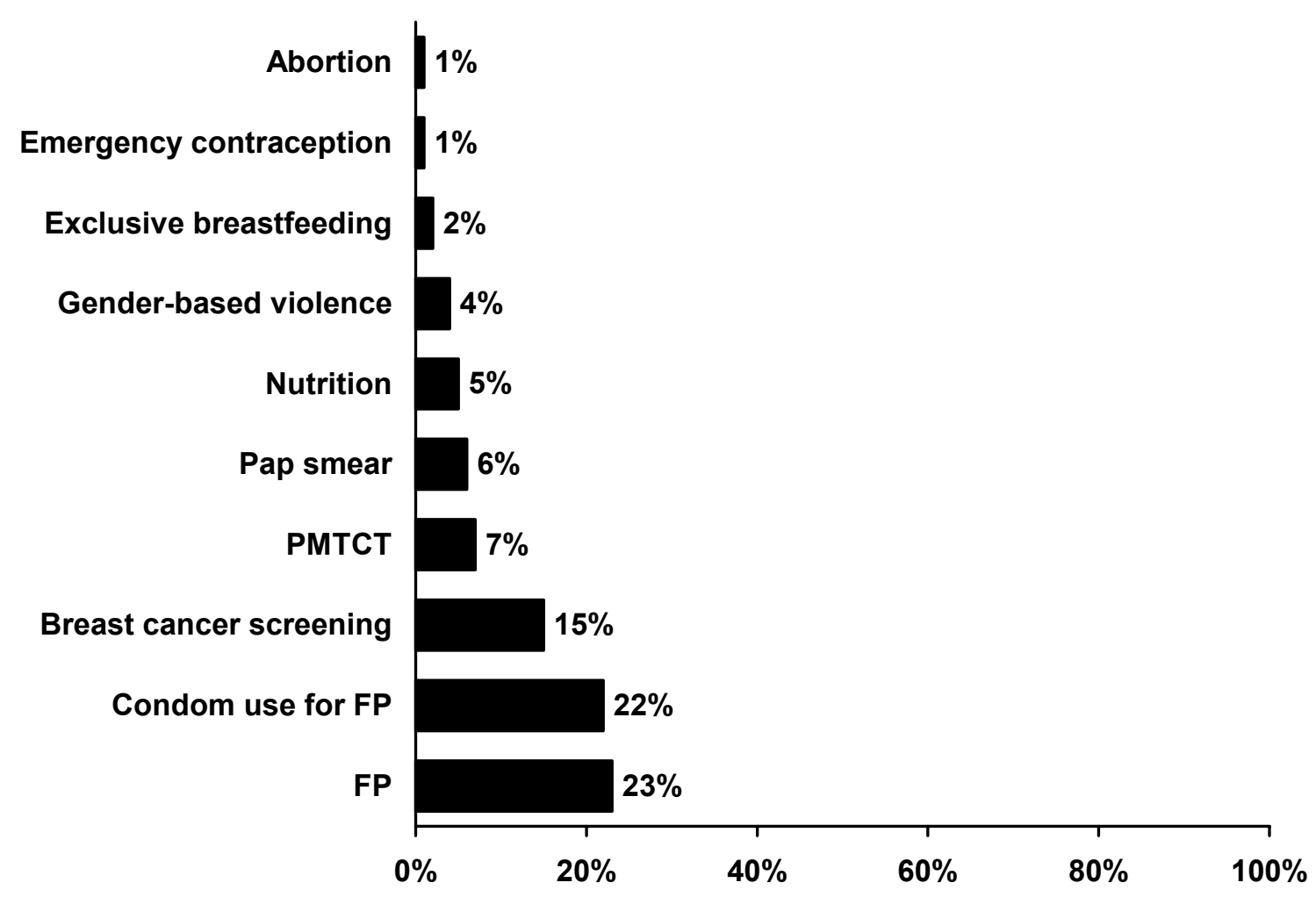

Most of the discussions between the provider and the client focused on STIs. Far fewer discussions were held about other topics. This suggests that there is relatively little "integration" of broader reproductive health into the discussions with the STI clients.

When the topics noted in the four figures above were discussed with 20 percent or more of the clients, surprisingly few statistically significant ( $p \leq .05$ by a chi square test) differences by gender existed. However, five topics shown in Table 6.6 did show statistically significant gender differences. 
KZN Situation Analysis

Table 6.6 Gender differences in topics discussed between client and provider

\begin{tabular}{lccc}
\hline Topic discussed & $\begin{array}{c}\text { Percent } \\
\text { discussed with } \\
\mathbf{6 5} \text { females }\end{array}$ & $\begin{array}{c}\text { Percent } \\
\text { discussed with } \\
\text { 31 males }\end{array}$ & $\begin{array}{c}\text { Statistical } \\
\text { significance }\end{array}$ \\
\hline Use of condoms to prevent pregnancy & 29 & 7 & $p=.009$ \\
Family planning & 32 & 3 & $p=.001$ \\
$\begin{array}{l}\text { Referral of partner for STI diagnosis and } \\
\text { treatment }\end{array}$ & 63 & 84 & $p=.03$ \\
Risk of having multiple partners & 34 & 68 & $p=.002$ \\
Risk of HIVIAIDS & 57 & 81 & $p=.01$
\end{tabular}

Though the providers discussed the use of condoms to prevent pregnancy with almost a third of the female STI clients, they discussed this topic with only about 7 percent of the male STI clients. Similarly, while they discussed family planning with 32 percent of the female clients, they discussed this topic with only 3 percent of the male clients. In contrast, providers were far more likely to engage males than females in a discussion of referral of a partner for STI diagnosis and treatment, the risk of having multiple partners, and the risks of HIV/AIDS.

The reasons for the gender differences in Table 6.6 are not self-evident. They may suggest that when it comes to the topic of family planning, providers consider this an area far more appropriate for females than for males. Although males at STI services hear a message that condoms can be used to prevent STIs, they are far less likely to hear a message that condoms can be used for dual protection-against disease as well as pregnancy. One could also hypothesize from these data that providers believe males have a greater responsibility for preventing STIs than do females. They are definitely more likely to discuss topics concerning STIs and HIV with males than with females. The fact that only half as many males go to these facilities for STD services as do females suggests they may be going elsewhere for care of STIs (or may not be receiving STI care).

Figures 6.1 through 6.3 indicate that during the interaction between the provider and the client, topics related directly to STIs, HIV, and the use of condoms for STI and HIV disease prevention are fairly extensively covered. There is less discussion about other prevention strategies such as reduction of the number of partners or abstinence. Also, though there is some discussion of other reproductive health issues, this occurs relatively infrequently. In addition, females are more likely to hear about family planning, and males hear more about STIs and HIV.

\section{Client health complaints and symptoms, provider examinations, and diagnosis and treatment}

Client health complaints and symptoms. Figure 6.4 shows the most common complaints and symptoms presented by 65 female clients and 31 male clients. Statistically significant differences 


\section{Hgrizons}

between females and males occurred in three areas: abnormal discharge, burning pain while urinating, and genital sores and itching.

Figure 6.4 Percentage of 65 female and 31 male STI clients presenting with complaints and symptoms

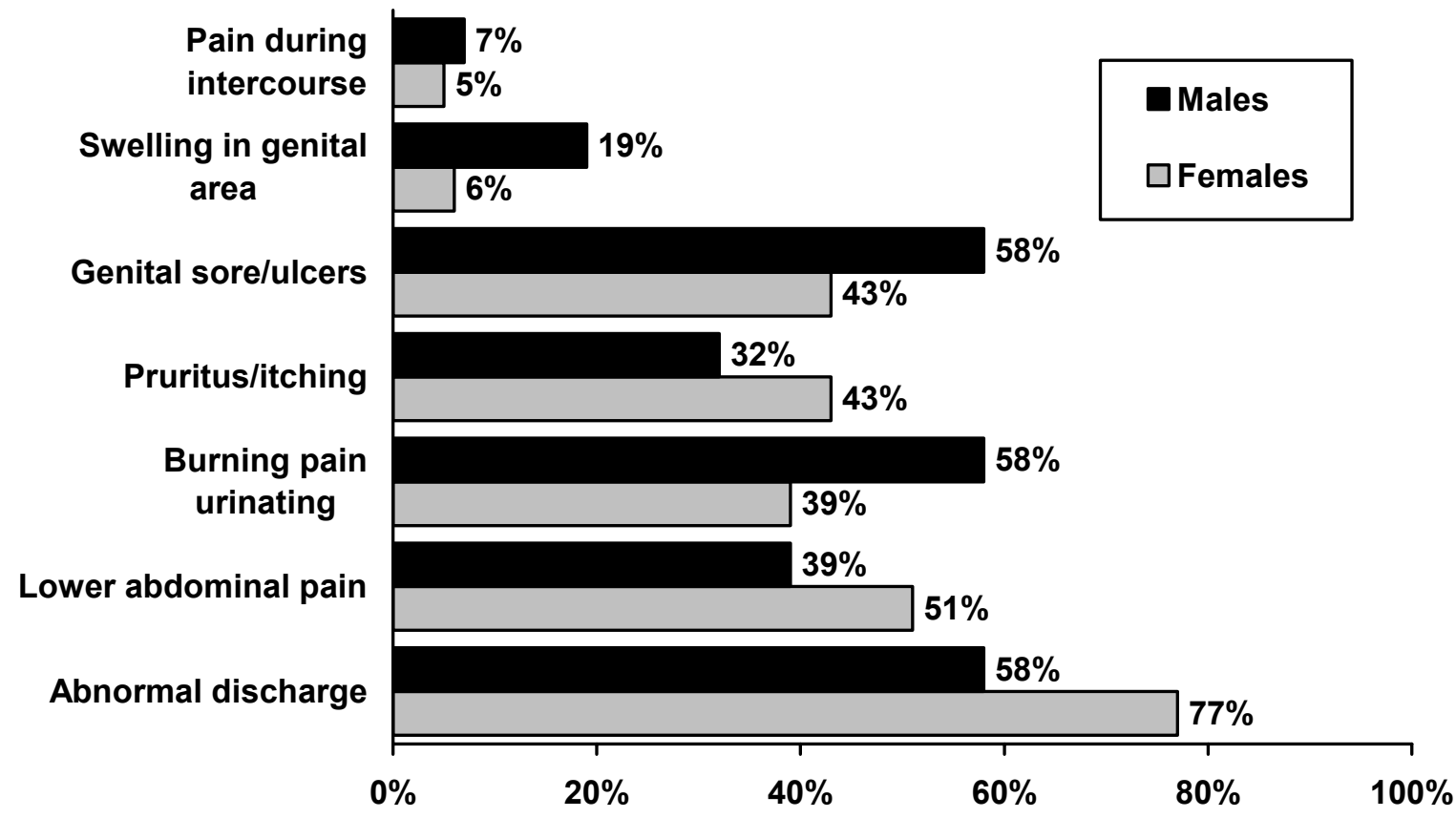

In 94 percent of the interactions, the provider's initial response to these client health complaints was to ask about the nature of the symptoms, and in 87 percent of the interactions the provider asked about the onset and duration of the symptoms. However, in only 56 percent of the interactions did the provider ask the client about a previous STI diagnosis or problem, and in only 47 percent of the interactions did the provider ask about previous STI treatment. 


\section{KZN Situation Analysis}

Examination of 65 female clients. Table 6.7 below shows the procedures performed during the physical examination of 65 female STI clients. Among these clients, 66 percent ( 43 clients) received a pelvic examination by the provider. These examinations were usually conducted in private. In 2 of the 43 examinations, the observer recorded that an unauthorized person was present. In 17 of the 43 examinations, a speculum was used. Among these 17 examinations, the provider explained the examination procedure to 15 of the clients, washed hands before 9 of the examinations, used sterile or disinfected instruments during 12 examinations, and used gloves while examining all of the 17 clients. In 16 of the 17 examinations, the provider examined the cervix and vaginal mucosa, but did a bimanual examination for only 1 of the clients. A pap smear was performed on only 2 of the clients, and for both of these swabs the provider applied fixative to the smear.

The interpretation of these data is not always straightforward without knowing the context of the examination and the diagnosis. The vast majority of female clients were diagnosed as having an STI. This diagnosis suggests that most of those presenting are correctly seeking care. If the diagnoses were accurate, all of these female clients probably should have been given a pelvic examination under sterile conditions, when the provider washes hands and uses sterile gloves. The providers also should have inspected the cervix and vaginal mucosa and performed a bimanual examination. Considering that cervical dysplasia is sexually transmitted, few women received a pap smear, as this procedure requires laboratory facilities and trained staff.

\section{Table 6.7 Procedures performed with female STI clients}

Pelvic examination given to 43 of 65 clients

Speculum used with 17 of the 43 clients

Provider explains procedure to 15 of the 17 clients

Provider washes hands before 9 of the 17 examinations

Provider puts on gloves before all 17 examinations

Provider uses sterile or disinfected instruments with 12 of the 17 clients

Provider inspects cervix and vaginal mucosa in 16 of the 17 examinations

Provider does bimanual exam in 1 of the 17 examinations

Provider takes pap smear in 2 of the 17 examinations

Provider applies fixative to pap smear for the 2 pap smear swabs

Examination of 31 male clients. Table 6.8 shows the examination procedures conducted with the 31 male STI clients. As with the procedures used among the female clients, it is somewhat difficult to know whether good clinical practice is being followed without knowing more about the context of the examination and the presenting symptoms of the client. However, it is possible to make a few comments on these data. As we will discuss in a subsequent section, 30 of the male clients were diagnosed as having an STI, and 1 as having a reproductive tract infection. In this situation, it seem 


\section{${ }^{\text {Hrizons }}$}

appropriate that the provider should have examined the genitalia of all 31 clients. Also it would seem appropriate that for all 31 clients, the provider should have washed hands before the examination, used gloves, checked the testicles, and checked the urethra. Depending on whether laboratory facilities were available, a swab may or may not have been appropriate.

\section{Table 6.8 Procedures performed with male STI clients}

External genitalia examined with 28 of 31 clients

Provider explains procedure to 27 of the 28 clients

Provider washes hands before 7 of the 28 examinations

Provider puts on gloves before 13 of the 28 examinations

Provider checks testicles in 9 of the 28 examinations

Provider checks urethra in 18 of the 28 examinations

Provider takes a swab for test in 1 of the 28 examinations

Treatment and counseling by provider after the examination. Table 6.9 shows the diagnosis and treatment that 65 female and 31 male STI clients received. An overwhelming majority of these clients, 82 percent of the females and 97 percent of the males, were diagnosed with an STI. Also, almost all of the clients, whether female or male, were either prescribed drugs to treat the STIs and/or given the drugs, but only 69 percent of the females and 86 percent of the males were instructed to complete the full course of the medication. 
Table 6.9 Percentage of 65 female and 31 male STI clients receiving providers' diagnosis, treatment, and other actions

\begin{tabular}{|c|c|c|}
\hline Item & $\begin{array}{l}\text { Percent of } 65 \\
\text { females }\end{array}$ & $\begin{array}{c}\text { Percent of } 31 \\
\text { males }\end{array}$ \\
\hline \multicolumn{3}{|l|}{ Diagnosis } \\
\hline STI & 82 & 97 \\
\hline RTI & 19 & 3 \\
\hline Pregnancy-related & 3 & - \\
\hline HIV-positive & 3 & 0 \\
\hline No infection & 2 & 0 \\
\hline Prescribes drugs & 94 & 77 \\
\hline Gives drugs & 85 & 84 \\
\hline Instructs patient on completing full treatment & 69 & 86 \\
\hline Recommends use of condoms & 83 & 97 \\
\hline Has positive or neutral attitude toward condom use & 97 & 100 \\
\hline Provides male condoms & 34 & 71 \\
\hline Provides female condoms & 2 & 7 \\
\hline Mean number of male condoms provided & 13 & 14 \\
\hline Asks client to make a revisit & 59 & 52 \\
\hline Gives slip for partner notification & 74 & 71 \\
\hline \multicolumn{3}{|l|}{ Diagnostic tests conducted } \\
\hline Wet mount & 0 & 0 \\
\hline Microscopy & 0 & 0 \\
\hline Gram stain & 0 & 0 \\
\hline BW/VDRL & 11 & 16 \\
\hline Rapid HIV test & 2 & 0 \\
\hline Hepatitis B & 0 & 0 \\
\hline Elisa & 0 & 0 \\
\hline Pap smear & 6 & - \\
\hline \multicolumn{3}{|l|}{ Drugs prescribed } \\
\hline Systemic antibiotics & 86 & 84 \\
\hline Local antibiotic & 6 & 10 \\
\hline Intravaginal antibiotic & 6 & - \\
\hline Wash solution & 0 & 0 \\
\hline Tonic & 0 & 0 \\
\hline
\end{tabular}




\section{${ }^{H}{ }^{\text {rizons }}$}

For 83 percent of the female clients and 97 percent of the male clients, the provider recommended the use of condoms. The nurse fieldworkers judged that in almost all cases the provider's attitude toward condom use was either positive or at least neutral. However, only 34 percent of the female clients were given male condoms and only 2 percent were given female condoms. On average, females received 13 male condoms. However, 71 percent of the males were given male condoms, 7 percent were given female condoms, and, similar to the female clients, clients received 14 condoms on average.

Somewhat more than half of both female and male clients were asked to make a revisit and slightly more than 70 percent of both females and males were given a partner notification slip. Very few diagnostic tests were performed, the most common being BW/VDRL for syphilis. A wet mount test was not used with any of the clients. In this setting, where providers are trained to use the syndromic approach to diagnose and treat STIs, laboratory diagnostic tests are not relied on heavily. Providers also use the syndromic approach because the government has promoted syndromic management as a necessary "second best" solution. More than 80 percent of both females and males received systemic antibiotics.

Overall, a high percent of this population of STI clients received drugs for their illness, were given instructions on completing the full treatment, were given partner notification slips, and were instructed to use condoms.

\section{Clients' experience with and views about service provision}

Information and services clients said they received. Despite the clients having to spend one hour to get to the clinic and almost two and a half hours waiting at the clinic, 94 percent of them said that they received the service they wanted and 98 percent said they received the information they wanted. If these findings can be taken as a measure of satisfaction, it is very high.

Most of the information and services the clients received were related to STIs, as can be seen in Figure 6.5. 
KZN Situation Analysis

\section{Figure 6.5 Information $92 \mathrm{STI}$ clients said they received during consultation}

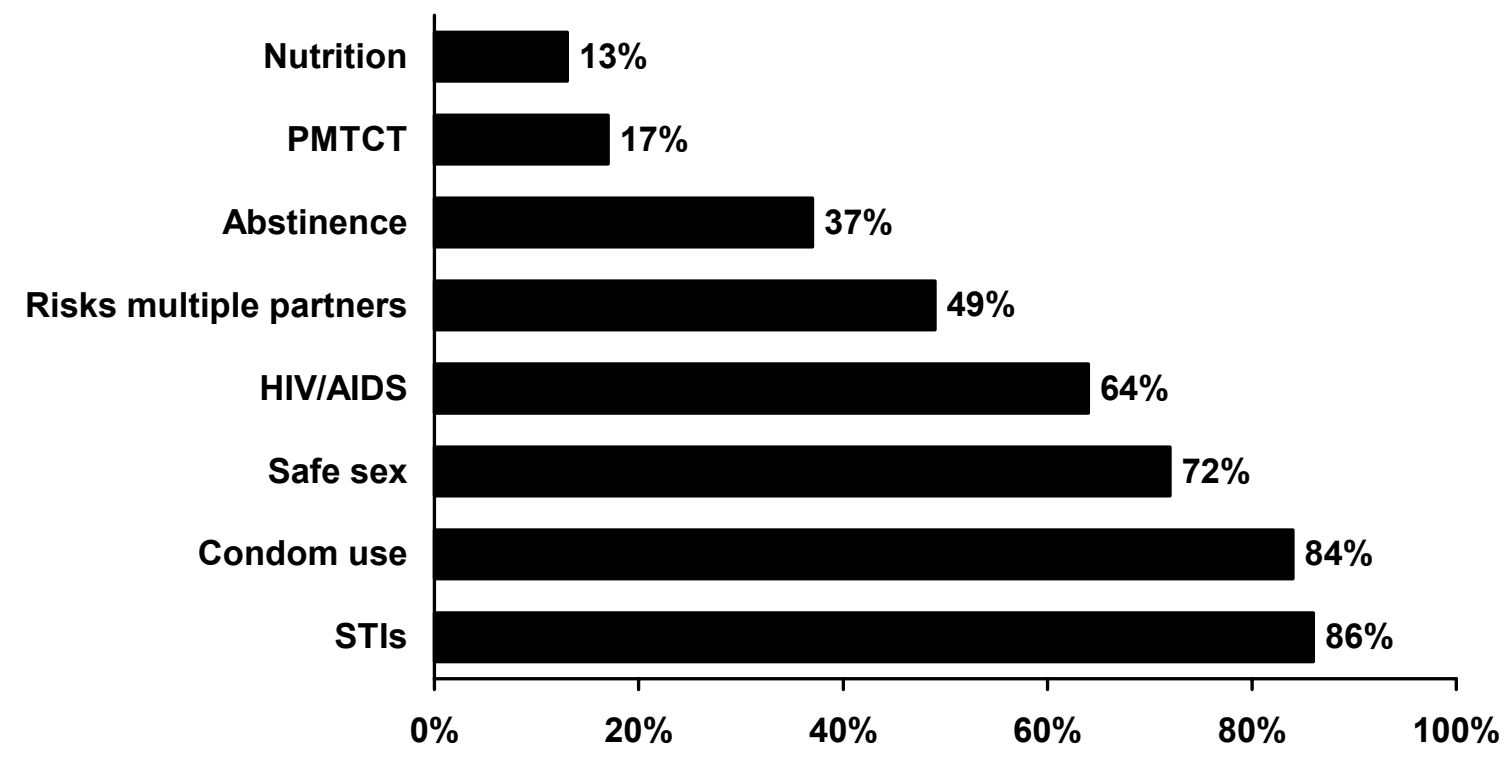

The only major gender differences in information received were with information on multiple partners and HIV/AIDS. About 36 percent of females received information on the risks of multiple partners, but 85 percent of the males said they received this information. Similarly, 59 percent of the females said they received information on HIV/AIDS, but 81 percent of the males said they received information on this topic. Information on other topics, such as emergency contraception, termination of pregnancy, breastfeeding, and gender-based violence, were mentioned by only 3 percent of the 92 clients.

Figure 6.6 shows the services received by the 92 STI clients. Almost all of the services the clients said they received were related to STIs and more directly to the diagnosis, counseling, and treatment of an STI. About 45 percent of the clients also said they received counseling on condom negotiation, and 17 percent were counseled about HIV/AIDS. Only 13 percent of the STI clients said they received family planning services, 9 percent an HIV test, and 5 percent a pregnancy test. Among female clients, 64 percent said they received a gynecological examination, 13 percent said they received breast cancer screening, and 7 percent said they received a pap smear. 


\section{${ }^{\mathrm{H}} \boldsymbol{K}^{\text {rizons }}$}

Figure 6.6 Percentage of 92 STI clients reporting receipt of services

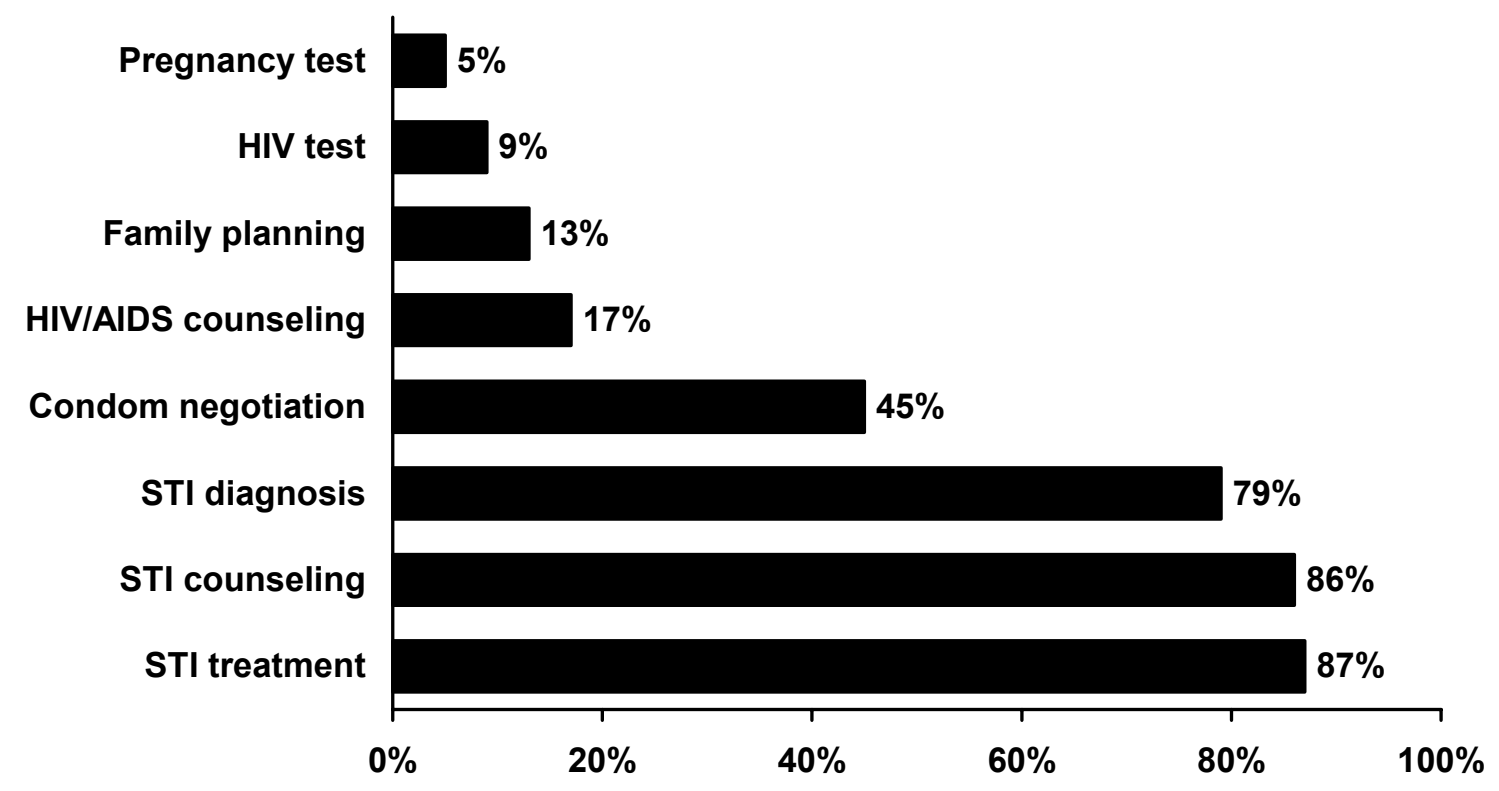

Quality of care: communication and interaction between provider and client. From the clients' perspective, the providers did an excellent job of communication. During the exit interviews, 95 percent of the clients said that the provider explained about the examination procedure before starting the procedure. Ninety-eight percent said the provider explained the results of the examination, 95 percent said the provider explained how to take or use the medicines given or prescribed, and 97 percent said that the provider was easy for them to understand.

Besides the communication from the providers to the clients, there was also communication from the clients to the providers. About 37 percent of all clients ( 31 percent of females and 50 percent of males) said that they had questions they wanted to ask the provider. Of those who had questions, 79 percent asked the question and 100 percent of these clients said that the provider responded to the question.

Other indicators of quality of care were also very high. For example, 84 percent of the clients felt that they had visual privacy during the consultation and examination, and 83 percent felt they had auditory privacy. Equally important, 97 percent felt that they had enough time with the provider, and 95 percent said they were fully satisfied with the consultation visit. Only 4 percent said they were partially satisfied and only 1 percent said they were not at all satisfied. Finally, 96 percent said that they would recommend the facility to a friend.

Although clients communicated and interacted very well with the provider, only 8 percent of the clients received any written material to take home with them. As noted in the inventory section of 
this report (Chapter 2), one reason for this is a general lack of written materials available in clinic settings for clients.

\section{Client Awareness and Knowledge of HI V/ AI DS}

During the exit interviews, clients were asked a series of questions about HIV/AIDS. Many of these questions included "skips," meaning that if a respondent answered "no" to a particular question the interviewer skipped to another set of questions. As a result of this method, the number of respondents who answer any given question varies.

Clients were asked whether the provider talked to them about how to protect themselves against the transmission of STIs including HIV. Ninety percent of 86 clients said yes ( 85 percent of 61 female clients and 100 percent of 25 male clients), and 24 percent of the clients said that the provider referred them for an HIV/AIDS test.

\section{Knowledge about HIV/AIDS}

Of 92 STI clients, 85 percent said they knew that diseases could be transmitted through sexual intercourse, and 75 percent said they also knew some of the common signs and symptoms of sexually transmitted infections. Table 6.10 below shows the signs and symptoms most frequently mentioned among all 92 STI clients:

Table 6.10 Percentage of 92 STI clients able to mention signs and symptoms of STIs, unprompted (multiple responses were possible)

\begin{tabular}{lc}
\hline Signs and symptoms of STIs mentioned & Percent \\
\hline Lesions and sores & 50 \\
Abnormal vaginal discharge & 45 \\
Painful urination & 29 \\
Urethral discharge & 26 \\
Genital itching & 17 \\
Lower abdominal pain & 15 \\
Loss of weight & 11 \\
Genital warts & 8 \\
Abnormal vaginal bleeding & 3 \\
Painful intercourse & 1
\end{tabular}




\section{Hgrizons}

Most clients could name at least one, and sometimes more than one, sign or symptom of an STI. Moreover, though half of the clients recognized lesions and sores as signs of STIs, few recognized the other predictive signs. Only 26 percent recognized urethral discharge as a sign of STIs, only 8 percent know that genital warts were a sign of STIs, and only 11 percent thought that loss of weight was an indicator of STIs, though this symptom is usually apparent only at the terminal stages of illness such as AIDS.

Regarding prevention, 85 percent of the 92 clients said that they knew the ways in which HIV/AIDS was transmitted. Table 6.11 below shows the most frequently mentioned modes of transmission mentioned. Indeed, the responses accurately reflect the reality that most HIV/AIDS transmission in KZN is via sexual intercourse.

$\begin{aligned} & \text { Table 6.11 Percentage of 92 STI clients able to mention ways that HIVIAIDS is } \\
& \text { transmitted (unprompted) }\end{aligned}$
\begin{tabular}{lc} 
Ways that HIVIAIDS is transmitted & Percent \\
\hline Sexual intercourse & 97 \\
Needles & 33 \\
Blood transfusion & 23 \\
Mother-to-child transmission & 4
\end{tabular}

A final question asked whether the respondents knew how they could protect themselves from sexually transmitted infections, and 92 percent said they did know. Table 6.12 below shows the most frequently mentioned ways that clients said they could protect themselves from STIs:

Table 6.12 Percentage of 92 STI clients able to mention ways to protect against HIVIAIDS (unprompted)

\begin{tabular}{lc}
\hline Ways to protect against HIVIAIDS & Percent \\
\hline Use condoms & 85 \\
Stay faithful to one partner & 28 \\
Abstinence & 27 \\
Avoid sharing needles & 10 \\
Encourage partner to stay faithful & 9
\end{tabular}

\section{Protective behavior against STIs including HIV/AIDS}

About 51 percent of 92 clients said they had ever used a condom ( 45 percent of the females and 60 percent of the males). When asked if they or their partner were currently doing anything to avoid or 
prevent an STI or HIV, only 40 percent of the 92 clients said yes (33 percent of the females and 46 percent of the males). This lack of protective behavior is likely the basis for the STIs identified in the majority of these clients. Of those who said they were taking action to prevent STIs, 94 percent said they were using condoms when sexually active, and 6 percent, or 2 clients, mentioned abstinence or being faithful to only one partner. Among those who said they were not doing anything to protect themselves, the main reasons mentioned were: they are monogamous (10 percent); want a child (4 percent); are not at risk (16 percent); "nothing I can do" (8 percent); other responses (45 percent); and “don't know (18 percent).

In summary, as one might expect for a population of STI clients living in a South African province with a high rate of HIV prevalence, general awareness of HIV/AIDS as well as general knowledge about modes of transmission and ways to protect themselves against HIV/AIDS and other STIs is very high. However, poor recognition of the few predictive signs and symptoms of STIs and the low percent of clients who are actually taking protective behaviors are far less than desired, and well below the percent who know about the risks. Indeed, 17 percent said they were not at risk and another 8 percent took the fatalistic position that there is nothing that they can do to protect themselves.

\section{Travel and Waiting Times}

About 74 percent of all 92 clients who agreed to an exit interview said they came to the clinic by walking. Most of the remaining clients, 26 percent, used a taxi or minibus. The average time from home to the clinic was one hour. The average waiting time in the clinic was two hours and 24 minutes, and 46 percent of the clients felt that the waiting time was too long while 54 percent felt it was reasonable. Half of the clients received their first consultation by 11:00 a.m. The last client was seen at 3:05 p.m. About 11 percent of the clients said that in the past they had been turned away from the clinic because of overcrowding or other unspecified reasons.

\section{Summary}

As one would expect, the consultation between the provider and the STI client focused primarily on STI diagnosis and treatment. Condoms were most frequently mentioned as a means to prevent STIs including HIV. Topics less frequently discussed were condom negotiation skills, how to use a condom, or strategies to avoid STIs such as abstinence and being faithful to one partner. Though family planning was discussed with about 23 percent of STI clients, other reproductive health topics such as breast cancer, PMTCT, nutrition, and gender-based violence, were discussed with less than a fifth of all clients. In short, while there was some integration of other reproductive health topics into the discussion between the provider and the client, this occurred only with relatively few clients.

During the physical examination of female clients, 66 percent were given a digital vaginal examination but a speculum exam was used in only 40 percent of these examinations. Also, the 


\section{${ }^{H}{ }^{\text {rizons }}$}

observers of the interaction between the provider and the client reported that while the providers used gloves in all speculum examinations, they did not always wash their hands before putting on the gloves, and in only one case was a bimanual examination performed. With the 31 male STI clients, external genitalia were examined for 90 percent, or 28 , of these clients. However, the testicles were examined in only 9 of these 28 cases.

After the examination, most clients were either given drugs or prescribed drugs. Condom use was recommended to 97 percent of the male clients and 83 percent of the females, and 71 percent of the males received supplies of male condoms but only 34 percent of the females received male condoms. The assessment methodology does not permit judgment of the accuracy of the diagnoses or the treatment.

In exit interviews, 86 percent of the clients said they received information on STIs and 87 percent said they received STI treatment. Clients also said that they received information on safe sex (72 percent), HIV/AIDS (64 percent), and the risks of multiple partners (49 percent). According to these clients, in addition to STI services, some of them also received other services such as HIV/AIDS counseling (17 percent), family planning (13 percent), an HIV test ( 9 percent), and a pregnancy test (5 percent). These findings suggest some integration of services, although this occurred with less than a fifth of the clients.

When asked about communication with the provider, clients overwhelming gave a very positive picture. Slightly less than 100 percent of them said that the provider explained the examination procedures to them, explained the results of the examination, and explained how to take the medication. These findings indicate a very positive interaction with the provider.

Finally, with regard to the clients' understanding of STIs and HIV/AIDS, most clients could name one or more of the signs and symptoms of STIs and most understood one or more of the ways HIV is transmitted, but less than half recognized the most predictive symptoms. As for protecting themselves from HIV, 85 percent mentioned the use of condoms and 51 percent said they had ever used a condom. About 40 percent said they were currently doing something to avoid or prevent STIs and HIV, and, of these clients, 94 percent said they were using condoms while 6 percent, or 2 clients, mentioned abstinence or being faithful to one partner as a strategy to avoid STIs and HIV. 
KZN Situation Analysis

\section{Chapter 7 Voluntary Counseling and Testing Services}

\section{KZN VCT Services}

Provision of HIV voluntary counseling and testing has grown dramatically in recent years and is critical for helping people know their serostatus, reduce HIV risk behaviors, and plan for the future (Sweat 2003). VCT is also an important first step in identifying persons eligible for antiretroviral drug therapy. Despite these important reasons for providing VCT, the extent to which it is effective in increasing protective behaviors such as abstinence, monogamy, and consistent condom use has not been well established (Myer et al. 2003). There are, however, some studies which have focused on the effects of VCT on behavior and HIV transmission. (Zachariah et al. 2003; Allen et al. 2003; Pronyk et al. 2002; Matovu et al. 2002; Kowalczyk et al. 2002; Ginwalla et al. 2002; Forsyth et al. 2002; Chama and Kayawe 2000).

The KZN Situation Analysis teams visited 98 SDPs and in 32 of these facilities VCT clients were observed and interviewed. In this section, we highlight some of the findings from Chapter 2

(describing available supplies and equipment) and focus more specifically on the characteristics of the 32 facilities. In these facilities, $74 \mathrm{VCT}$ clients were observed as they received services from a provider. Subsequently, 67 clients were interviewed using a structured interview schedule as they exited. This section also uses data from 229 providers who were interviewed.

Although service statistics are often inaccurate or, in some facilities, missing altogether, they do give an indication of program activity and the relative number of clients served by different services. The data collected for the month of August 2002 at the facilities where data were available show that the number of clients who are provided with family planning services, antenatal care services, and STI services is far greater than the number provided with VCT services. These differences are evident in Figure 7.1. 


\section{${ }^{\mathrm{H}} \boldsymbol{K}^{\text {rizons }}$}

Figure 7.1 Mean number of clients served during month of August* 2002 at facilities reporting ( $n=$ number of facilities reporting)

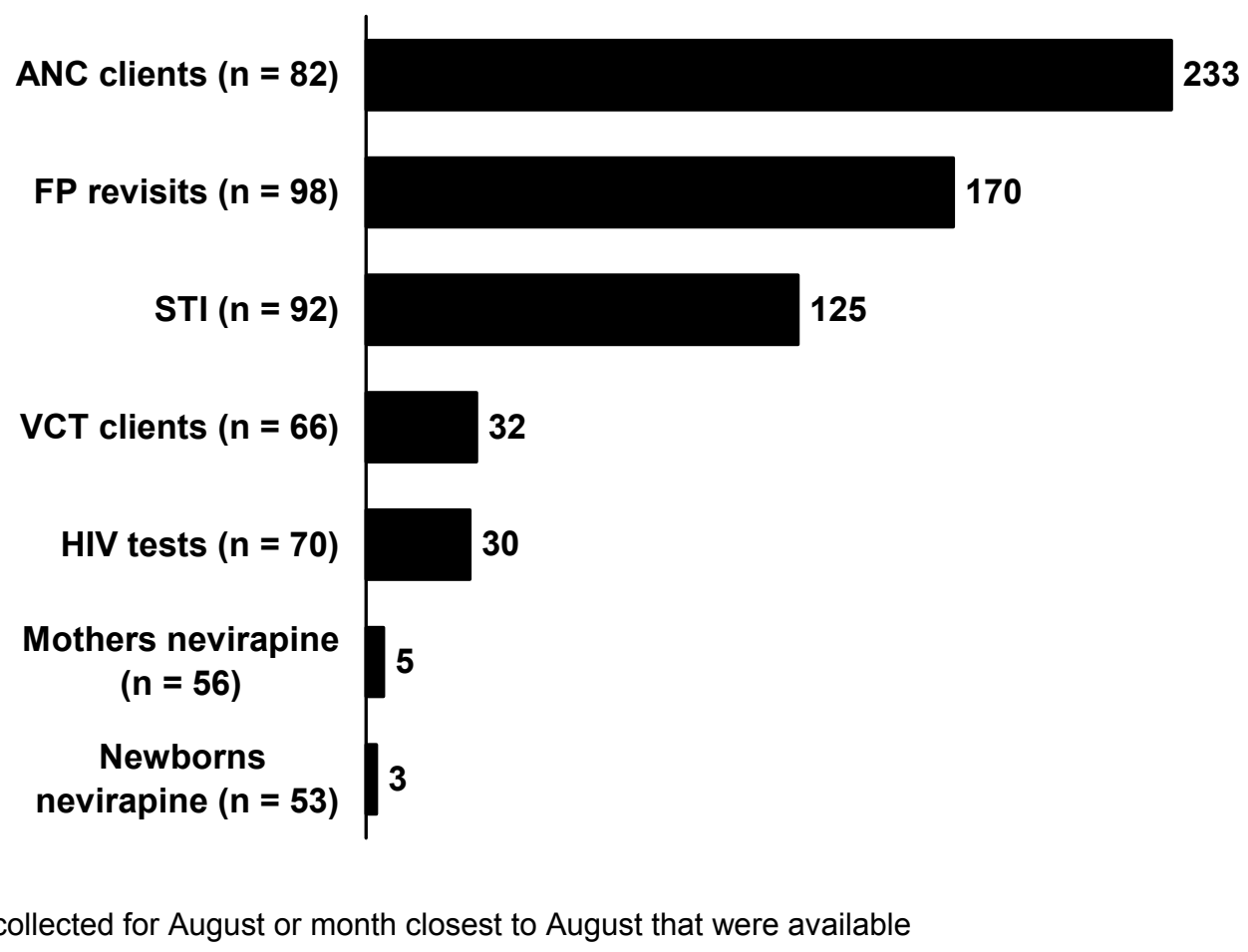

While on average, each facility provided services in one month (with 20 working days) to a total of more than 100 revisiting family planning, STI, and ANC clients, on average each clinic provided services to only $32 \mathrm{VCT}$ clients in the month and conducted an average of only $30 \mathrm{HIV}$ tests. In addition, on average each facility provided only 5 pregnant mothers with nevirapine and only 3 newborn babies with nevirapine. These data suggest that a facility is likely to see only about 1 to 2 VCT clients a day, which does not indicate a high client load. The client load is far less for motherto-child transmission (MTCT) services. On average the clinics where data were available provided counseling and nevirapine to about one woman every week. They provided nevirapine to about one baby every seven working days. Again, these figures suggest a low MTCT client load.

There may be a number of reasons for the relatively low number of VCT clients, such as the fear of stigma and discrimination associated with HIV/AIDS and the relatively recent introduction of nevirapine in only a few facilities. Furthermore, compared with FP, STI, and ANC services, which are offered in almost all facilities, according to the providers questioned at the 98 facilities, VCT is offered in only 52 percent of these facilities. Also, MTCT counseling, including the availability of nevirapine, is offered in only 28 percent of the 98 SDPs. 
In short, greater attention needs to be given to publicizing and expanding VCT and HIV/AIDS services. In a province with one of the highest HIV prevalence rates in the country, these services are vital for helping to control the epidemic through prevention as well as care and support activities.

\section{VCT Client Characteristics}

As noted in Table 7.1 below, of the 67 VCT clients who provided exit interviews, the median age was 26 years, 78 percent were females, and 86 percent were single.

Table 7.1 indicates that although most VCT clients (58 percent) were above the age of 25, almost 18 percent of them were below the age of 20 and slightly less than half, 43 percent, were below the age of 25. This age distribution suggests not only the need for "youth-friendly" VCT services but also a need to focus on older age groups as well.

\section{Table 7.1 Characteristics of 67 VCT clients}

\begin{tabular}{lc}
\hline Characteristics & Percent \\
\hline Age & 3 \\
$9-14$ & 15 \\
$15-19$ & 25 \\
$20-24$ & 30 \\
$25-29$ & 8 \\
$30-34$ & 20 \\
$35+$ & \\
Sex & 78 \\
Female & 22 \\
$\quad$ Male & \\
Marital status & \\
Single & 86 \\
Other & 14
\end{tabular}

\section{Readiness of Facilities to Deliver VCT Services}

In this section, we examine the readiness of facilities to deliver VCT services. Of the 32 facilities where 74 VCT clients were observed and 67 were interviewed, 9 facilities were district hospitals, 6 were community health centers, and 17 were clinics. Six of the facilities were in urban areas, 6 in peri-urban, and 20 in rural areas. 


\section{Hgrizons}

Slightly less than half of the 32 facilities where VCT was observed advertised the availability of VCT services (47 percent), HIV/AIDS services (44 percent), or STI services (41 percent). Figure 7.2 shows that almost two-thirds (63 percent) of the 32 facilities where VCT service provision was observed had written material on HIV/AIDS prevention for clients to take home. However, only 38 percent had materials for clients on breastfeeding and RTI/STI prevention, 34 percent on HIV/AIDS treatment and care, 28 percent on nutrition, and 16 percent on the prevention of motherto-child transmission of HIV. These findings suggest that greater availability of written materials for clients in clinic settings are needed, particularly in the critical area of PMTCT.

\section{Figure 7.2 Percentage of $\mathbf{3 2}$ facilities providing VCT services with educational materials for clients to take home}

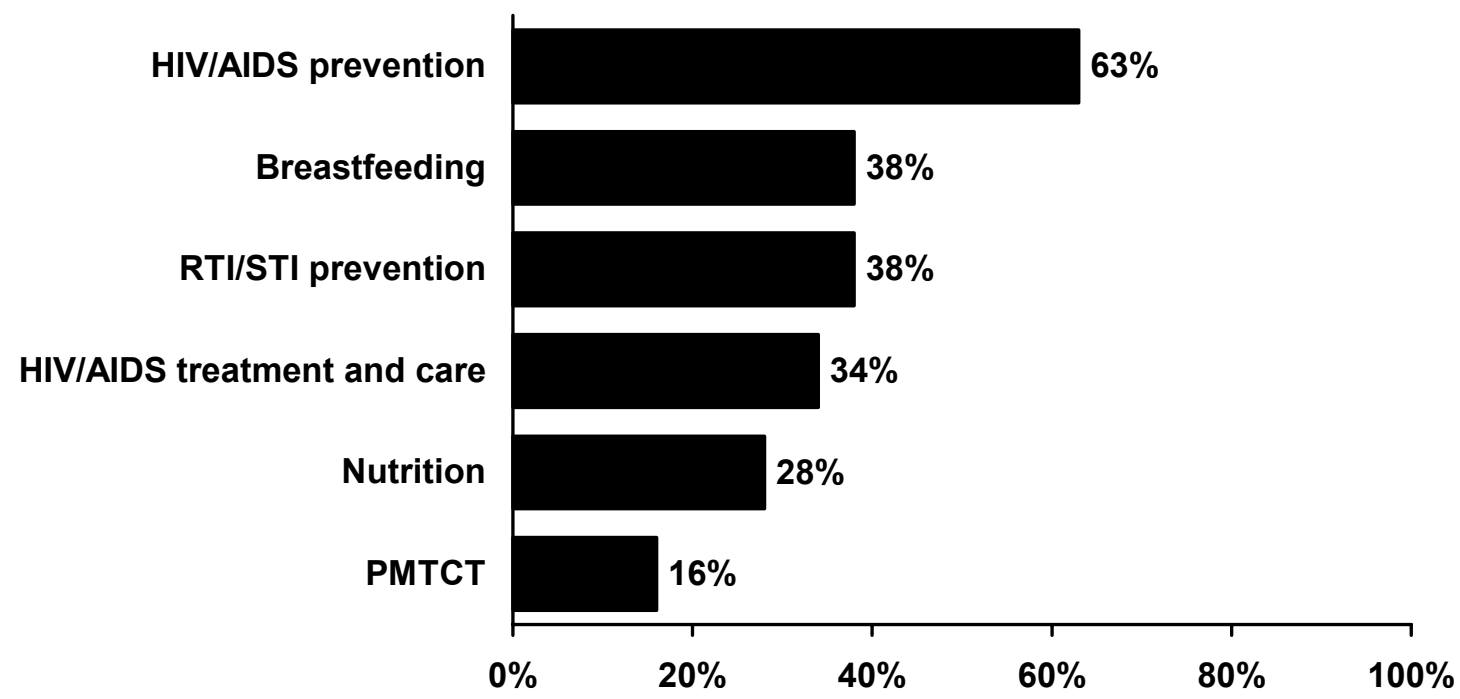

Figure 7.3 shows that among all the 98 facilities visited, 96 percent provided STI services, 52 percent VCT services, but only 28 percent had PMTCT services with nevirapine and only 27 percent offered rape counseling. All of the 32 facilities where VCT was observed had male condoms available. However, at the time data was collected, only a small number of facilities had female condoms available because female condoms were available in a few pilot sites. 
Figure 7.3 Percentage of 98 facilities with HIV/AIDS services available

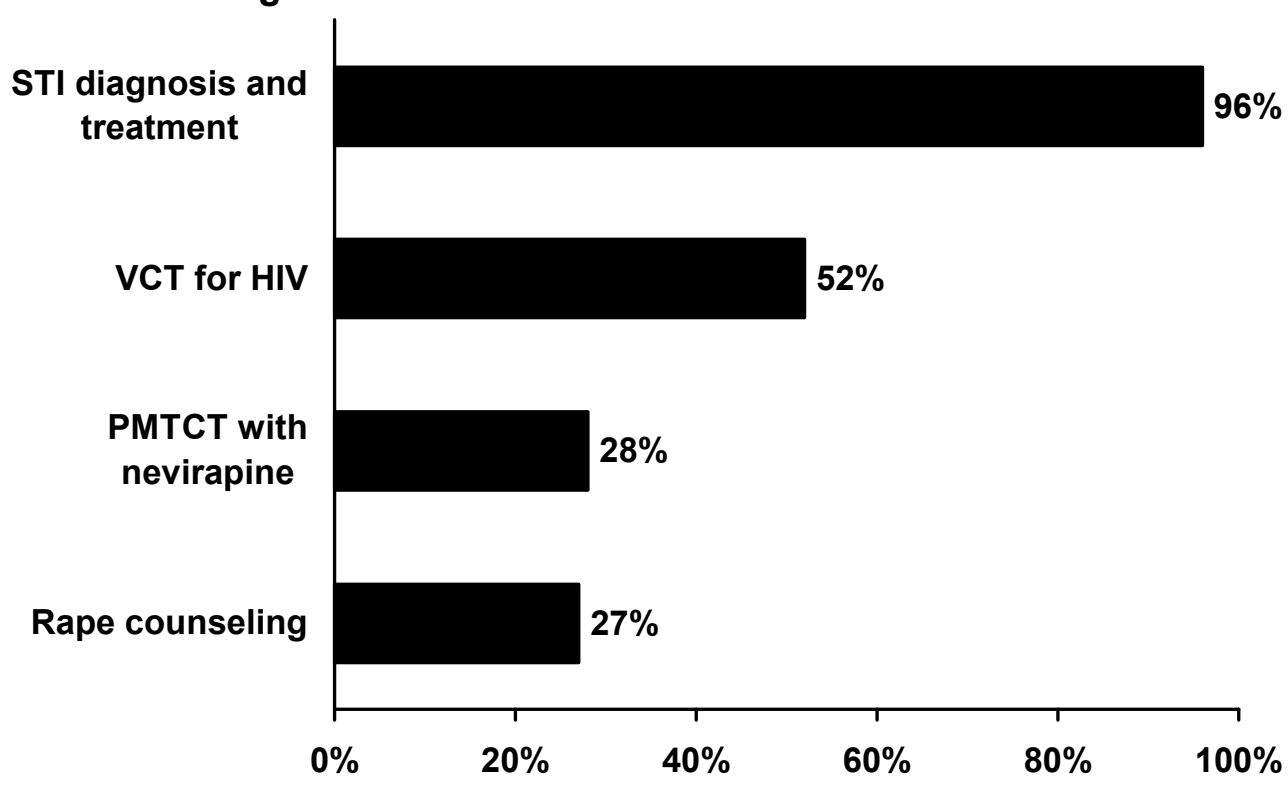

Figure 7.4 below shows the availability of viral load services, CD4 cell services, and DOTS (directly observed treatment short course) for TB at all of the 98 facilities visited and at the 32 facilities with VCT services. Among all 98 facilities, 42 percent had the ability to provide viral load counts and 41 percent could do CD4 cell counts either by doing these tests at the facility itself or by sending blood out to another facility. Among the $32 \mathrm{VCT}$ facilities, 41 percent could provide viral load counts and 51 percent could provide CD4 cell counts either by doing these tests at the facility itself or by sending blood out to another facility. Also, 75 percent of the VCT facilities and 78 percent of all 98 facilities had a DOTS program for TB. 


\section{Herizons}

Figure 7.4 Percentage of all 98 facilities and 32 VCT facilities able to provide viral load, CD4 cell counts, and DOTS services

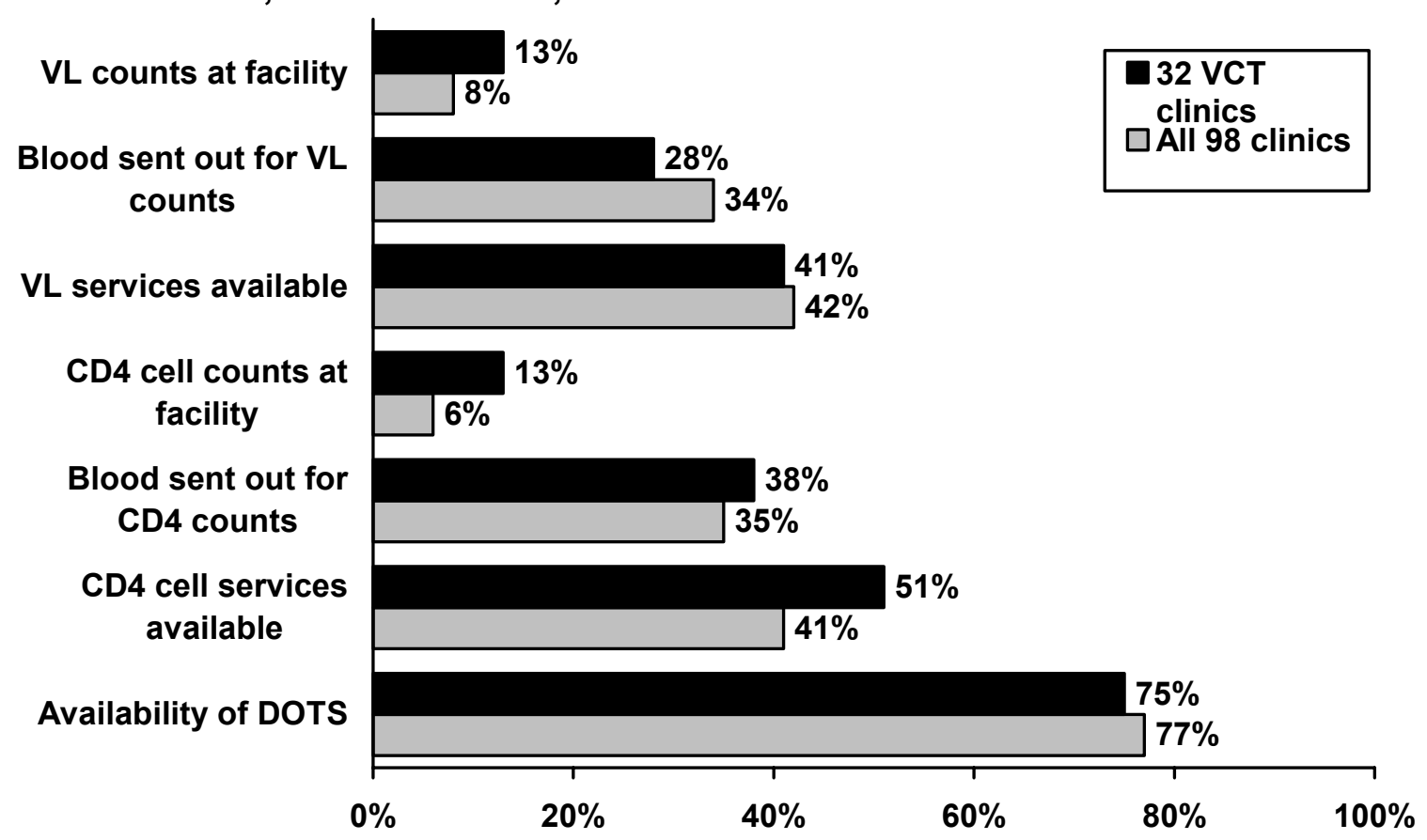

Although viral load testing may not be essential to the provision of ARVs, the CD4 cell count is frequently used, in combination with other clinical features, to identify people who need treatment with ARVs. Figure 7.4 indicates that there is a substantial capacity in the public sector to identify people eligible for treatment with ARVs and to monitor people who are taking ARVs. These findings suggest that antiretroviral treatment could be introduced widely in KwaZulu Natal if staff have the requisite skills to administer these drugs. The DOTS program for TB is also widely available. In addition, as can be seen in Figure 7.5, essential drugs for controlling STIs as well as other conditions are almost always available. These findings reflect very positive aspects of the current situation in the province and indicate that some of the basic components necessary for implementing an ARV program and for managing patients with opportunistic infections are in place. 


\section{Figure 7.5 Percentage of 98 facilities with drugs for STI treatment available}

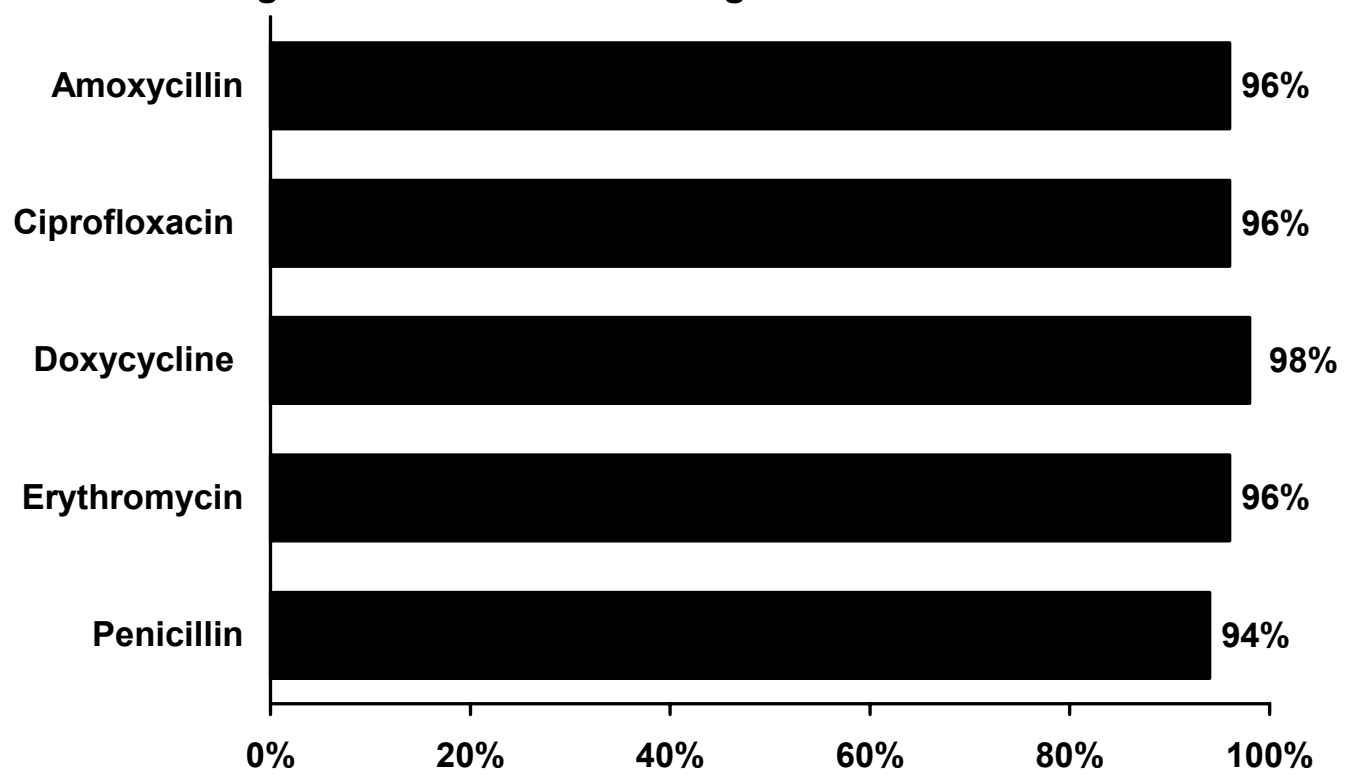

\section{Infrastructure, Equipment, and Staff}

As noted in Chapter 2, in general, the infrastructure of the 98 facilities varied, with some (20 percent) of the clinics lacking sufficient safe water and a few (6 percent) also lacking electricity. Most facilities, however, had basic equipment, with 100 percent having stethoscopes and disposable gloves, 98 percent having blood pressure gauges and disposable syringes, and 96 percent having thermometers. In terms of staff, 97 percent of the facilities had one or more nurses. However, relatively few had a full-time specialist physician (4 percent) or even a full-time general physician (10 percent).

In summary, because most of the facilities have a fairly low VCT client load, they are not overwhelmed with VCT clients. There are even fewer clients who are provided MTCT services including nevirapine. Most of the clients attending VCT are female and single. They are almost equally split between those who are under 25 and over 25 years of age Even though more than half of the facilities have written material on HIV/AIDS for clients, additional materials are needed on other topics, particularly mother-to-child transmission. Almost all facilities provide STI services, but only about half offer VCT services and slightly more than a quarter offer MTCT services. Facilities have a fairly good capacity to monitor HIV viral loads and CD4 cell counts among clients who are HIV-positive. This finding suggests that the public sector has the capacity to monitor substantial numbers of people when ARVs become more widely available. Also on the positive side, almost all facilities have available essential drugs for controlling STIs. Furthermore, although a number of weaknesses exist in infrastructure, equipment, and staffing, most facilities have the 


\section{${ }^{H} \boldsymbol{X}^{\text {rizons }}$}

capacity to deliver VCT and related STI services. This capacity or readiness to deliver services could probably be improved rapidly though staff training, greater availability of information and education materials, and greater attention to infrastructure and equipment problems in some facilities.

\section{Client-Provider I nteraction and the Quality of VCT Service Delivery}

The interaction between VCT counselors and a total of 74 clients before an HIV test (pretest counseling) and after the test (posttest counseling) was observed by trained nurse midwives at 32 facilities. Slightly more than three-fourths (77 percent) of the 74 VCT clients were female. Not all clients received HIV test precounseling or posttest counseling. Some clients were tested without having received pretest counseling. Others received pretest counseling but did not remain at the facility for posttest counseling. Figure 7.6 shows that of the 74 VCT clients, 85 percent received pretest counseling, 69 percent agreed to be tested, 68 percent (or 50 clients) were tested, and 47 percent (or 35 clients) received posttest counseling. Among the 50 clients who were tested, 40 were females and 10 were males. All 10 of the males tested negative, while 23 of the 40 females tested HIV-positive. These $23 \mathrm{HIV}$-positive clients represent 31 percent of all $74 \mathrm{VCT}$ clients who were observed.

\section{Figure 7.6 Experience of 74 VCT clients}

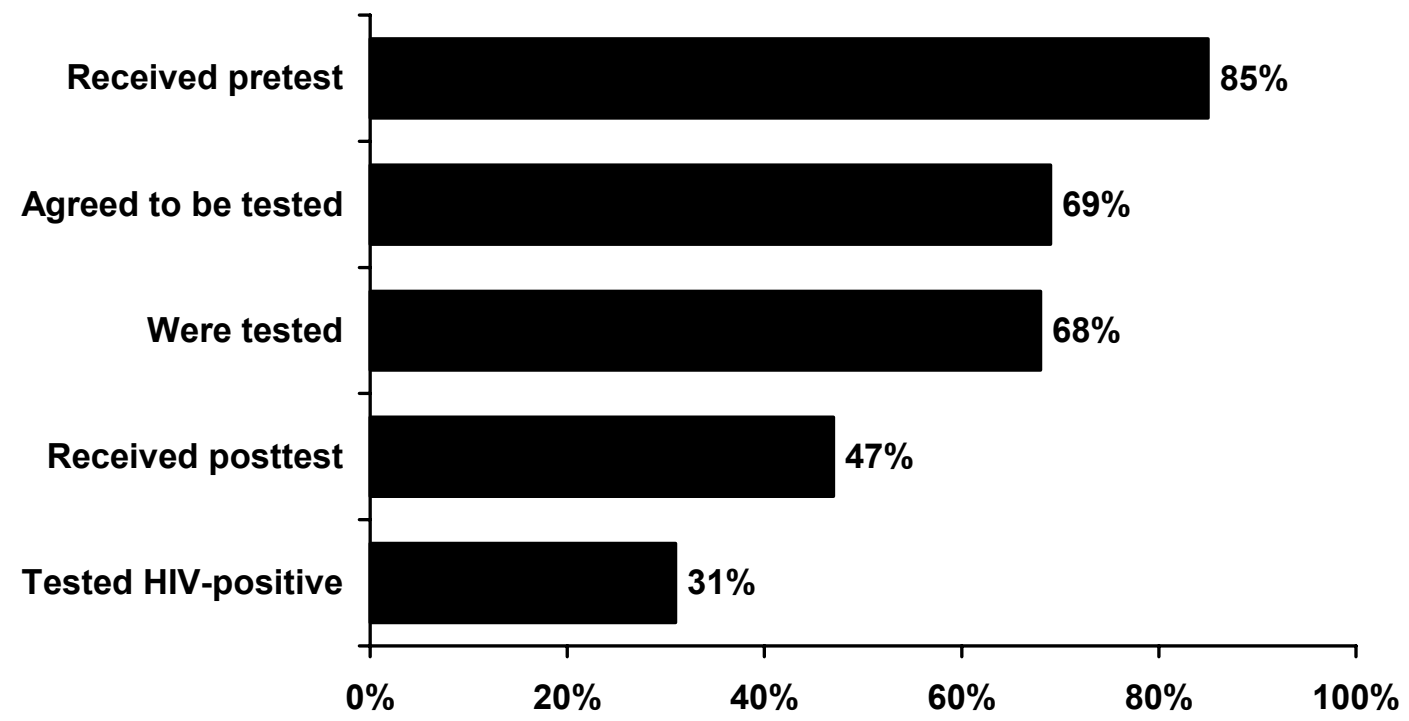

The counselor was female in 80 percent of the counseling sessions. Seventy-eight of these sessions were conducted by a lay counselor, 15 percent by nurses, 4 percent by HIV counselors, and 3 percent by other service providers. All of the counseling took place one-on-one, between the 
counselor and the client. Most counseling sessions also took place in an atmosphere of privacy. About 91 percent were held in a separate room, and 78 percent of the time the door was closed and in 69 percent of the sessions, the nurse observer judged that the discussion between the counselor and client could not be heard by others. However, in 23 percent of the 74 counseling sessions, the nurse observer recorded that an interruption occurred.

The mean time for clients who received pretest counseling sessions was 32 minutes, for those who received posttest counseling 14 minutes, and for those who received both pretest and posttest counseling, the mean time spent with a counselor was 39 minutes. However, the amount of time the counselors spent with HIV-positive clients and HIV-negative clients varied. With HIV-positive clients, they spent an average of 49 minutes, while with HIV-negative clients they spent an average of 35 minutes.

Figure 7.7 below shows some of the general actions taken by counselors during either the pretest or the posttest counseling sessions with 74 clients. In virtually all sessions, the observer felt that the counselor made an effort to establish rapport, and in 92 percent of the sessions the counselor assured the client that all information would be kept confidential. In about three-quarters of the sessions ( 76 percent), the counselor discussed the follow-up actions the client would need to take after counseling and summarized the decisions that had been made during the counseling session (73 percent). 


\section{${ }^{\mathrm{H}} \boldsymbol{K}^{\text {rizons }}$}

Figure 7.7 Percentage of 74 VCT provider-client interactions in which counselors take various actions

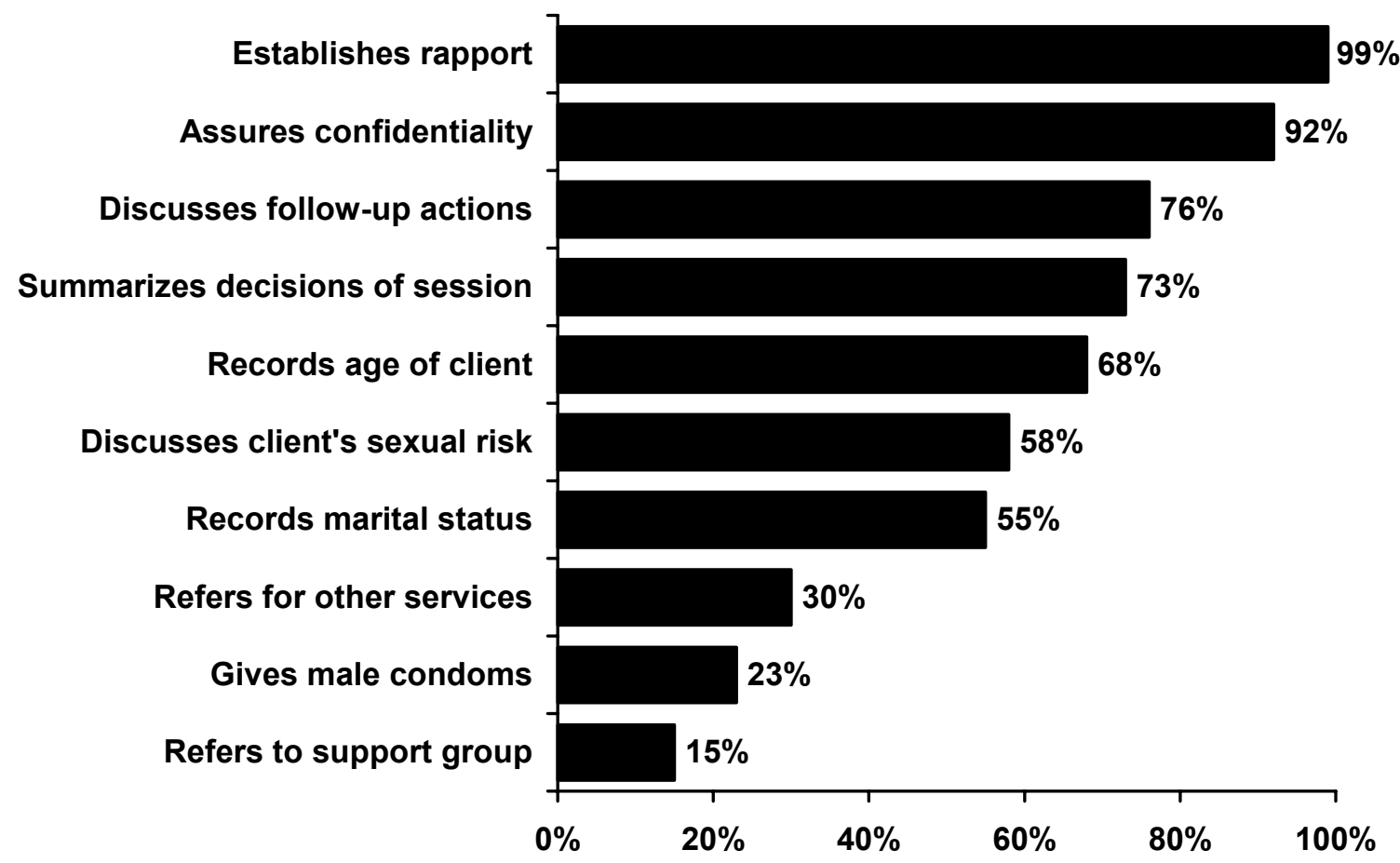

In slightly more than half of the $74 \mathrm{VCT}$ sessions, the counselor recorded the age of the client (68 percent), discussed the client's sexual risk behaviors ( 58 percent), and recorded the marital status of the client (55 percent). Far less frequently, however, did the counselor refer the client for other medical services (30 percent), give the client male condoms (23 percent), or refer the client to support groups (15 percent). When male condoms were given, the average number of condoms provided was 22 . The nurse observers were asked to rate the counselors' technical support skills and emotional support skills on a scale of 1 to 10, with 1 being low and 10 being high. The median score recorded by the nurse observers for the counselors' technical skills was 6 , while their median score for emotional support skills was 7 .

\section{Pretest Counseling}

Pretest counseling was given to 63 clients. The topics discussed during these counseling sessions are shown in Figures 7.8 and 7.9. 
KZN Situation Analysis

\section{Figure 7.8 Percentage of 63 VCT pretest counseling sessions in which various topics were discussed}

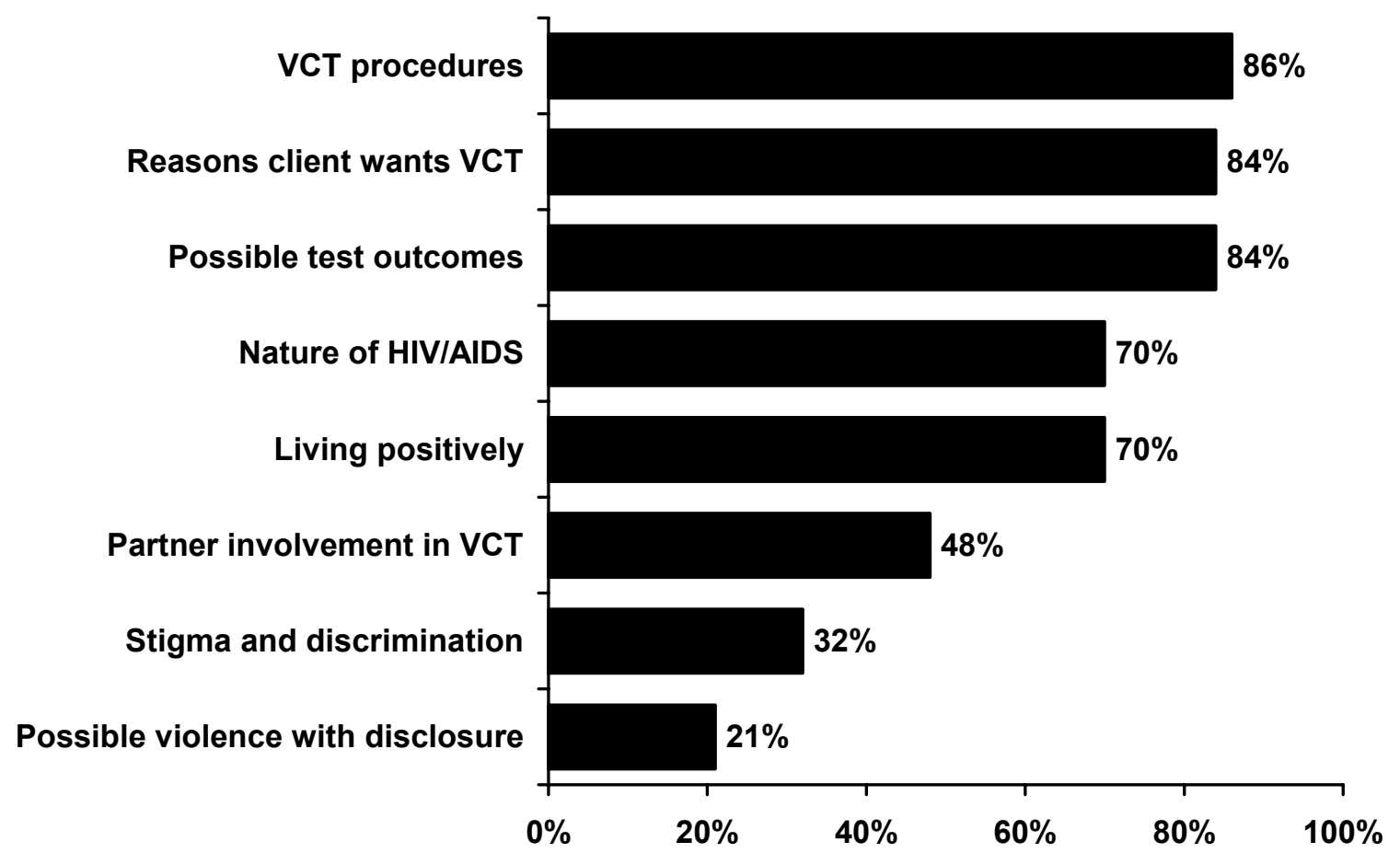

With more than 80 percent of the clients, the counselors discussed the VCT procedures, asked about the reasons the client wanted VCT, and reviewed the implications of possible HIV test outcomes. However, the counselors discussed the involvement of the client's partner in VCT with only about half the clients (48 percent). With 70 percent of the clients the counselors discussed the nature of HIV/AIDS and living positively if the client tested HIV-positive. However, stigma and discrimination were discussed in only 32 percent of the sessions, and possible violence as a result of public disclosure of a client's HIV-positive status was discussed in only 21 percent of the sessions.

Figure 7.9 shows the extent to which various HIV prevention strategies were discussed during the 63 pretest counseling sessions. In 68 percent of these sessions the counselor asked if the client knew about prevention strategies, and in 71 percent of the sessions the counselors discussed condom use as a means to prevent HIV transmission. However, in only 18 percent of the sessions was there also a discussion of condoms as a means of preventing pregnancy. While condom use with partners was discussed with 68 percent of the clients, the proper use of condoms was discussed with only 21 percent of the clients and condom use was demonstrated using a penis model in only 11 percent of the sessions. Finally, in only about a third of the counseling sessions were other strategies discussed besides condom use to prevent HIV transmission, namely, abstinence and monogamy. 


\section{Hgrizons}

Figure 7.9 Topics discussed in pretest counseling with 63 clients

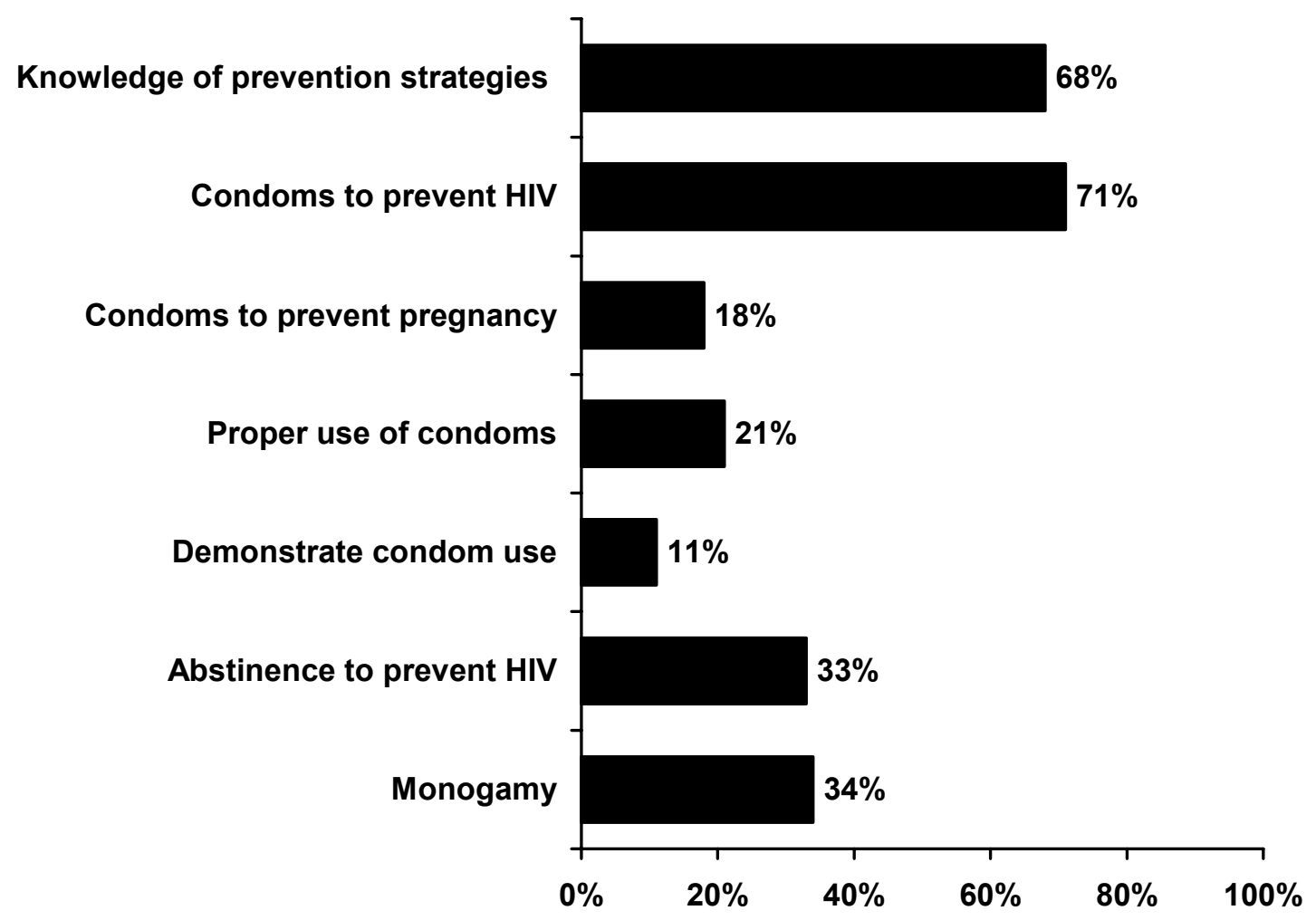

In summary, the counselors appear to do a very good job of establishing rapport, assuring confidentiality, discussing needed client actions, and summarizing decisions made during the counseling session. However, more attention probably needs to be given to discussing the clients' sexual risk behaviors and providing condoms to the clients. The primary prevention strategy discussed during the pretest sessions focused on condom use, and far less attention was given to proper use of condoms or to other prevention strategies such as abstinence and monogamy. Also, partner involvement in VCT was discussed with only half the clients, and difficult issues such as stigma, discrimination, and possible violence were discussed with less than a third of the clients. These latter areas probably need greater attention in the counseling sessions.

\section{Testing decisions}

During the pretest counseling, 31 clients, or about half (49 percent) of the 63 clients, asked the counselor what benefits the HIV test offered. Figure 7.10 shows the counselors' response to this question. 


\section{Figure 7.10 Benefits of HIV testing counselor mentions to 31 clients}

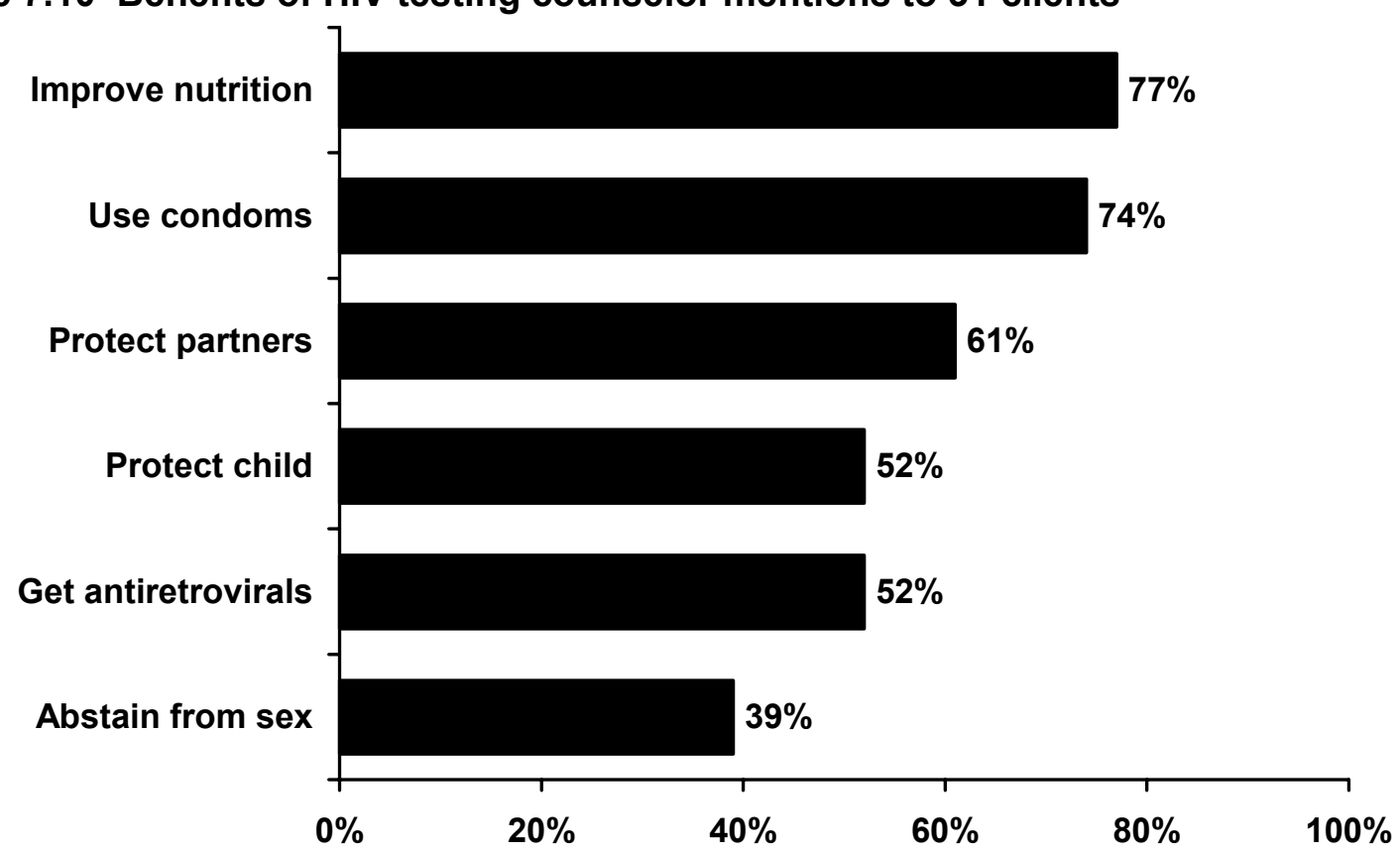

From the counselors' perspective, it is important for clients to know their status in order to develop a sound strategy for living positively. If the test was positive, the counselor mentioned to 77 percent of 31 clients that it was important to improve nutrition, and to 74 percent of the clients that it was crucial they use condoms consistently. In 61 percent of the interactions the counselors mentioned that the client needed to protect their partners, and in 52 percent of the sessions the counselors mentioned that knowing the clients' HIV status was important in order to protect a child if the mother was pregnant. Surprisingly, since antiretroviral drugs were not widely available in KwaZulu Natal at the time of the study, the counselors told 52 percent of the clients that knowing their HIV status was important because then the client would know whether they should start taking antiretroviral drugs. The counselors told 39 percent of the clients that if the test was positive, they should abstain from sex.

\section{Posttest Counseling}

Of the 50 clients who were tested, 49 received posttest counseling. Figure 7.11 shows the topics the counselors discussed with these clients. With all clients, the counselors explained the meaning of the HIV test, and with 92 percent of those clients, they assessed their understanding of the implications of the HIV test result. With 71 percent of the clients, the counselors discussed whether they wanted to disclose their HIV status. 


\section{Hgrizons}

With 74 percent of the posttest clients, the counselor mentioned the use of male or female condoms, but the proper use of condoms was discussed with only 22 percent of the clients and the actual use of a condom was demonstrated using a penis model with only 10 percent of the posttest clients. For all these topics there was no statistically significant difference between clients who tested HIV-positive and clients who tested HIV-negative. However, for the areas shown in Figure 7.12, there were statistically significant differences between HIV-positive and HIV-negative clients.

Figure 7.11 Topics discussed in posttest counseling (49 VCT clients)

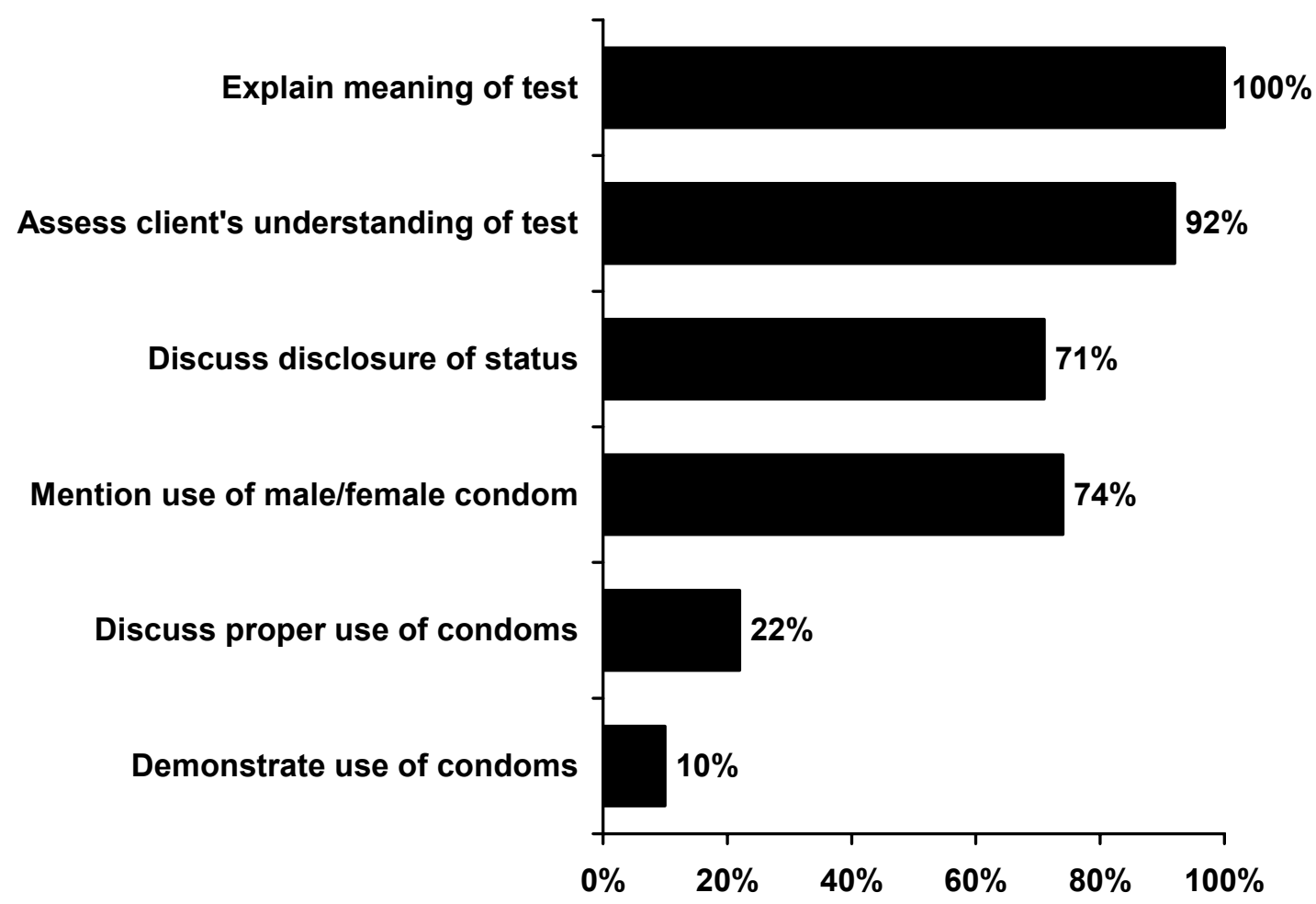


KZN Situation Analysis

Figure 7.12 Actions counselor takes during posttest with 23 HIV-positive and 26 HIV-negative clients (differences significant $p \leq .05$ )

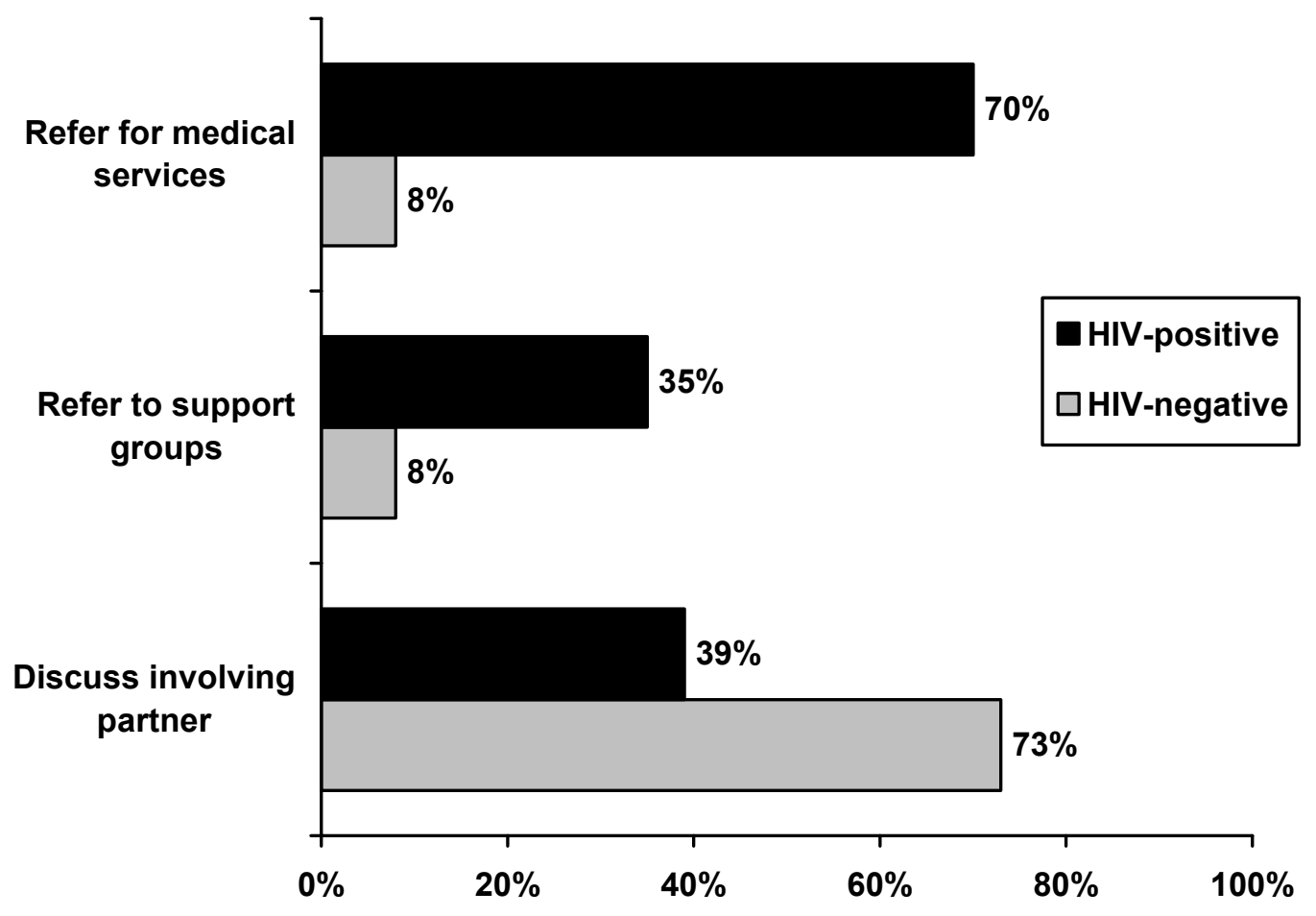

Not surprisingly, 70 percent of the HIV-positive clients were referred for medical services, but only 8 percent of the HIV-negative clients were referred for medical services. Also, 35 percent of the HIV-positive clients were referred to community support groups, but only 8 percent of the HIVnegative clients were referred to support groups. However, counselors were far more likely to encourage HIV-negative clients rather than HIV-positive clients to discuss the test results with their partner. Among the $26 \mathrm{HIV}$-negative clients who received posttest counseling, involvement of the partner was discussed with 19 of them, or 73 percent. Among the $23 \mathrm{HIV}$-positive clients, this topic was discussed with only 9 of them, or 39 percent. This difference was statistically significant (chi square test, $p \leq .02$ ). The reasons for this difference are not clear. One would think that counselors would recommend that HIV-positive clients involve their partners as much as they would recommend this action to HIV-negative clients The reason for this discrepancy may be that it is easier for HIV-negative clients to disclose their HIV status than for HIV-positive clients.

Figure 7.13 shows that with 84 percent of the 49 posttest clients, the counselors helped the clients establish an immediate plan of action either for maintaining an HIV-negative status or for living with an HIV-positive status. Also, with 80 percent of these clients the counselors discussed the need for a follow-up appointment, and with 71 percent they discussed sexual risk behaviors. However, the counselors actually gave condoms to only 31 percent these posttest clients. 


\section{${ }^{\text {Hrizons }}$}

Figure 7.13 Actions counselor takes with 49 posttest clients

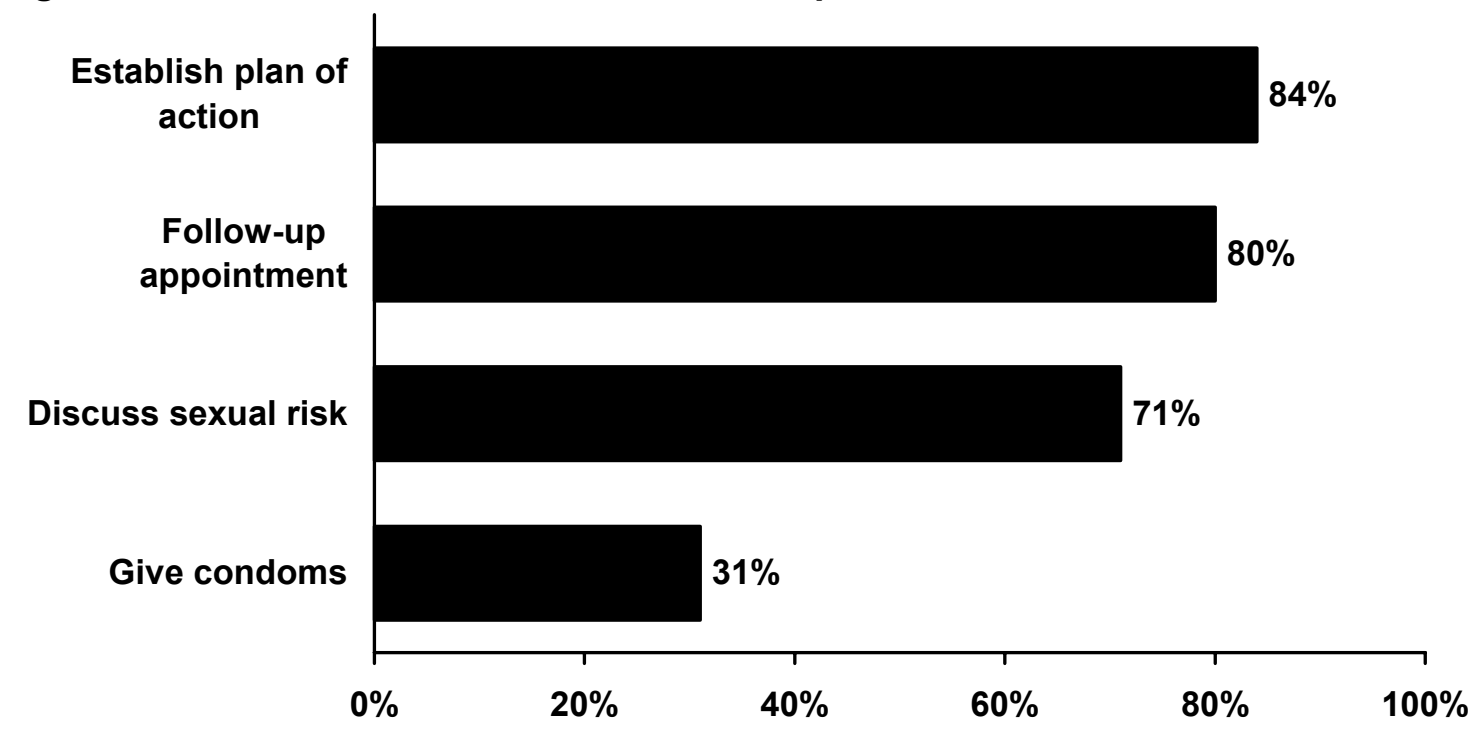

\section{Posttest counseling with HIV-positive clients}

Although the number of HIV-positive clients is small (23 clients), the counselor talked with these clients about several different topics during the posttest session. Table 7.2 shows the topics that were discussed. 
KZN Situation Analysis

\begin{tabular}{|c|c|c|}
\hline Topic discussed & $\begin{array}{c}\text { Number of } 23 \\
\text { clients with } \\
\text { whom topic was } \\
\text { discussed }\end{array}$ & $\begin{array}{l}\text { Percent of } 23 \\
\text { HIV-positive } \\
\text { clients with } \\
\text { whom topic was } \\
\text { discussed }\end{array}$ \\
\hline Living positively & 20 & 87 \\
\hline Client's need for other medical services & 20 & 87 \\
\hline Client's need for nutrition counseling & 16 & 70 \\
\hline Opportunistic infections & 14 & 61 \\
\hline Treatment options & 10 & 46 \\
\hline Referral to community support groups & 8 & 35 \\
\hline TB services & 6 & 27 \\
\hline Pregnancy and mother-to-child transmission & 6 & 26 \\
\hline Family planning services & 3 & 14 \\
\hline Possible violence as a result of disclosure & 3 & 14 \\
\hline
\end{tabular}

In almost all cases, the counselors engaged the client in a discussion of living positively with HIV and discussed the client's need to obtain other medical services. With 16 of the 23 clients the counselors discussed the need for the client to maintain good nutrition, and with 14 of the 23 clients the counselors discussed opportunistic infections and how to handle them. However, only 8 of the 23 clients were referred to community HIV/AIDS support groups, only 6 were given information on TB services or ways to prevent mother-to-child transmission of HIV, and only 3 received information on family planning or possible violence as a result of disclosure. These are all possible areas for improvement. Many HIV-positive people could benefit from being associated with a community support group. They also need to know about TB services, since this is one of the major opportunistic infections of HIV-positive people. Certainly discussions of family planning and prevention of mother-to-child transmission are needed with young, sexually active, HIVpositive women.

\section{Topics discussed with 27 HIV-negative clients during posttest counseling sessions}

Figure 7.14 shows that among the 27 clients who tested negative, counselors discussed the use of condoms with 93 percent, or 25 of the clients. However, other safe sex practices such as monogamy were discussed with only 36 percent of the clients, and abstinence was discussed with only 32 percent of the clients. 


\section{H ${ }^{\text {rizons }}$}

Figure 7.14 Safe sex topics discussed with 27 HIV-negative clients in posttest
counseling

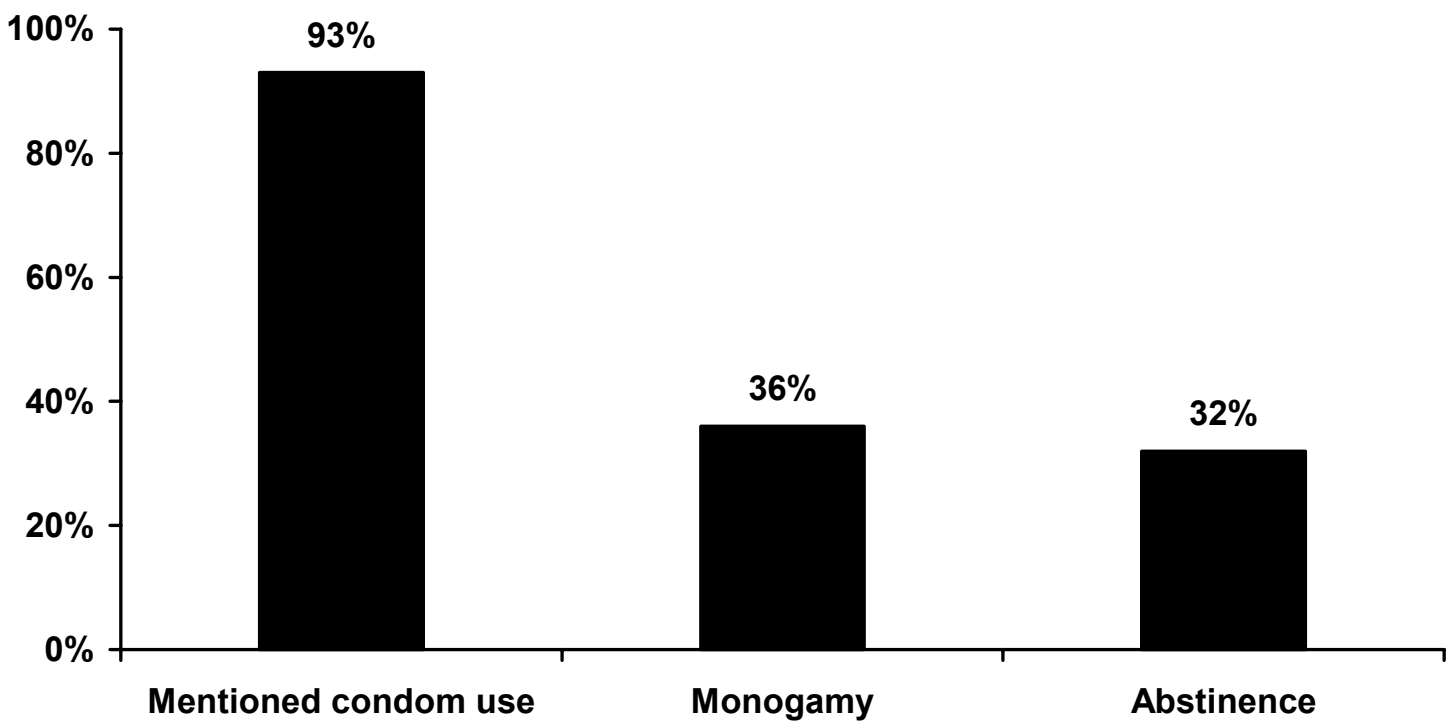

In summary, observers of the interaction between counselors and clients during VCT sessions saw that most clients received information about the testing process. The pretest sessions were approximately half an hour long and the post-test sessions lasted about 15 minutes. In most cases the counseling was conducted in a private setting. Most of the sessions were conducted by lay counselors who covered a variety of topics with the clients and made an effort to establish rapport and answer the clients' questions. With most clients sexual risk behaviors were discussed. Condom use was emphasized with about three-fourths of the clients as a prevention strategy, but abstinence or being faithful to one partner was discussed with only about one-third of the clients. With HIVpositive clients, the counselors talked about living positively, obtaining needed medical services, and maintaining good nutrition. They were less likely to refer these clients to community support groups or discuss difficult subjects such as stigma, discrimination, or possible violence as a result of disclosing their HIV status.

\section{Clients' Experience With and Views About Service Provision}

After the counseling session, 67 of the clients agreed to exit interviews. Of these clients, 78 percent were female and 86 percent said they were single. They ranged in age from 15 to 56 , with the median age being 26 years. For 45 percent of the clients this was their first visit to the facility providing VCT services. 
Among all 67 clients, only 42 percent said they had talked with someone previously about HIV testing, and 31 percent were accompanied by someone else when they came to the VCT center. Clients were asked where they learned about the availability of HIV counseling and testing. Figure 7.15 below shows the sources of information about VCT services most frequently mentioned. Multiple responses were possible.

Figure 7.15 Sources of information on VCT, 67 clients (multiple responses possible)

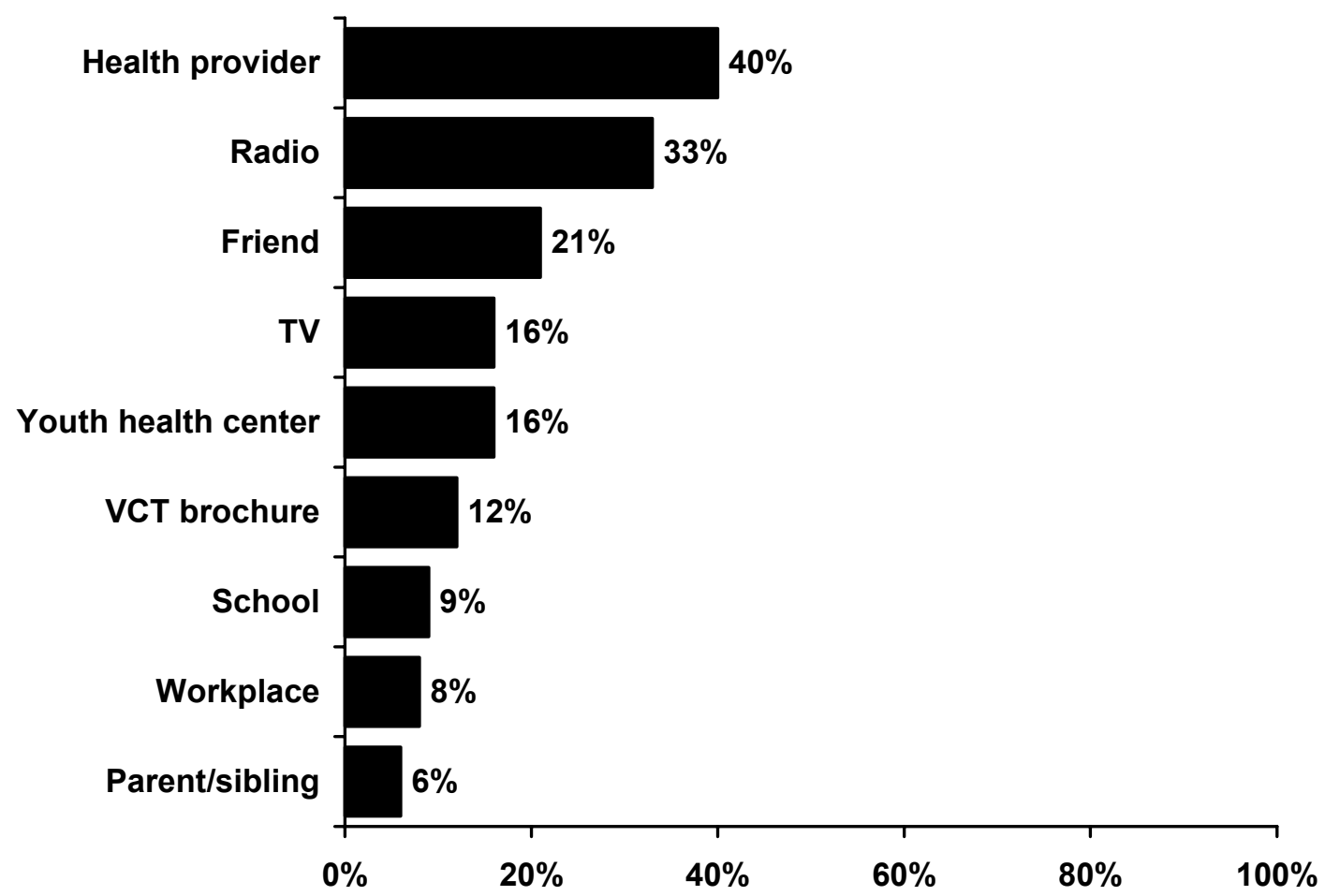

Looking at this figure and keeping in mind that only 42 percent of the clients said that they had previously talked with someone about HIV testing, one can see that there is relatively little interpersonal discussion with friends and relatives about HIV testing. While a third of the clients obtained information from the radio, only 21 percent received information from a friend and only 6 percent from a parent or sibling. The finding that 40 percent of the clients received VCT information from a health provider has important implications. It suggests that if all providers were to emphasize VCT to their clients, people might use this service much more frequently.

Figure 7.16 shows the major reasons listed by the 67 exit interview clients for coming to the VCT facility. Respondents could give multiple responses. Not surprisingly, about half the clients said they came to the VCT center because they wanted to know their HIV status. More than a third 


\section{Hgrizons}

came because they felt ill and suspected this might be related to HIV. Very few came because they were pregnant and wanted to know their status before delivery, or because they wanted to know their status before marriage.

Figure 7.16 Reasons 67 clients said they came to the VCT center

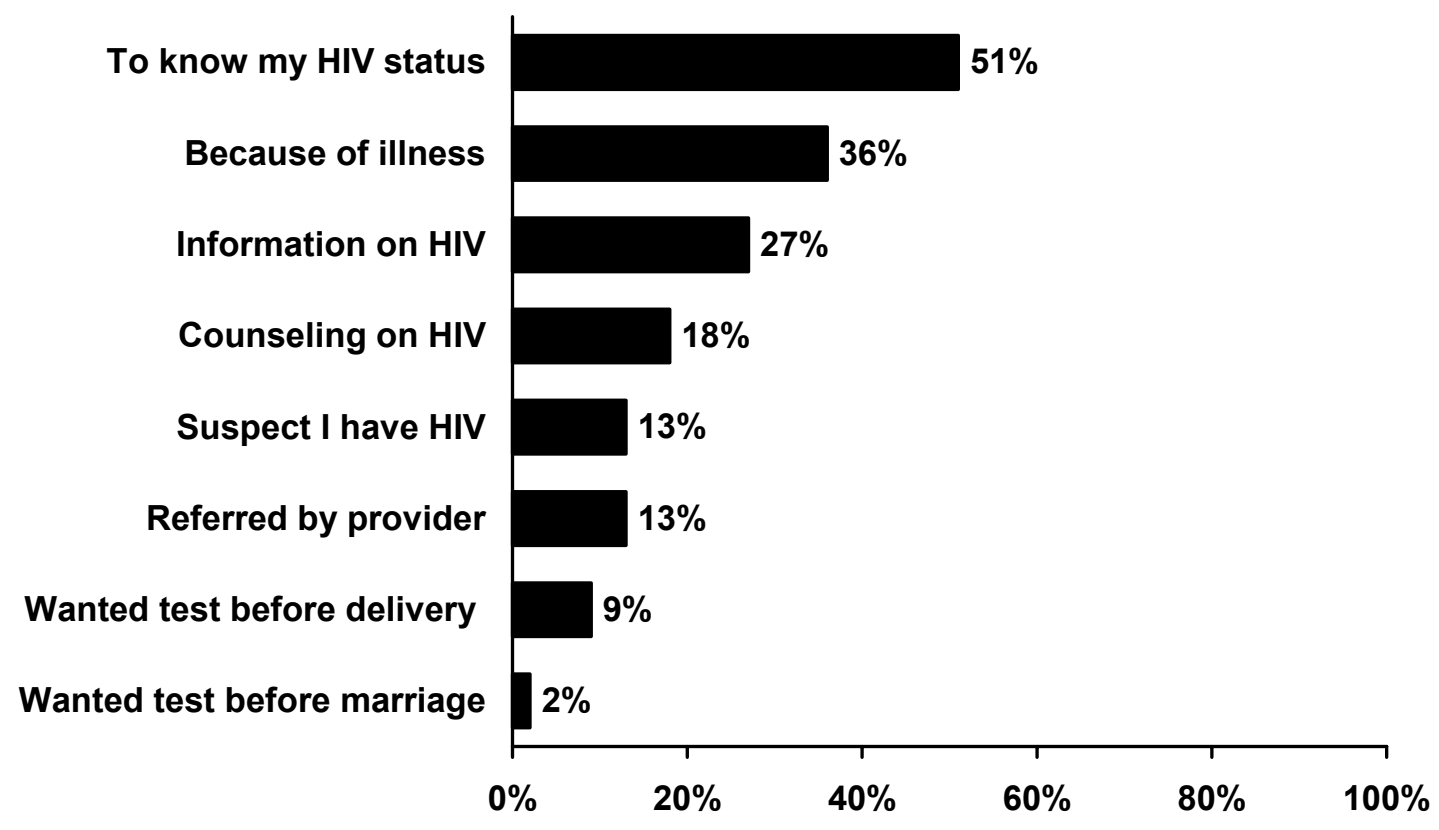

When asked about the services they received, 93 percent of the 67 clients interviewed after the VCT counseling session said they received HIV counseling and information, 63 percent said they received an HIV test, and 34 percent said they had previously been tested for HIV. Only 12 percent said they were given condoms.

Slightly more than three-fourths of the 67 clients (76 percent) said that they were referred by the counselor to specific services. Figure 7.17 shows the services they were referred to. About half of the 51 clients who were referred for services were asked to come back for more counseling and almost a third were asked to come back to the VCT facility for care and other support services. About a fifth (22 percent) were referred for specific treatments, 18 percent for initial HIV counseling, and 12 percent to a community support group. Among those referred for a service, 61 percent were told where to get the service and 77 percent were told when to get the service. 


\section{Figure 7.17 Services counselor refers 51 clients to receive}

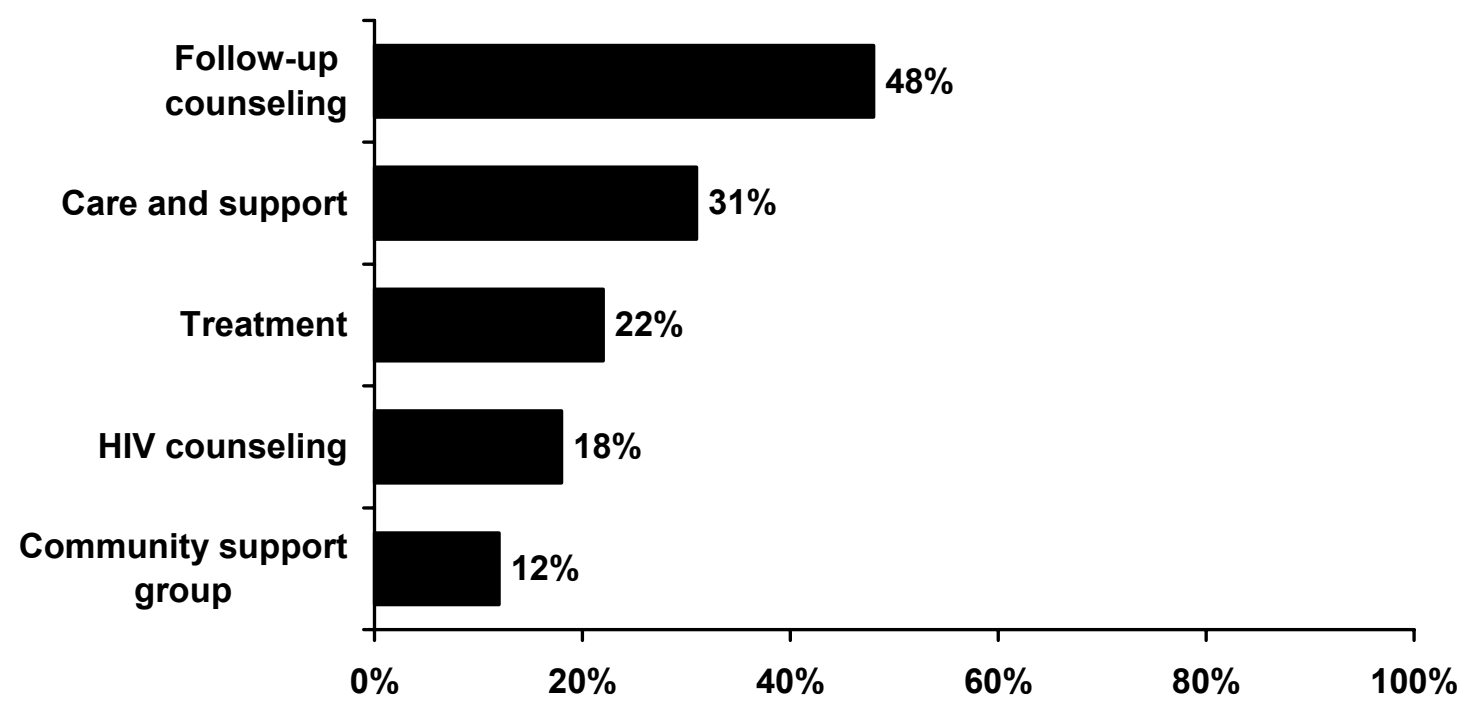

Table 7.3 below shows the perceptions of the 67 exit interview clients to the interaction with the counselor.

Table 7.3 Reports of 67 clients on the interaction with the counselor

\begin{tabular}{lc}
\hline Interaction with the counselor & $\begin{array}{c}\text { Percent } \\
\text { responding } \\
\text { yes }\end{array}$ \\
\hline Did the counselor greet you? & 97 \\
Did the counselor assure you of confidentiality? & 96 \\
Did the counselor encourage you to ask questions? & 94 \\
Did the counselor listen attentively? & 96 \\
Did you feel that the counselor gave you support? & 94 \\
Was the counselor respectful? & 100 \\
Did the counselor praise you for your courage to come for VCT? & 85 \\
Did you understand everything the counselor said? & 96 \\
Did the counselor give you enough time to ask questions? & 100 \\
Did the counselor respond to your concerns and worries? & 96 \\
Did the counselor criticize your sexual behavior? & 30
\end{tabular}




\section{${ }^{\text {Hrizons }}$}

From the clients' perspective, the interaction with the counselor was very positive. Table 7.3 clearly indicates that the clients felt they received emotional and psychological support from the counselors. Clients reported that they where greeted, assured of confidentiality, and encouraged to ask questions. They said that the counselor gave support to them, was respectful, listened and responded to their concerns, provided information that was understandable, gave praise for coming to the VCT center, and didn't rush them. However, despite the very favorable rating the 67 clients gave to the counselors' behavior, 30 percent of them did feel that the counselor criticized their sexual behavior.

Table 7.4 shows information about more specific discussions between the clients and counselors and about the actions of the counselors concerning condom use.

\section{Table 7.4 Reports of 67 clients on the discussions with and actions of counselors on condoms}

\begin{tabular}{lc}
\hline Discussion and actions on condoms & $\begin{array}{c}\text { Percent } \\
\text { responding } \\
\text { yes }\end{array}$ \\
\hline Did the counselor discuss use of condoms for protection against HIV/STIs? & 78 \\
Did the counselor discuss use of condoms for protection against pregnancy? & 67 \\
Did the counselor ask you if you use condoms? & 67 \\
Did the counselor give you any male condoms? & 22 \\
Did the counselor give you any female condoms? & 2
\end{tabular}

Although 78 percent of the clients reported that the counselors discussed condoms for the protection against HIV and STIs, only 67 percent reported that the counselor discussed the use of condoms for protection against pregnancy and only 67 percent said that the counselor asked them if they used condoms. However, only 22 percent of the clients said they were given male condoms and only 2 percent said they were given female condoms.

Table 7.5 shows the recollections of 60 clients about the topics discussed with the counselor during the pretest counseling session. 
KZN Situation Analysis

\section{Table 7.5 Recollections of 60 clients about topics discussed or actions taken} during pretest counseling

\begin{tabular}{lc}
\hline Topics discussed or actions taken during pretest counseling & $\begin{array}{c}\text { Percent } \\
\text { responding yes }\end{array}$ \\
\hline $\begin{array}{l}\text { Did the counselor give you information about the HIV testing } \\
\text { process? }\end{array}$ & 97 \\
Did the counselor discuss meaning of HIV-positive and -negative & 90 \\
results and implications? & 88 \\
Did the counselor discuss ways to prevent HIV infection? & 85 \\
Did the counselor ask what you would do if HIV test is positive? & 82 \\
Did the counselor give you information about the window period? & 72 \\
Did the counselor ask you questions about your sexual partner? & 63 \\
Did the counselor discuss having your partner come for testing? &
\end{tabular}

According to the reports from the 60 pretest clients, the counselors engage the clients in discussions of important topics related to HIV/AIDS. The decision to take an HIV test is not an easy one, and 90 percent of the clients reported that the counselors discussed the implications for their lives of a positive or a negative result. They also discussed ways to prevent infection with 88 percent of the clients and asked 85 percent of the clients what they would do if they tested HIVpositive. In addition, 82 percent of the clients reported that they were informed about the window period during which they might test HIV-negative but actually be HIV-positive. Finally, 72 percent of the clients reported that the counselors engaged them in discussions about their sexual partner, and 63 percent reported that the counselor discussed having the partner come for testing. All of these topics are important in helping clients make decisions about their health and their sexual behavior.

In the exit interviews with 67 clients, 70 percent, or 47 clients, said that they took an HIV test during the visit to the VCT center, and 39 said they received the results of the test. Among these 39 clients, 87 percent, or 34 clients said that they planned to disclose the results of the test to someone else. Table 7.6 shows the people with whom the 34 clients plan to share the results of their test. 


\section{Herizons}

Table 7.6 Persons with whom 34 clients said they would share results of HIV test

\begin{tabular}{lc}
\hline $\begin{array}{l}\text { Person with whom clients would disclose } \\
\text { HIV test results }\end{array}$ & $\begin{array}{c}\text { Percent mentioning } \\
\text { this person }\end{array}$ \\
\hline Partner & 41 \\
Mother & 41 \\
Sister & 18 \\
Spouse & 18 \\
Friend & 15 \\
Father & 3 \\
Brother & 3 \\
Other relative & 3
\end{tabular}

Most clients said that they would disclose their HIV status to their partner or their mother, (41 percent). Far fewer clients would disclose to a sister or a spouse (18 percent each), and only 15 percent of the clients said they would disclose to a friend. Clients were the least likely to disclose their status to a father, a brother, or other relative.

\section{Summary}

Compared with family planning, STI, or ANC services, relatively few clients access VCT services. Although about 52 percent of the 98 facilities offer VCT, the client load is relatively light. Overall, the infrastructure and equipment at facilities offering VCT is fairly good, with most facilities having basic equipment and supplies of drugs.

Among the 32 facilities where VCT clients were observed and interviewed, client load averages approximately 3 VCT clients a month. Far fewer mothers receive Nevirapine. Since VCT facilities are not overloaded, their client load probably could be increased without overburdening the system.

Most of the counseling (78 percent) is conducted by lay counselors in an atmosphere of privacy. Both the nurse observers of the counseling and the clients in exit interviews report that counselors are very attentive to establishing rapport, maintaining confidentiality, listening to clients' concerns, responding to those concerns, and giving support. These findings suggest that counselors are sensitive to the emotional needs of their clients.

In terms of topics discussed during pretest counseling sessions, counselors emphasized possible outcomes and implications of an HIV test, talked about living positively if the test were positive, and covered prevention strategies if the test were negative. With the clients whose test was negative, the counselors emphasized condom use (mentioned to 71 percent of 63 clients) but placed less emphasis on abstinence and monogamy (mentioned to approximately a third of the clients). In 
the posttest counseling, issues of disclosure and the use of condoms were discussed. With HIVpositive clients, the counselors discussed the need to live positively, obtain other medical services, and maintain good nutrition. Far less frequently did the counselors discuss referral to community groups, family planning services, or possible violence as a result of disclosure.

In exit interviews, clients said that their main source of information on VCT came from a health provider ( 40 percent), followed by radio ( 33 percent) and a friend ( 21 percent). Of the clients who were interviewed and had received the result of their HIV test, about 41 percent said they would discuss the test result with a partner or their mother, 18 percent would do this with their sister, and 15 percent would do this with a friend. These findings suggest that clients may be reluctant to discuss HIV test results with a friend or with some relatives. 


\section{Hgrizons}

\section{Chapter 8 \\ Follow-up}

Results of the study were presented to a large audience of DOH, NGO and donor agency staff in a dissemination workshop held at the Edward Hotel in Durban on 1-2 July 2003 (in collaboration with two other ANC related OR studies sponsored by the FRONTIERS Program). About 75 attendees representing the DOH, NGOs and donor agencies were welcomed by Dr. Eddy Mhlanga, (National Department of Health, Cluster Manager: Maternal, Child and Women's Health and Nutrition), who discussed the importance of the DOH at the national level seeing what is happening at the provincial level, and identifying how the national and provincial levels can work together. He also noted that research frequently is not disseminated to the health workers at the field level, and, commenting on the number of field workers who were in attendance at this meeting, expressed hope that this workshop will set a trend for feedback and the use of research for service improvement.

Workshop participants heard reports on the study methodology and the findings from each of the services-FP, ANC, STI/RTI, VCT. Lively discussion followed each of the presentations. The issues raised by participants with questions and discussion, organized by service, are noted below:

\section{Family planning}

- The quality of record keeping

- Discontinuation of FP use

- The possible de-prioritization of FP training

- The need to improve supervision

- Lack of privacy may be preventing the discussion of more sensitive topics

- Strengthening counseling on breastfeeding, and more sensitive partnership/HIV issues

- Little questioning about serostatus and little promotion of VCT

- Emergency contraception and LAM not being discussed

- Increased emphasis required on dual protection

- More comprehensive discussion of sexual risk and prevention strategies

- Services for the disabled

- Lack of screening for STIs and few examinations performed

ANC

- Integration of services

- Condom provision

- Gender violence

- Signs and symptoms of STIs

- The low provision of nevirapine compared to the need

- The high rate of STIs during pregnancy 
KZN Situation Analysis

\section{STI/RTI}

- Syndromic management and its implications for whether screening is necessary

- The efficacy of syndromic management for females

- The relevance of new, cheaper diagnostic tests to the South African situation

- The tendency for providers to blame men for STIs

\section{VCT}

- Poor collection of data in SDPs

- How to increase the demand for services

- The important role of health providers in promoting VCT

- The need to have people come earlier for VCT, before they are ill

- Strengthening condom promotion

- Strengthening counseling on more sensitive issues

- The curriculum of lay counselors

- Lack of referral to community support groups

- Issues around access to laboratory services and capacity

- The need to stress STI prevention during VCT services

- The amount of time spent in counseling

- The definition of "single" marital status

The second day of the workshop began with a panel of four DOH staff presenting their reactions to the findings, and their views on priority issues for follow-up. The panel members included Miss Janet Dalton (deputy director, MCWH), Dolly Nyasula (MCWH, Maternal Health), Mrs. Gcaba (Human Resource Development), and Mrs. Kay Naidoo (District Office, Durban Metropolitan). Ms. Dalton began the discussion by noting the many positive findings from the Situation Analysis study. She cited four areas in which substantial progress was noted in comparison to previous studies. These included: drug supply and management; equipment availability; client satisfaction and attitudes of providers; and the level of privacy which she considered surprisingly good considering existing infrastructural problems.

Workshop organizers requested the participants to make suggestions on policy, programs, and research for each of the four service areas, i.e. FP, ANC, STI/RTI, and VCT based on the presentations of research findings. The following matrix includes many of the participants' suggestions: 


\section{${ }^{H}$ rizons}

\begin{tabular}{|c|c|c|c|c|}
\hline Level & \multicolumn{4}{|c|}{ Service } \\
\hline & FP & ANC & STI & VCT \\
\hline Policy & $\begin{array}{l}\text { Eliminate condom } \\
\text { stock-outs. } \\
\text { Offer dual protection } \\
\text { to all clients. } \\
\text { Strengthen infection } \\
\text { control policy. } \\
70 \% \text { of all health } \\
\text { workers to be trained } \\
\text { in each service, } \\
\text { including medical } \\
\text { officers. }\end{array}$ & $\begin{array}{l}\text { Assure transport } \\
\text { availability for } \\
\text { emergency obstetric } \\
\text { cases. } \\
\text { Standardize package } \\
\text { of care offered at } \\
\text { various levels. } \\
\text { All hospitals provide } \\
\text { emergency obs. care. } \\
\text { Norms for coverage of } \\
\text { services with } \\
\text { advanced midwives. }\end{array}$ & $\begin{array}{l}\text { All STI clients tested } \\
\text { for RPR. } \\
\text { VCT offered to all STI } \\
\text { clients. }\end{array}$ & $\begin{array}{l}\text { Provide all HIV+ } \\
\text { pregnant women } \\
\text { nevirapine. }\end{array}$ \\
\hline Programs & $\begin{array}{l}\text { Promote better } \\
\text { contraceptive method } \\
\text { mix. } \\
\text { Provide training. } \\
\text { Community } \\
\text { messages re } \\
\text { methods available. } \\
\text { Develop standard } \\
\text { procedures for } \\
\text { exams. } \\
\text { Develop IEC } \\
\text { materials. } \\
\text { Improved counseling } \\
\text { for providers, esp. in } \\
\text { violence, rape, HIV, } \\
\text { STIs. }\end{array}$ & $\begin{array}{l}\text { Routine updates for all } \\
\text { service providers. } \\
\text { All women asked at } \\
\text { each visit about } \\
\text { prevention of HIV, } \\
\text { VCT, and presence of } \\
\text { signs of STIs. } \\
\text { Develop IEC } \\
\text { materials. } \\
\text { Make breast feeding } \\
\text { counseling more } \\
\text { available. } \\
\text { Routine ANC health } \\
\text { education messages } \\
\text { and materials. }\end{array}$ & $\begin{array}{l}\text { Provide penis model } \\
\text { in all services. } \\
\text { Demonstration of } \\
\text { condom use part of } \\
\text { routine services. } \\
\text { Develop standard } \\
\text { procedures for exams. } \\
\text { Increase screening of } \\
\text { all clinic/hospital } \\
\text { clients for STI. } \\
\text { Improve counseling } \\
\text { skills. }\end{array}$ & $\begin{array}{l}\text { Increase in-service } \\
\text { training for all } \\
\text { providers, } \\
\text { especially } \\
\text { midwives. } \\
\text { Improve ability of } \\
\text { programmes at } \\
\text { Provincial and } \\
\text { district level to work } \\
\text { together. } \\
\text { Improve interface of } \\
\text { lay counselors and } \\
\text { other providers. } \\
\text { Develop support } \\
\text { groups. }\end{array}$ \\
\hline Research & $\begin{array}{l}\text { Investigate services } \\
\text { needed by people } \\
\text { under } 16 \text { years. } \\
\text { Best training } \\
\text { practices to change } \\
\text { offering of method } \\
\text { mix, and providing } \\
\text { service to young } \\
\text { people. } \\
\text { Post-training } \\
\text { evaluation at } 6 \\
\text { months, and } 12 \\
\text { months. }\end{array}$ & $\begin{array}{l}\text { IEC method } \\
\text { acceptability. } \\
\text { Cultural issues } \\
\text { surrounding every } \\
\text { ANC attendance. }\end{array}$ & $\begin{array}{l}\text { Assess feasibility of } \\
\text { using new, simple } \\
\text { diagnostics for } \\
\text { women. } \\
\text { Evaluate current IEC } \\
\text { materials. } \\
\text { Post-training } \\
\text { evaluation at } 6 \\
\text { months and } 12 \\
\text { months. }\end{array}$ & $\begin{array}{l}\text { How to increase } \\
\text { MTCT services for } \\
\text { HIV+. } \\
\text { Investigate } \\
\text { judgmental } \\
\text { statements made by } \\
\text { counselors. }\end{array}$ \\
\hline
\end{tabular}


Many suggestions were captured on newsprint during the panel presentation (as above). After the panel members presented, the discussion was opened for the all participants to add to the list of suggestions. They added dozens of additional suggestions. This large list of suggestions was prioritized through the following group process mechanism: each participant was given five "stickers" and was invited to attach these to what they viewed as their five highest priority issues for follow-up.

As is usually the case in work settings where opportunities for presenting staff concerns directly to departmental leadership are infrequent, two types of suggestions were received - suggestions that related directly to the data presented, and other general or specific staff concerns related to working conditions or morale. Although the staff concerns may have an important impact on services, they did not necessarily arise specifically as a result of the study findings.

The suggestions for priority issues for follow-up are presented below in two Tables (8.1 and 8.2): Suggestions for follow-up directly related to the Situation Analysis (and ANC) studies, and General suggestions of staff interest and concern for follow-up, respectively. Only suggestions that received five or more votes from the participants are included. 


\section{Hgrizons}

Table 8.1 Suggestions for priority issues for follow-up directly related to the Situation Analysis study findings (and votes received for each)

\begin{tabular}{|c|c|}
\hline Votes & Priority issues for follow-up \\
\hline 25 & Strengthen community, male, and youth involvement in $\mathrm{RH}$ programs. \\
\hline 21 & $\begin{array}{l}\text { Strengthen supportive supervision for nurses through establishing supervisory } \\
\text { positions with transport. }\end{array}$ \\
\hline 14 & Increase information and emphasis on VCT and MTCT in ANC services. \\
\hline 13 & $\begin{array}{l}\text { Provide counseling training for all health care providers (and include counseling for } \\
\text { abuse and violence). }\end{array}$ \\
\hline 10 & Offer VCT and STI at every contact with clients in all RH services. \\
\hline 10 & $\begin{array}{l}\text { Increase gender sensitivity in RH services to increase male friendliness of VCT and } \\
\text { STI services. }\end{array}$ \\
\hline 10 & $\begin{array}{l}\text { Restart training of midwives as service providers and explore roles for utilizing } \\
\text { traditional birth attendants. }\end{array}$ \\
\hline 9 & $\begin{array}{l}\text { Improve communication and linkage with private sector practitioners and create } \\
\text { access to records and ANC cards. }\end{array}$ \\
\hline 8 & $\begin{array}{l}\text { Reconsider policies on confidentiality vs. partner protection regarding disclosure of } \\
\text { VCT results. }\end{array}$ \\
\hline 8 & HRD explore creative ways of providing in-service training. \\
\hline 7 & Strengthen youth friendliness, especially for clients under 16. \\
\hline 6 & Explore ways to reduce waiting times. \\
\hline 5 & Evaluate curricula for lay VCT counselors. \\
\hline
\end{tabular}

Table 8.2 General suggestions of staff interests and concerns for follow-up (and votes received for each)

\begin{tabular}{cl}
\hline Votes & \multicolumn{1}{c}{ Priority issues for follow-up } \\
\hline 36 & $\begin{array}{l}\text { Improve "care for the care-givers" through developing a more supportive } \\
\text { environment for providers, attending to health, welfare, and problems of staff related } \\
\text { to workload and number of staff per facility. }\end{array}$ \\
19 & Address staff exodus and turnover. \\
14 & Develop more creative use of resources in determining staff workload. \\
6 & Develop a policy on what "one nurse can do."
\end{tabular}

The Horizons Program is planning to provide support for work on these topics that is likely to lead to OR studies to explore ways of strengthening the HIV/AIDS prevention efforts in the KwaZulu Natal Province. 
KZN Situation Analysis

\section{References}

\section{Chapter 1}

Adar, J. and M. Stevens. 2000. Women's Health in South African Health Review 2000. Durban: Health Systems Trust.

Askew, I., G. Fassihan, and N.D. Maggwa. 1998. "Integrating STI and HIV/AIDS Services at MCH/Family Planning Clinics," in Clinic-Based Family Planning and Reproductive Health Services in Africa: Findings from Situation Analysis Studies, eds. K. Miller et al. New York: Population Council.

Barron, P. and U. Sankar. 2000. Developments towards a District Health System in South African Health Review 2000. Durban: Health Systems Trust.

Miller, K. et al. 1998. Clinic-Based Family Planning and Reproductive Health Services in Africa: Findings from Situation Analysis Studies. New York: Population Council.

Ministry of Health et al. 2000. Kenya Service Provision Assessment Survey 1999. Calverton, Maryland: ORC Macro.

Nhan, Vu Quy et al. 2000. A Situation Analysis of Public Sector Reproductive Health Services in Seven Provinces of Vietnam, Prepared for Ministry of Health and UNFPA, The Population Council, Hanoi.

SAHR. 2000. South African Health Review 2000. Durban: Health Systems Trust.

SAHR. 2002. South African Health Review 2002. Durban: Health Systems Trust.

Viljoen, R. et al. 2001. The National Primary Health Care Facilities Survey 2000. Durban: Health Systems Trust.

\section{Chapter 2}

SAHR. 2000. South African Health Review 2000. Durban: Health Systems Trust.

\section{Chapter 4}

Adar, J. and M. Stevens. 2000. "Women's Health," in South African Health Review 2000. Durban: Health Systems Trust. 


\section{${ }^{H}$ rizons}

Blacker, J.G.C. 1987. "Health impacts on family planning," Health Policy and Planning 2: 193203.

Bruce, J. 1990. "Fundamental elements of the quality of care: A simple framework." Studies in Family Planning 21(2): 61-91.

Department of Health. 2000. "The primary health care package for South Africa: A set of norms and standards." Pretoria. Available at http://www.doh.gov.za/docs.

ICPD. 1994. "Synthesis of regional population conferences convened as part of the substantive preparations for the International Conference on Population and Development." Population Bulletin United Nations 37-38: 3-19.

Ronsmans, C. and O. Campbell. 1998. "Short birth intervals don't kill women: Evidence from Matlab, Bangladesh," Studies in Family Planning 29(3): 282-290.

Trussell, J. and A.R. Pebley. 1984. "The potential impact of changes in fertility on infant, child, and maternal mortality," Studies in Family Planning 15(6): 267-279.

Walsh, T.D. et al. 1998. "Randomized controlled trial of prophylactic antibiotics before insertion of intrauterine devices: IUD Study Group." Lancet 351(9,108): 1,005-1,008.

\section{Chapter 5}

Adar, J. and Stevens M. 2000. "Women's Health" in South African Health Review 2000. Durban: Health Systems Trust.

Alexander, S. and M.J.N.C. Keirse. 1989. "Formal risk scoring during pregnancy," in Effective Care in Pregnancy and Childbirth, I. Chalmers, M. Enkin, and M.J.N.C. Keirse. Oxford: Oxford University Press, pp. 345-365.

Brunham, R.C., K.K. Holmes, and D. Eschenback. 1984. "Sexually transmitted diseases in pregnancy," in Sexually Transmitted Diseases, ed. K.K. Holmes et al. New York: McGraw-Hill.

Dallabetta, G., A.C. Gerbase, and K.K. Holmes. 1998. "Problems, solutions, and challenges in syndromic management of sexually transmitted diseases," Sexually Transmitted Infections 74: S1S12.

Department of Health and National Committee for Enquires into Maternal Deaths. 2000. Second Interim Report on Confidential Enquiries into Maternal Deaths in South Africa-Maternal Deaths in 1999, Pretoria. 


\section{KZN Situation Analysis}

Fortney, J.A. and J.B. Smith. 1999. "Measuring maternal morbidity," in Safe Motherhood Initiatives: Critical Issues. Berer M and Ravindran TKS, eds. Oxford, England, Blackwell Science Ltd., pp. 43-50.

Gerbase, A.C. et al. 1998. "Global prevalence and incidence estimates of selected curable STDs," in Sexually Transmitted Infections, 74: S12-S16.

Hauth, J.C. et al. 1995. "Reduced incidence of pre-term delivery with Metronidazole and Erythromycin in women with bacterial vaginosis,". New England Journal of Medicine, 333(26): $1,732-1,736$.

Hillier, S.L. et al. 1995. "Association between bacterial vaginosis and pre-term delivery of a lowbirth-weight infant,”. New England Journal of Medicine 333(26): 1,737-1,742.

Laga, M. 1992. "Human immunodeficiency virus infection prevention: The need for complementary sexually transmitted disease control," in Reproductive Tract Infections: Global Impact and Priorities for Women's Reproductive Health, ed. A. Germain et al. New York: Plenum Press, pp. 131-144.

Lumley, J. et al. 2003. "Periconceptional supplementation with folate and/or multivitamins for preventing neural tube defects (Cochrane Review)," in The Cochrane Library, Issue 1. Oxford: Update Software.

Mahomed, K. 2003. "Folate supplementation in pregnancy (Cochrane Review)," in The Cochrane Library, Issue 1. Oxford: Update Software.

Martin, D.H. et al. 1982. "Prematurity and perinatal mortality in pregnancies complicated by maternal Chlamydia trachomatis infection," The Journal of the American Medical Association 247(11): 1,585-1,588.

Rooks, J. and B. Winikoff. 1990. A Reassessment of the Concept of Reproductive Risk in Maternity Care and Family Planning Services. New York: Population Council.

Rooks, J.P. et al. 1989. "Outcomes of care in birth centers: The National Birth Center study," New England Journal of Medicine 321: 1,804-1,811.

Rooney, C. 1992. Antenatal care and Maternal Health: How Effective Is It? A Review of the Evidence. Geneva, Switzerland: World Health Organization, Division of Family Health, Maternal Health and Safe Motherhood Programme 92.4.

Sloan, N.L. et al. 2000. "Screening and syndromic approaches to identify gonorrhea and chlamydial infection in women,” Studies in Family Planning, 31(1): 55-68.

Sloan, N.L., E. Jordan, and B.Winikoff. 2002. "The effects of iron supplementation on maternal hematologic status in pregnancy," American Journal of Public Health, 92(2): 288-293 


\section{Hgrizons}

Starrs, A. 1998. The Safe Motherhood Action Agenda: Priorities for the Next Decade. New York: Safe Motherhood Interagency Group.

van Dam, C.J. et al. 1998. "Syndromic approach to STD case management: Where do we go from here?," Sexually Transmitted Infections, 74: S175-S178.

Villar, J. et al. 2001. "WHO antenatal care randomised trial for the evaluation of a new model of routine antenatal care," The Lancet, 357(9,268): 1,551-1,564.

Wang, E., and F. Smaill. 1989. "Infection in Pregnancy," in Effective Care in Pregnancy and Childbirth, Volume 1, ed. I. Chalmers, M. Enkin, M.J.N.C. Keirse. Oxford: Oxford University Press, pp. 534-564.

WHO/UNICEF. 1996. Revised 1990 Estimates of Maternal Mortality: A New Approach by WHO and UNICEF. Geneva: WHO.

World Health Organization. 1996. Development and Research Training in Human Reproduction (HRP) Biennial Report 1994-1995, UNDP/UNFPA/WHO/World Bank Special Programme of Research. Geneva: WHO.

\section{Chapter 6}

Brunham, R.C., K.K. Holmes, and D. Eschenback. 1984. "Sexually transmitted diseases in pregnancy," in Sexually Transmitted Diseases, K.K. Holmes et al. New York: McGraw-Hill.

Dallabetta, G., A.C. Gerbase, and K.K. Holmes. 1998. "Problems, solutions, and challenges in syndromic management of sexually transmitted diseases," Sexually Transmitted Infections 74: S1S12.

Hauth, J.C. et al. 1995. "Reduced incidence of pre-term delivery with Metronidazole and Erythromycin in women with bacterial vaginosis," New England Journal of Medicine 333(26): $1,732-1,736$.

Hillier, S.L. et al. 1995. "Association between bacterial vaginosis and pre-term delivery of a lowbirth-weight infant,” 333(26): 1,737-1,742.

Laga, M. 1992. "Human immunodeficiency virus infection prevention: The need for complementary sexually transmitted disease control," in Reproductive Tract Infections: Global Impact and Priorities for Women's Reproductive Health, ed. A. Germain et al. New York: Plenum Press, pp. 131-144.

Mabey, D. and R.W. Peeling. 2002. "Rapid diagnostics tests for sexually transmitted infections," 36: $1-3$ 


\section{KZN Situation Analysis}

Martin, D.H. et al. 1982. "Prematurity and perinatal mortality in pregnancies complicated by maternal Chlamydia trachomatis infection," Journal of the American Medical Association, 247(11): 1,585-1,588.

SDI (The Sexually Transmitted Diseases Diagnostics Initiative). 2003. Laboratory-Based Evaluation of Rapid Syphilis Diagnostics Manual of Operations. UNDP/World Bank/WHO Special Programme for Research and Training in Tropical Diseases (TDR). Geneva.

Sloan, N.L. et al. 2000. "Screening and syndromic approaches to identify gonorrhea and chlamydial infection in women," 31(1): 55-68.

van Dam, C.J. et al. 1998. "Syndromic approach to STD case management: Where do we go from here?," 74: S175-S178.

Wang, E. and F. Smaill. 1989. "Infection in pregnancy," in Effective Care in Pregnancy and Childbirth, Volume 1, ed. I. Chalmers, M. Enkin, and M.J.N.C. Keirse. Oxford: Oxford University Press, pp. 534-564.

World Health Organization. 1999. Laboratory Diagnosis of Sexually Transmitted Diseases. Geneva: WHO.

World Health Organization. Guidelines for Evaluation of Rapid Diagnostic Tests for Sexually Transmitted Infections, in press.

World Health Organization. 1996. Development and Research Training in Human Reproduction (HRP) Biennial Report 1994-1995. UNDP/UNFPA/WHO/World Bank Special Programme of Research. Geneva: WHO.

WPRO. 1999. Laboratory Tests for the Detection of Reproductive Tract Infections http://www.who.org.ph. Geneva: WHO.

\section{Chapter 7}

Allen, S. et al. 2003. "Sexual behavior of HIV discordant couples after HIV counseling and testing," 17(5): 733-40.

Chama, S. and I. Kayawe. 2000. "Sharing HIV test results with future and current marriage partners in Zambia," Sex Health Exchange 1: 7-8.

Forsyth, A.D. et al. 2002. "HIV infection and pregnancy status among adults attending voluntary counseling and testing in two developing countries," American Journal of Public Health 92(11): 1,795-1,800. 


\section{Hgrizons}

Ginwalla, S.K. et al. 2002. "Use of UNAIDS tools to evaluate HIV voluntary counselling and testing services for mineworkers in South Africa," 14(5): 707-726.

Kowalczyk, J. et al. 2002. "Voluntary counseling and testing for HIV among pregnant women presenting in labor in Kigali, Rwanda," Journal of Acquired Immune Deficiency Syndrome 31(4): 408-415.

Matovu, J.K. et al. 2002. "The Rakai Project counseling program experience," Tropical Medicine International Health 7(12): 1,064-1.067.

Myer, L. et al. 2003. "Structural and community-level interventions for increasing condom use to prevent HIV and other sexually transmitted infections (Protocol for a Cochrane Review)," The Cochrane Library, Update Software, Issue 2, Oxford.

Pronyk, P.M. et al. 2002. "Introduction of voluntary counselling and rapid testing for HIV in rural South Africa: From theory to practice," AIDs Care 14(6): 859-865.

Sweat, M. 2003. "Counseling and testing for preventing HIV infection (Protocol for a Cochrane Review)," The Cochrane Library, Issue 2, Update Software, Oxford.

Zachariah, R. et al. 2003. "Voluntary counselling, HIV testing and sexual behaviour among patients with tuberculosis in a rural district of Malawi," International Journal of Tuberculosis and Lung Disease 7(1): 65-71. 
KZN Situation Analysis

\section{Appendix}

\section{Population Council/ Dept of Health Dissemination Workshop 1 - 2 J uly 2003}

\section{List of Attendees}

\begin{tabular}{|c|c|c|c|c|c|}
\hline & Name & Organisation & Position & Telephone & Cellular \\
\hline 1 & Prof. Ahmed Z & DOH Intern & DD & 0333952756 & 0834571233 \\
\hline 2 & Badal R & DOH & DD & 0333952466 & \\
\hline 3 & Baloyi NH & Ekhombe PHC & PHC Trainer & 0358342076 & 0827403147 \\
\hline 4 & Baloyi SE & Stenga Hospital & & & 0806639064 \\
\hline 5 & Dr. Bekinska M & RHRU & Director & 0313048383 & 0827793134 \\
\hline 6 & Buthelezi NM & Ulundi District & AD Program & 0358742445 & 0731415377 \\
\hline 7 & Dr. Chege Jane & Pop Council & Program Associate & 0113250647 & 0825122138 \\
\hline 8 & de Klerk E & DOH - National & & & \\
\hline 9 & $\begin{array}{l}\text { Dube-Nxumalo } \\
\text { EM }\end{array}$ & RHRU & DD & 0313048383 & 0833613341 \\
\hline 10 & Florence & Ceza Hospital & $\mathrm{CPN}$ & $0358320001 / 2$ & 0837238384 \\
\hline 11 & Gcaba RS & DOH - HO & HRD - PHLDD & 0333952723 & 0839676469 \\
\hline 12 & Glajchen S & CHESS/CRH & Trainer/Facilitator & 0312601569 & \\
\hline 13 & Gosa Eva & $\mathrm{NDOH}$ & DD & 0124019670 & 0824507334 \\
\hline 14 & Govender T & Epidemiology & Specialist & 0333953003 & 0834681301 \\
\hline 15 & Gumede NA & & $\mathrm{CPN}$ & 0319078258 & 0833593108 \\
\hline 16 & Gumede RF & $\mathrm{DOH}$ & Fieldworker & 0334440818 & 0839678617 \\
\hline 17 & Hall Wendy & HST & Researcher & 0333943363 & 0828213675 \\
\hline 18 & Howard C & HRD - DOH & PMC & 0313322425 & 0837310625 \\
\hline 19 & Julius LC & $\mathrm{DOH}-\mathrm{D} 22$ & CPN - PHC Trainer & 0333457576 & 0828501048 \\
\hline 20 & Khanyile N & & $\mathrm{CPN}$ & 0315631236 & 0733079538 \\
\hline 21 & Koti G & DOH / Prov. AIDS Unit & $\mathrm{AD} / \mathrm{STI}$ & 0333940287 & 08346990017 \\
\hline 22 & Kunene B & RHRU & Project Coordinator & 0313048383 & 0832258484 \\
\hline 23 & Makho & DOH - DO & $\mathrm{DD}$ & 0315721368 & 0826508418 \\
\hline 24 & Matanhire D & CRH UniNatal & $\begin{array}{l}\text { Facilitator } \\
\text { Researcher }\end{array}$ & & 0825404708 \\
\hline 25 & Matebula N & RHRU & Researcher & 0313048383 & 0837103868 \\
\hline 26 & Mathe ZM & $\mathrm{DOH}$ & $\mathrm{RM}$ & 0349814892 & \\
\hline 27 & Mathebula CB & PSA & & & 0829583333 \\
\hline 28 & Mathebula TD & DOH WHT & Midwife & 0349331509 & 0725884674 \\
\hline 29 & Mbambo S & DC 26 & Coordinator & 0358730303 & 0833154778 \\
\hline 30 & Mchunu M & DOH Health & $\mathrm{AD}$ & 0357722417 & 0825028082 \\
\hline 31 & Mfeka N & $\mathrm{DOH}$ & Fieldworker CPN & 0333993181 & 0722478309 \\
\hline 32 & Dr. Mhlanga RE & & & & \\
\hline 33 & Mjali V & Population Council & Admin Assist & 0113419400 & 0113250647 \\
\hline 34 & Mkhulise & $\mathrm{DOH}$ & $\mathrm{CPN}$ & 0366377948 & 0836666730 \\
\hline 35 & Mkhungo JH & $\mathrm{DOH}$ & $\begin{array}{l}\text { CPN Facility } \\
\text { Manager }\end{array}$ & 0396991130 & 0824066162 \\
\hline 36 & Prof Moodley J & DOH - PMTCT & DIR & 0313077225 & \\
\hline 37 & Dr Moodley L & UniNatal Medical Sc. & Specialist & 0312604395 & \\
\hline
\end{tabular}




\section{${ }^{\mathrm{H}}$ rizons}

\begin{tabular}{|c|c|c|c|c|c|}
\hline 38 & Ms Moodley V & Health Promotion & DD & 0333952132 & 0834571166 \\
\hline 39 & Mpisane B & & SPN & 0393182118 & 0833290903 \\
\hline 40 & Msolo NC & $\mathrm{CRH}$ & $\begin{array}{l}\text { National Health } \\
\text { Coordinator }\end{array}$ & 0313322425 & 0835561763 \\
\hline 41 & Mthe SG & MP & & & 0822285199 \\
\hline 42 & Mthembu N & RHRU & Project Coordinator & 0313048468 & 0837103868 \\
\hline 43 & Mthsali D P & $\mathrm{DOH}$ & $\mathrm{CPN}$ & 0366377948 & 0847493321 \\
\hline 44 & Mthsali DD & DOH - KZN - D23 & Program Manager & 0366312202 & 0833753242 \\
\hline 45 & Dr Mullick S & Pop Council & Program Associate & 0113250647 & 0724557332 \\
\hline 46 & Ndebele T & $\mathrm{DOH}$ & PHC Manager & 0349814362 & 0836912604 \\
\hline 47 & Dr Ndhlovu L & Pop Council & $\begin{array}{l}\text { Country } \\
\text { Representative }\end{array}$ & 0113419400 & \\
\hline 48 & Ngcobo GET & $\mathrm{DOH}$ & Field Worker & 03229400002 & 0822550291 \\
\hline 49 & Nicholson K & District Office & $\mathrm{AD}$ & 03132777862 & \\
\hline 50 & Nkosi NM & DC 26 & & 0349813365 & 0834571196 \\
\hline 51 & Ntabethe M & $\begin{array}{lll}\text { DOH } & \text { KZN } & \text { Maternal } \\
\text { Health } & & \\
\end{array}$ & Coordinator & & 0833662875 \\
\hline 52 & Ntanzi EB & Health MCWH & Coordinator & 0342711900 & \\
\hline 53 & Ntlangothi EL & Simdlangothi & Coordinator & 0344132318 & 0732812158 \\
\hline 54 & Ntuli GT & MCWH & EPI Manager & 0313322425 & 0834146011 \\
\hline 55 & Queen & RHRU & Project Coordinator & 0313048468 & \\
\hline 56 & Dr Ramkissoon A & RHRU & $\begin{array}{l}\text { Program Director } \\
\text { STI/HIV }\end{array}$ & 0313048468 & 0837774116 \\
\hline 57 & Ms Searle C & Pop Council & Program Assistant & 0113419400 & \\
\hline 58 & Sibisi TD & & $\mathrm{CPN}$ & 0317046269 & 0827411865 \\
\hline 59 & Sibiya ATS & $\mathrm{DOH}$ & PHC Trainer & 0349814362 & 0837205672 \\
\hline 60 & Sibiya RS & DOH - Benedectine & PHC Manager & 0358310314 & 0834988660 \\
\hline 61 & Silvestri A & Italian Cooperative & Coordinator & 0333952974 & \\
\hline 62 & Simelane NL & Emakhosini Sub Distr. & District Coordinator & 0358742461 & 0834571198 \\
\hline 63 & Singh SA & DOH - Rehab Program & Program Manager & 0333952919 & 0834571167 \\
\hline 64 & Smit Jenni & RHRU & Coordinator & 0313048383 & 0829265762 \\
\hline 65 & Snyman E & $\mathrm{DOH}(\mathrm{MCWH})$ & $\mathrm{AD}$ & 0313322425 & 0823784724 \\
\hline 66 & Sopiseka NT & DHC Kokstad & & 0342252969 & 0834121944 \\
\hline 67 & Spies L & DOH - KZN & Director & 0333952726 & \\
\hline 68 & Prof. Sturm & Microbiology & HOD & 0312607395 & \\
\hline 69 & Dr Tlebere D & DOH - National & Specialist & 0123120406 & \\
\hline 70 & Tseku NG & $\mathrm{DOH}$ & & 0349817362 & \\
\hline 71 & Vajey Ahmed & DOH Oral Health & Program Manager & 0313322444 & \\
\hline 72 & Dr Vlok W & PMTCT - DOH & DD & 0313077225 & \\
\hline 73 & Dr Williams E & Population Council & Program Associate & 0113250518 & 0825991944 \\
\hline 74 & Wilson LN & DOH Maternal & $\mathrm{AD}$ & 0313322425 & 0835602740 \\
\hline 75 & Wohlfarht D & Engender Health & Regional Tech Adv. & 0254204449 & \\
\hline 76 & Zondi S & RHRU & Junior Coordinator & 0313048383 & 0837175428 \\
\hline
\end{tabular}




\section{Hgrizons}

Horizons is a global operations research program designed to:

- Identify and test potential strategies to improve HIVIAIDS prevention, care, and support programs and service delivery.

- Disseminate best practices and utilize findings with a view toward scaling up successful interventions.

\section{(2) Population Council}

Horizons is implemented by the Population Council in collaboration with

- International Center for Research on Women (ICRW)

- International HIVIAIDS Alliance

- Program for Appropriate Technology in Health (PATH)

- Tulane University

- Family Health International (FHI)

- Johns Hopkins University

For more information, please contact:

Horizons Program, Communications Unit 4301 Connecticut Avenue, NW Suite 280 Washington, DC 20008 USA

Tel: 202-237-9400

Fax: 202-237-8410

Email: horizons@pcdc.org www.popcouncil.org/horizons 